MANOEL DE ARCISIO MIRANDA FILHO

\title{
EFEITOS ELÉTRICOS DE ÁCIDOS GRAXOS LIVRES \\ EM BICAMADAS LIPÍDICAS PLANAS
}

Tese apresentada ao Instituto de Ciências Biomédicas da Universidade de São Paulo, para obtenção do Título de Doutor em Ciências (Fisiologia Humana).

São Paulo

2007 
MANOEL DE ARCISIO MIRANDA FILHO

\section{EFEITOS ELÉTRICOS DE ÁCIDOS GRAXOS LIVRES \\ EM BICAMADAS LIPÍDICAS PLANAS}

Tese apresentada ao Instituto de Ciências Biomédicas da Universidade de São Paulo, para obtenção do Título de Doutor em Ciências.

Área de concentração: Fisiologia Humana

Orientador: Prof. Dr. Joaquim Procopio de Araujo Filho

São Paulo 
DEDICATÓRIA

A minha avó, incentivadora eterna. 


\section{AGRADECIMENTOS}

A DEUS, Nossa Senhora de Aparecida, São Vito e São Miguel por me ajudarem a cumprir mais uma etapa;

Ao professor Procopio pela oportunidade, dedicação e estímulo a realização deste trabalho; também, no auxílio a minha formação geral. Muitos professores orientam alunos, porém poucos são verdadeiros orientadores como você. Com enorme carinho, obrigado por tudo;

Aos meus pais pelo apoio e incentivo incansáveis, vocês são os meus maiorais;

A Juliana (esposa) pela compreensão e dedicação durante estes anos de trabalho, você é um alicerce fundamental na minha vida;

Aos meus irmãos, Hederson e Fabiano, exemplos de dedicação e luta profissional e, as minhas irmãs, Lílian e Joelma, pela compreensão nos momentos difíceis. Ainda, as cunhadas, Elaine e Suzeli, pelas inestimáveis palavras de apoio;

Aos meus sobrinhos que com pequenos sorrisos injetam quantidades de ATPs indispensáveis para minha alegria do dia-a-dia;

Ao professor Rui Curi cujas palavras me faltam para agradecer. Sua participação é imensurável no sentimento de felicidade que tenho ao fazer pesquisa;

Aos amigos Fernando Abdulkader e Kellen Brunaldi, verdadeiros parceiros e amigos de laboratório. Também, ao amigo Fabio Diniz, pela simplicidade louca e admirável em tudo;

Ao Dr. Luiz Carlos Salay, pelo apoio de auto-estima e pelos valiosos conselhos em diversas etapas da minha pequena carreira científica;

As professoras Maria de Oliveira Souza, Luciana Venturini Rossoni e Sonia Malheiros Lopes Sonioto e ao Professor Francisco Lacaz Vieira, exemplos de dedicação à carreira científica e acadêmica; 
As amigas Ana Maria e Fátima Del Fava, pela alegria e apoio em momentos decisivos para a realização deste trabalho;

Aos demais professores, pós-graduandos e pós-doutorandos do Departamento de Fisiologia e Biofísica/ICB-USP; tenham certeza que todos tiveram grande importância e foram fundamentais durante minha "formação" como pesquisador;

Ao CAPES e CNPQ, pelo apoio financeiro indispensável para a realização deste trabalho. 
Miranda Filho, M.A. Efeitos elétricos de ácidos graxos livres em bicamadas lipídicas planas. 2007. 110f. Tese (Doutorado em Fisiologia Humana) - Instituto de Ciências Biomédicas, Universidade de São Paulo, São Paulo, 2007.

Ácidos graxos livres (FFA) são importantes mediadores do transporte de prótons através de membranas. Porém, pouco se sabe sobre a influência estrutural tanto dos FFA como do ambiente lipídico na translocação de prótons através de membranas. Tanto os efeitos do comprimento da cadeia e número de insaturações dos FFA como a composição da membrana foram analisados por medidas elétricas em bicamadas lipídicas planas. Condutância a prótons $\left(\mathrm{G}_{\mathrm{H}}{ }^{+}\right)$e condutância de vazamento $\left(\mathrm{G}_{\text {leak }}\right)$ foram calculadas a partir de medidas de voltagem em circuito aberto e de corrente de curto-circuito obtidas através de um eletrômetro ou um amplificador de patch-clamp (modo de voltage-clamp). Nossos resultados mostram que FFA com cis-insaturações causam um efeito mais pronunciado no transporte de próton quando comparados com FFA saturados ou trans-insaturação. Colesterol e cardiolipina diminuem $\mathrm{G}_{\text {leak }}$ de membranas. Cardiolipina também diminui $\mathrm{G}_{\mathrm{H}}{ }^{+}$. Esses efeitos indicam uma dupla modulação do transporte de prótons: pelo mecanismo de flip-flop dos FFA e por uma via difusional simples adicional.

Palavras-chave: Ácidos graxos. Bicamada lipídica. Medidas elétricas. Permeabilidade. Condutância. Próton. 
Miranda Filho, M.A. Electrical effects of free fatty acids in planar lipid bilayers. 2007. 110f. Doctorate thesis (Human physiology) - Instituto de Ciências Biomédicas, Universidade de São Paulo, São Paulo, 2007.

Free fatty acids (FFA) are important mediatiors of proton transport across membranes. However, little is known about the structural influence of both FFA and the membrane environment have in proton translocation across phospholipid membranes and by which means this influence is brought about. Both the effects of FFA chain length and insaturation and membrane composition on proton transport have been addressed in this study by electrical measurements in planar lipid bilayers. Proton conductance $\left(\mathrm{G}_{\mathrm{H}}{ }^{+}\right)$and leak conductance $\left(\mathrm{G}_{\text {leak }}\right)$ were calculated from open-circuit voltage and short-circuit current measurements obtained using either an electrometer or a patch-clamp amplifier (voltage-clamp mode). We found that cis-unsaturated FFA caused a more pronounced effect on proton transport as compared to saturated or trans-unsaturated FFA. Cholesterol and cardiolipin decreased $\mathrm{G}_{\text {leak }}$. Cardiolipin also decreased $\mathrm{G}_{\mathrm{H}}{ }^{+}$. These effects indicate a dual modulation of protein-independent proton transport by FFA through flip-flop and by an additional simple diffusional pathway.

Key words: Fatty acids. Lipid bilayer. Eletrical measurements. Permeability. Conductance. Proton. 


\section{LISTA DE ILUSTRAÇÕES}

Figura 1. Estrutura geral e classificação dos ácidos graxos. 21

Figura 2. Modelos propostos para a captação celular de ácidos graxos. 24

Figura 3. Possíveis mecanismos difusionais de prótons em membranas biológicas 28

Figura 4. Mecanismo de transporte de prótons por ácidos graxos 30

Figura 5. Estrutura molecular do colesterol e da cardiolipina 34

Figura 6. Câmaras utilizadas para a formação de bicamadas lipídicas planas 38

Figura 7. Representação molecular da forma aniônica dos ácidos graxos utilizados 40

Figura 8. Representação elétrica dos três modos de operação do eletrômetro 44

Figura 9. A) Representação esquemática do probe da técnica de patch-clamp com a membrana e seu respectivo funcionamento no modo voltage-clamp. B) parâmetros elétricos obtidos a a partir de relações I-V 46

Figura 10. Representação elétrica do modelo de condutâncias paralelas e sua conexão com o eletrômetro 49

Figura 11. Efeito de ácidos graxos saturados e cis insaturados na condutância total $\left(\mathrm{G}_{\mathrm{m}}\right)$ de membranas de DPhPC puras 52

Figura 12. Efeito de ácidos graxos saturados e cis insaturados na condutância a prótons $\left(\mathrm{G}_{\mathrm{H}}{ }^{+}\right)$ de membranas de DPhPC

Figura 13. Efeito de ácidos graxos saturados e cis insaturados na condutância de vazamento inespecífica $\left(\mathrm{G}_{\text {leak }}\right)$ de membranas de $\mathrm{DPhPC}$ 53

Figura 14. Contribuição das condutâncias a prótons $\left(\mathrm{G}_{\mathrm{H}}{ }^{+}\right)$e de vazamento inespecífica $\left(\mathrm{G}_{\text {leak }}\right)$ para a condutância total $\left(\mathrm{G}_{\mathrm{m}}\right)$ de membranas de $\mathrm{DPhPC}$ 54

Figura 15. Efeito de ácidos graxos saturados e cis insaturados na relação $\mathrm{E}_{\mathrm{m}} / \mathrm{E}_{\mathrm{H}}{ }^{+}$de membranas de DPhPC puras

Figura 16. Comparação entre o efeito do ácido graxos cis oléico e do ácido graxo trans elaídico na relação $\mathrm{E}_{\mathrm{m}} / \mathrm{E}_{\mathrm{H}}{ }^{+}$de membranas de DPhPC puras 58

Figura 17. Comparação entre o efeito do ácido graxos cis oléico e do ácido graxo trans elaídico na condutância a prótons $\left(\mathrm{G}_{\mathrm{H}}{ }^{+}\right)$e na condutância da via inespecícica $\left(\mathrm{G}_{\text {leak }}\right)$ de membranas de DPhPC puras

Figura 18. Parâmetros elétricos de membranas fosfolipídicas não modificadas por ácidos graxos

Figura 19. Efeito do colesterol e da cardiolipina na condutância a prótons determinada pelo ácido oléico 
Figura 20. Efeito dos ácidos graxos palmítico, oléico e araquidônico nos parâmetros elétricos de membranas de Azolectina

Figura 21. Esquematiza os mecanismos de transporte de prótons em bicamadas lipídicas ..... 69

Figura 22. Mostra a interação entre as moléculas de colesterol e de fosfolipídeos .................. 72

Figura 23. Efeitos da incorporação de cardiolipina em membranas fosfolipídicas .................. 74

Figura 24. Representação cinética do transporte de prótons por ácidos graxos em membranas

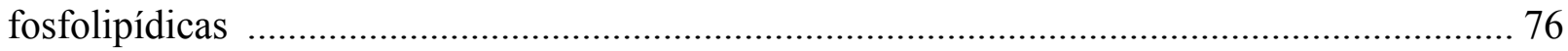

Figura 25. Representação dos efeitos dos diferentes ácidos graxos em membranas de DPhPC e Azolectina 79

Figura 26. Efeito da cardiolipina em membranas modificadas por ácido oléico 


\section{LISTA DE TABELAS}

Tabela 1 - Características gerais dos fosfolipídeos (e respectivas misturas) utilizados para a obtenção de parâmetros elétricos em bicamadas lipídicas planas

Tabela 2 - Efeito de ácidos graxos saturados e cis insaturados na corrente de curto-circuito (CCC) e na permeabilidade $\left(\mathrm{P}_{\mathrm{H}}{ }^{+}\right)$de membranas de $\mathrm{DPhPC}$

Tabela 3 - Compara o efeito do ácido elaídico com os efeitos dos ácidos oléico e esteárico na corrente de curto-circuito (CCC) e na permeabilidade $\left(\mathrm{P}_{\mathrm{H}}{ }^{+}\right)$de membranas de DPhPC 60

Tabela 4 - Efeito da composição da membrana na corrente de curto-circuito (CCC) e na permeabilidade $\left(\mathrm{P}_{\mathrm{H}}{ }^{+}\right)$basal de membranas de DPhPC pura, DPhPC-colesterol, DPhPCcardiolipina

Tabela 5 - Efeito dos ácidos graxos palmítico, oléico e araquidônico na corrente de curtocircuito (CCC) e na permeabilidade $\left(\mathrm{P}_{\mathrm{H}}{ }^{+}\right)$de membranas de Azolectina 67 


\section{LISTAS DE ABREVIATURAS E SIGLAS}

$\beta_{i}-$ coeficiente de partição do íon $\mathrm{i}$

CCC - corrente de curto-circuito

$\mathbf{C}_{\mathbf{H}}{ }^{+}$- concentração de prótons

d - espessura da membrana

$\mathbf{D}_{\mathbf{i}}-$ coeficiente de difusão do íon i

DPhPC - Di-fitanoil-fosfatidil-colina

$\mathbf{E}_{\mathbf{H}}{ }^{+}-$potencial de equilíbrio para o proton

$\mathbf{E}_{\mathbf{m}}$ - potencial de equilíbrio da membrana

FABP - fatty acid binding protein (inglês) ou proteína ligadora de ácidos graxos (português)

FAT/CD36 - fatty acid translocase/CD36

FATP - fatty acid transporter protein (inglês) ou proteína transportadora de ácidos graxos (português)

FCCP - carbonylcyanide p-trifluoromethoxyphenylhydrazone

G - condutância

$\mathbf{G}_{\mathbf{m}}$ - condutância da membrana

$\mathbf{G}_{\mathbf{H}}{ }^{+}-$condutância a prótons

$\mathbf{G}_{\text {leak }}-$ condutância de vazamento inespecífica

i - corrente

$\mathbf{J}_{\mathbf{H}}{ }^{+}-$fluxo de prótons

$\mathbf{i}_{\mathbf{E}}-$ corrente que passa pelo eletrômetro

$\boldsymbol{k}_{f f}-$ constante de velocidade de flip-flop

$\boldsymbol{k}_{\boldsymbol{o n}}$ - constante de velocidade de inserção

MMI - membrana interna da mitocôndria

$\mathbf{P}_{\mathbf{i}}$ - permeabilidade da membrana a um íon genérico

$\mathbf{P}_{\mathbf{H}}{ }^{+}-$permeabilidade a prótons

pK - constante de ionização

$\mathbf{p K}_{\mathbf{a}}-\mathrm{pK}$ aparente

PPAR - receptor ativado pela proliferação de peroxissomas

PPT - poro de transição de permeabilidade

$\mathbf{R}_{\mathbf{i E}}$ - resistência interna do eletrômetro

$\mathbf{R}_{\mathbf{m}}$ - resistência da membrana

$\mathbf{r}$ - raio 
SUV - vesícula unilamelar pequena

Tris - tris-hidroxi-aminometano

UCP - uncoupling protein (inglês) ou proteína desacopladora (português)

$\mathbf{v}$ - valência do íon

$\mathbf{V}_{\mathbf{m}}-$ voltagem através da membrana

$\mathbf{V}_{\text {rev }}-$ potencial de reversão de corrente 


\section{LISTA DE SÍMBOLOS}

\section{ÁCIDOS GRAXOS}

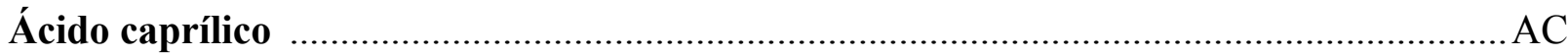

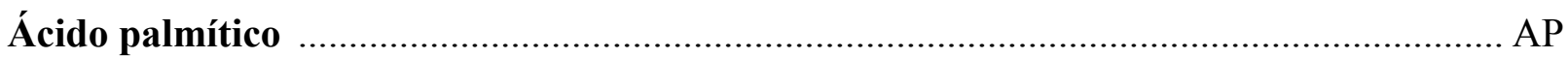

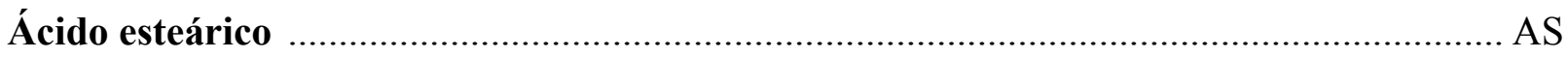

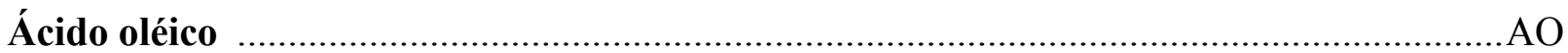

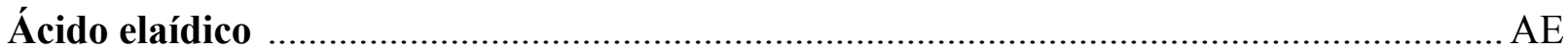

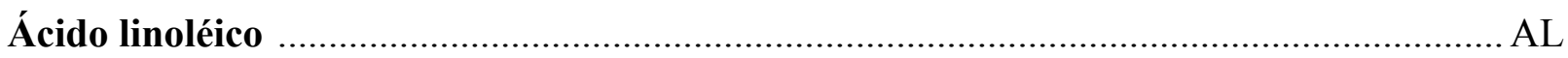

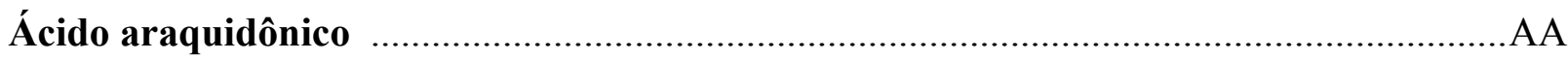

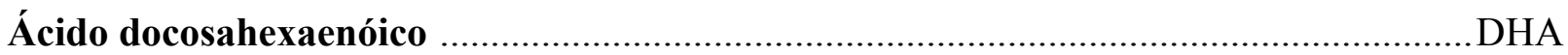

\section{FÍSICOS}

Ampère

$\mathbf{O h m}$

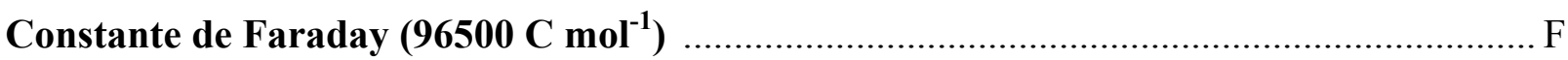

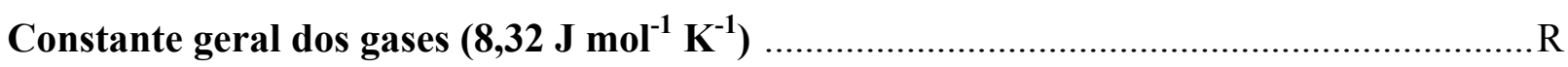

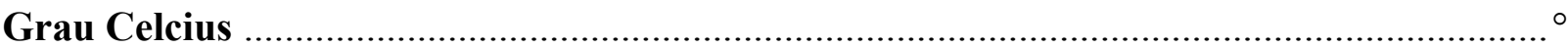

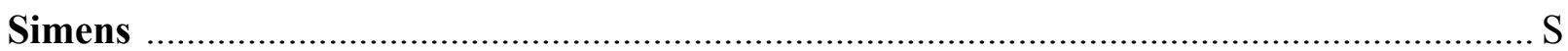

Temperatura absoluta (300 Kelvins) …………………………………………… T

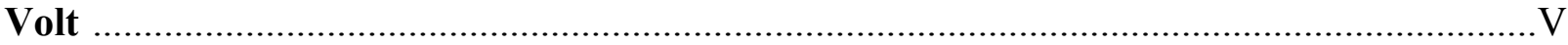




\section{LISTA DE FÓRMULAS}

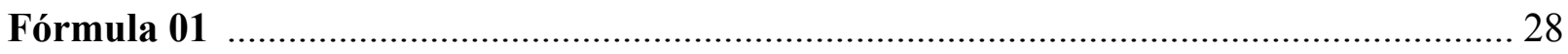

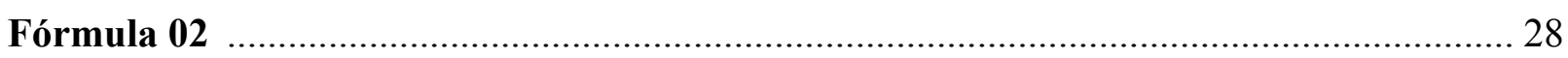

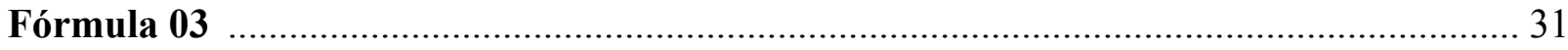

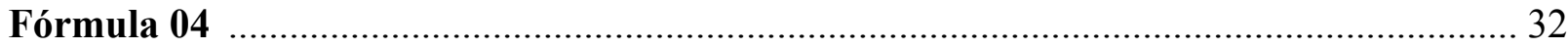

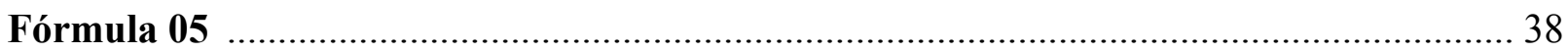

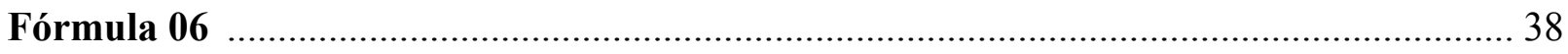

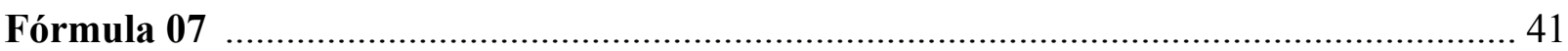

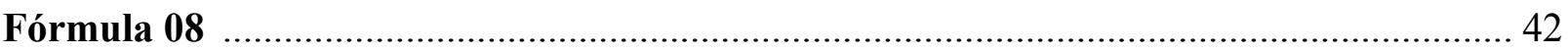

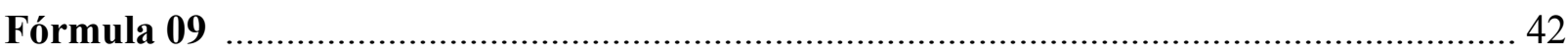

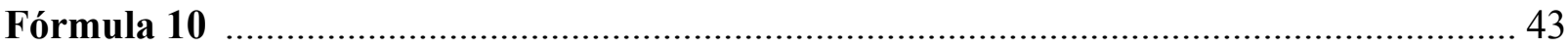

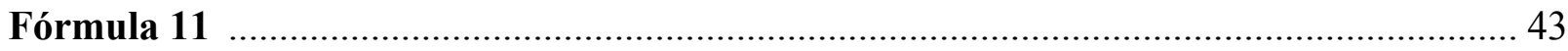

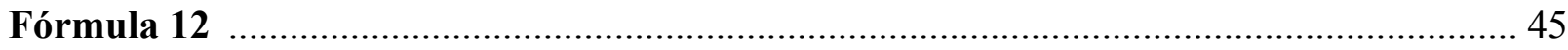

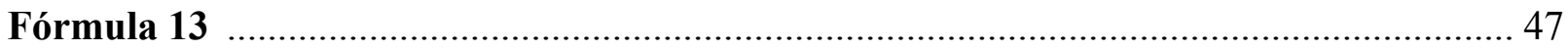

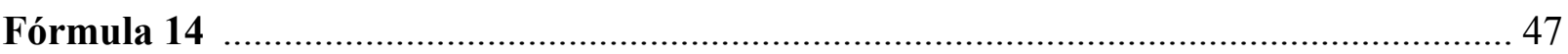

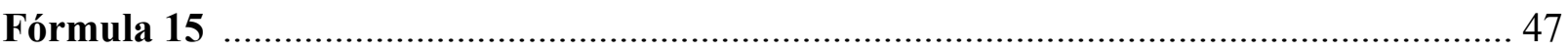

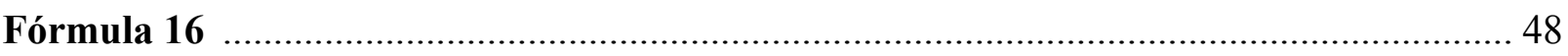

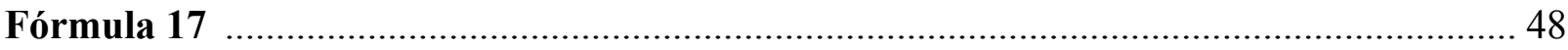

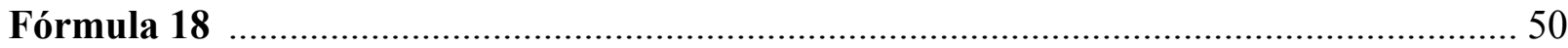




\section{SUMÁRIO}

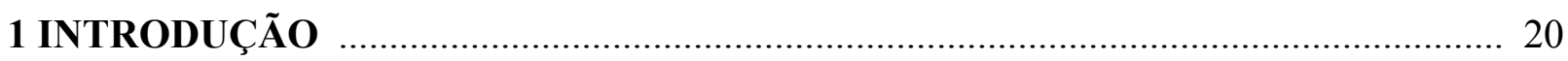

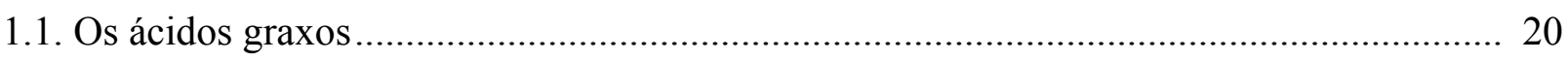

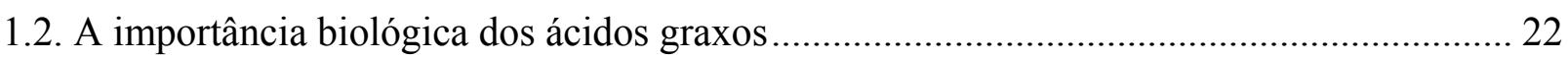

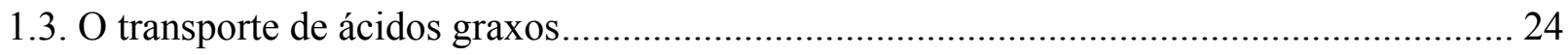

1.4. O transporte de prótons e sua importância biológica ....................................................... 27

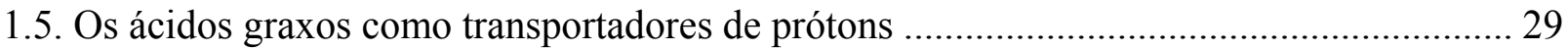

1.6. Os ácidos graxos e as membranas biológicas ................................................................... 32

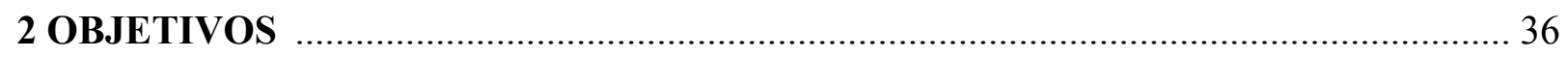

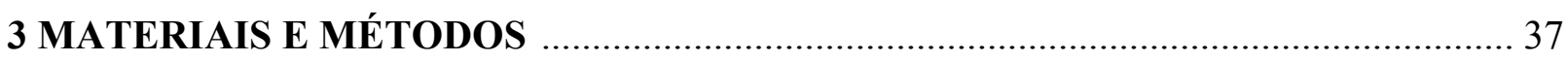

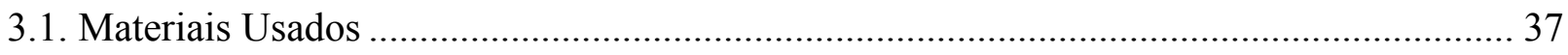

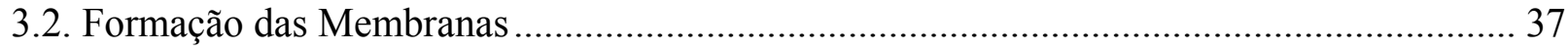

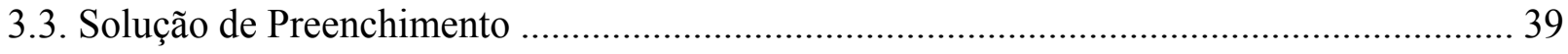

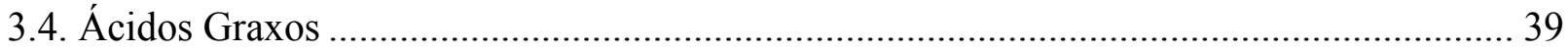

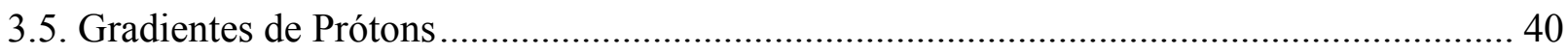

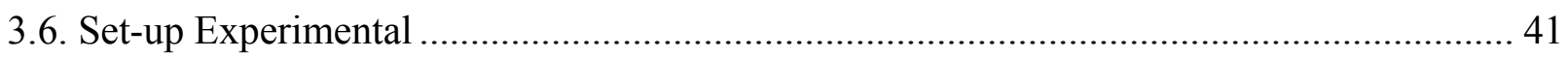

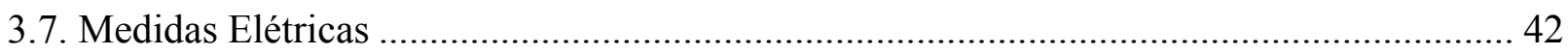

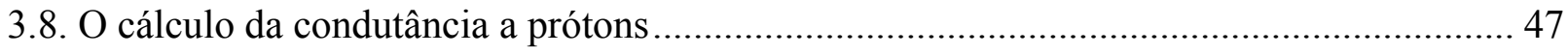

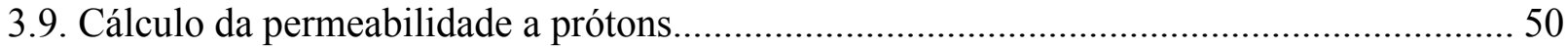

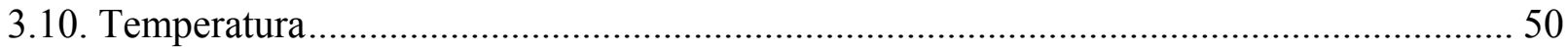

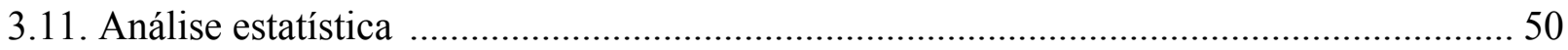

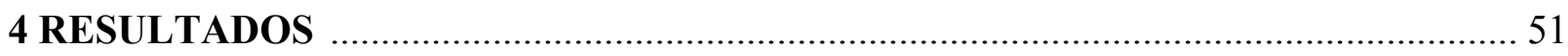

4.1. Efeito de ácidos graxos saturados e cis insaturados nas propriedades elétricas de

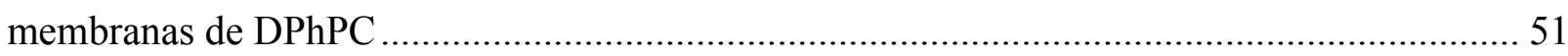

4.2. Efeito de ácidos graxos trans nas propriedades elétricas de membranas de DPhPC ......... 57

4.3. Efeito da composição da membrana no transporte de prótons por ácidos graxos ............... 60

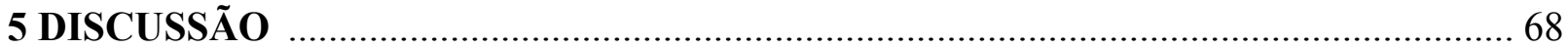

5.1. Fluxo difusional simples de prótons através de bicamadas fosfolipídicas ......................... 70

5.2. Como o colesterol e a cardiolipina podem interferir no fluxo difusional de prótons .......... 71

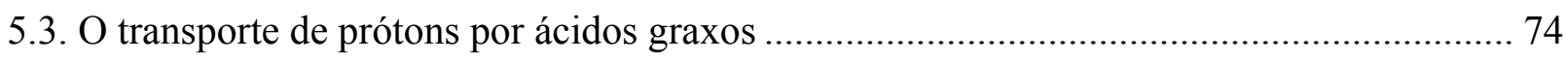

5.4. Efeito do colesterol e da cardiolipina no transporte de prótons por ácidos graxos ............. 79

5.5. Importância para o transporte de ácidos graxos nas células............................................... 82

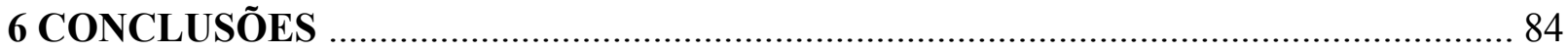




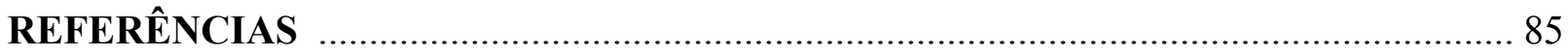

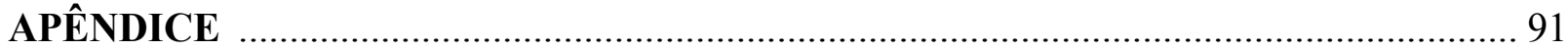

Apêndice 1. Programa computacional da família Chnew.bas ................................................ 91

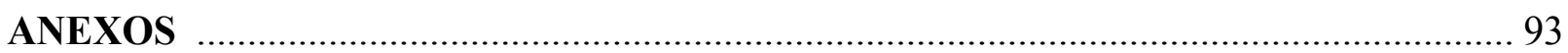

Anexo 1. Câmaras para formação de bicamada lipídica plana ................................................ 93

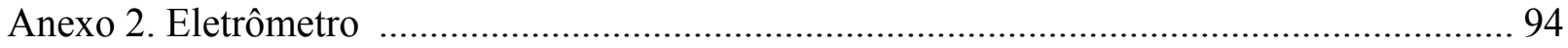

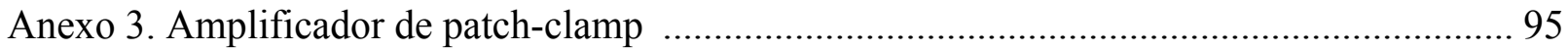

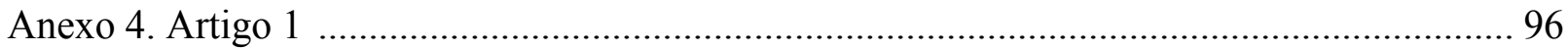

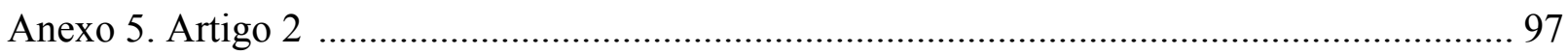

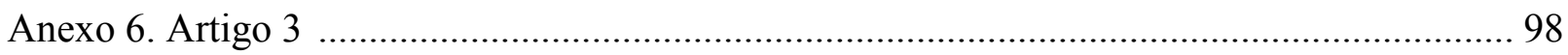




\section{INTRODUÇÃO}

\subsection{Os ácidos graxos}

Os ácidos graxos são compostos orgânicos de caráter anfifílico que apresentam em sua estrutura duas regiões com características físico-químicas distintas (Figura 1): um grupamento carboxila $\left(-\mathrm{COO}^{-}\right)$- região polar - e uma cadeia carbônica longa - região apolar.

Atualmente os ácidos graxos são classificados com base em diversas características estruturais (MARSZALEK \& LODISH, 2005). Considerando o número de carbonos na cadeia acila, os ácidos graxos podem ser divididos em:

- ácidos graxos de cadeia curta - possuem no máximo 11 carbonos;

- ácidos graxos de cadeia média - possuem de 12 a 18 carbonos; e

- ácidos graxos de cadeia longa - apresentando mais que 19 carbonos.

Com relação ao número de insaturações na cadeia acila, os ácidos graxos podem ser divididos em três classes (Figura 1):

- ácidos graxos saturados: não apresentam dupla ligação;

- ácidos graxos monoinsaturados: apresentam apenas uma dupla ligação; e

- ácidos graxos poliinsaturados: apresentam duas ou mais duplas ligações.

Além disso, os ácidos graxos monoinsaturados e os poliinsaturados ainda podem ser divididos em três grupos de acordo com a posição da primeira dupla ligação, considerando como referência inicial o grupamento metila terminal (i.e., carbono 1), em: $\boldsymbol{\omega}-\mathbf{3}$ (ou n-3): primeira dupla ligação posicionada no carbono 3; $\mathbf{\omega - 6}$ (ou n-6): primeira dupla ligação posicionada no carbono 6; e $\omega \mathbf{- 9}$ (ou n-9): primeira dupla ligação posicionada no carbono 9.

Ácidos graxos com cadeias ramificadas, ou seja, apresentando grupamentos laterais ainda podem ser normalmente encontrados em archea bactérias (HAINES, 2001). 


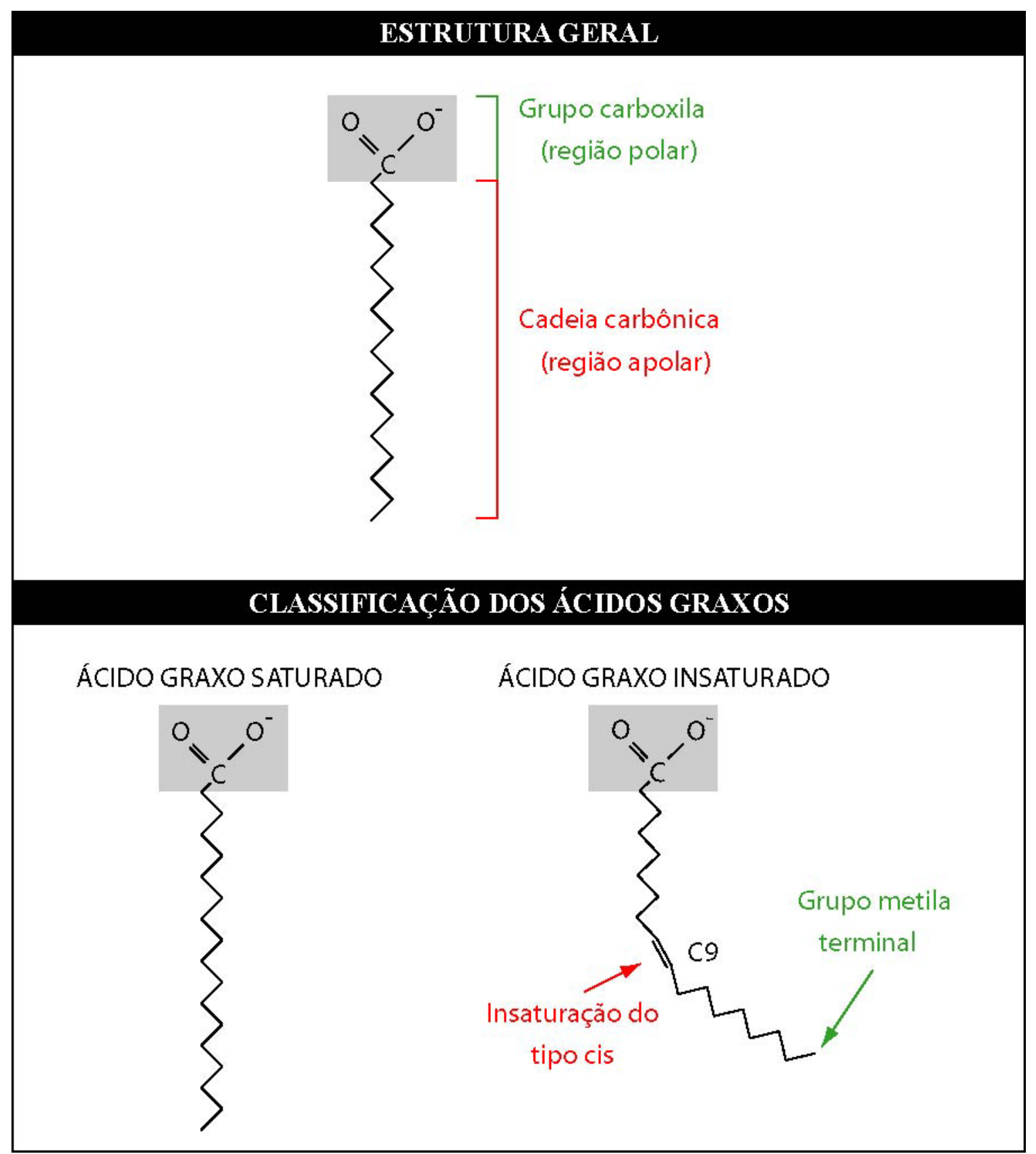

Figura 1: Estrutura geral e classificação dos ácidos graxos. Porção superior: estrutura anfifílica geral a todos os ácidos graxos. Porção inferior: classificação dos ácidos graxos com relação ao número de insaturações da cadeia acila. Mais detalhes são apresentados no texto.

As propriedades físico-químicas dos ácidos graxos estão altamente relacionadas com sua estrutura, sendo influenciadas tanto pelo comprimento da cadeia acila como pelo número de insaturações presentes.

A solubilidade dos ácidos graxos em água é pequena, e diminui com o aumento do tamanho da cadeia acila e com a redução do número de insaturações em sua cadeia; por exemplo, o limite de solubilidade em água para o ácido palmítico é da ordem de poucos $\mu \mathrm{M}$ (HAMILTON \& KAMP, 1999). Um fator interessante na solubilidade aquosa dos ácidos 
graxos é a influência do $\mathrm{pH}$ do meio; a elevação do $\mathrm{pH}(>10)$ aumenta a solubilidade, fazendo com que os ácidos graxos se associem em estruturas micelares. No entanto, em pH neutro e acima do limite de solubilidade os ácidos graxos formam estruturas ácidas insolúveis, sendo compostas de uma mistura de ácidos graxos ionizados e não ionizados. Abaixo do limite de solubilidade ou em equilíbrio com as estruturas ácidas, os ácidos graxos são monoméricos ou dímeros facilmente dissociáveis.

Diferentemente da solubilidade, o coeficiente de partição óleo-água dos ácidos graxos é bastante elevado e, como seria de se esperar, está inversamente relacionado com a baixa solubilidade em água. Assim, quanto maior o comprimento da cadeia acila e menor o número de insaturações, maior é o coeficiente de partição. Além disso, estudos mostram que o coeficiente de partição óleo-água não depende da concentração de ácido graxo na solução banhante (ANEL et al., 1993).

Outro aspecto interessante dos ácidos graxos é o seu pK aparente (pKa). Em um compartimento com $\mathrm{pH}$ 7,4 ( $\mathrm{pH}$ fisiológico) e em baixas concentrações, o pK dos ácidos graxos em solução é da ordem de 4,5 e a espécie monomérica ionizada predomina. No entanto, após se adsorverem em um hemifolheto da bicamada lipídica, a cadeia acila dos ácidos graxos alinha-se com a cadeia acila dos fosfolipídeos, permanecendo o grupo carboxila (cabeça polar) posicionado na interface aquosa. Isso determina uma alteração no grau de ionização do grupo carboxila, passando seu $\mathrm{pK}_{\mathrm{a}}$ a 7,6 no ambiente lipídico. HAMILTON \& KAMP (1999) mostraram que a alteração do pK dos ácidos ao se inserirem na membrana independe do comprimento da cadeia acila, do número de insaturações e do tipo de fosfolipídeo que constitui a membrana. Assim, ao se inserir na membrana, todo e qualquer ácido graxo está por volta de 50\% na forma ionizada e 50\% na forma não ionizada. Esta alteração do $\mathrm{pK}$ foi atribuída a uma diminuição do $\mathrm{pH}$ próximo à membrana pela própria inserção de moléculas de ácidos graxos da forma aniônica, ou seja, carregados negativamente (HAMILTON, 1998).

\subsection{A importância biológica dos ácidos graxos}

No organismo, os ácidos graxos se apresentam principalmente na forma esterificada, sendo componentes da cadeia carbônica dos fosfolipídeos de membrana ou formando triacilgliceróis. Entretanto, sua fração livre (i.e., não esterificada), que constitui apenas um pequeno percentual dos lipídeos corporais, exerce importantes funções metabólicas. 
Além da reconhecida participação dos ácidos graxos como fonte de energia para o organismo (VOET \& VOET, 1995), outras funções de caráter regulador de diversas funções celulares vêm sendo descritas. Por exemplo, através da ação de ativação dos fatores de transcrição dos PPAR ("receptor ativado pela proliferação de peroxissomas") os ácidos graxos podem modular a expressão de diversas proteínas, influenciando processos como diferenciação e replicação celular (CLARK et al., 1999). Sabe-se que esta ação é altamente influenciada pelo tipo de cadeia carbônica dos ácidos graxos, onde certas classes de PPARs são preferencialmente reguladas por ácidos graxos insaturados.

Na membrana interna da mitocôndria de mamíferos, os ácidos graxos apresentam um importante papel na termogênese e, como conseqüência, na termorregulação do organismo (SKULACHEV, 1998). Esta ação ocorre pela dissipação do gradiente de prótons gerado pela cadeia de transporte de elétrons, por um mecanismo próprio de flip-flop (ver tópico 1.5.) ou por promoverem a abertura do poro de transição de permeabilidade PTP, ou ainda por ativação de proteínas da família das UCPs (“uncoupling proteins"ou "proteínas desacopladoras").

Outras funções dos ácidos graxos como sinalização intracelular (HANNIGAN \& WILLIAMS, 1991), ativação ou inibição, direta ou indiretamente, de canais iônicos (ORDWAY et al., 1989 \& BRUNO et al., 2007), modulação da captação celular de lipoproteínas plasmáticas (Bihain et al., 1989), na atividade física de longa duração (HIRABARA et al., 2006) e ativação de mecanismos que resultam em apoptose celular (WILLIAMSON \& SCHLEGEL, 2002) também tem sido descritas.

Além da participação dos ácidos graxos em processos físiológicos, estudos vêm mostrando sua ação em diversas condições patológicas. De grande importância, vêm se mostrando o papel dos ácidos graxos na patogênese do diabete melito do tipo 2, onde os ácidos graxos contribuem para o desenvolvimento da resistência periférica à insulina. No entanto, os mecanismos específicos no qual os ácidos graxos participam ainda não estão bem estabelecidos (DAYS et al., 2004).

Dessa forma, uma vez que os ácidos graxos desempenham diversas funções no metabolismo celular e em diversas situações patológicas, é necessário entendermos como ocorre sua captação celular e a possível relação entre os fluxos de prótons e ácidos graxos através de membranas biológicas. 


\subsection{O transporte de ácidos graxos}

A captação celular de ácidos graxos, como propuseram HAMILTON \& KAMP (1999), envolve uma seqüência de etapas distintas (Figura 2):

(1) dissociação da molécula de ácidos graxo da albumina ou de lipoproteínas plasmáticas para o meio aquoso extracelular;

(2) adsorção, ou seja, inserção ao hemifolheto externo da membrana;

(3) movimento através da membrana (flip-flop), passando do hemifolheto externo para o hemifolheto interno;

(4) desorção, ou seja, dissociação da molécula de ácido graxo do hemifolheto interno para o citosol;

(5) difusão, como molécula monomérica ou ligado a uma proteína citoplasmática ligante de ácido graxo (FABP - fatty acid binding protein ou proteína ligadora de ácidos graxos), através do citosol até os sítios de ligação e utilização (mitocôndrias, peroxissomos e retículo endoplasmático); e

(6) metabolização.

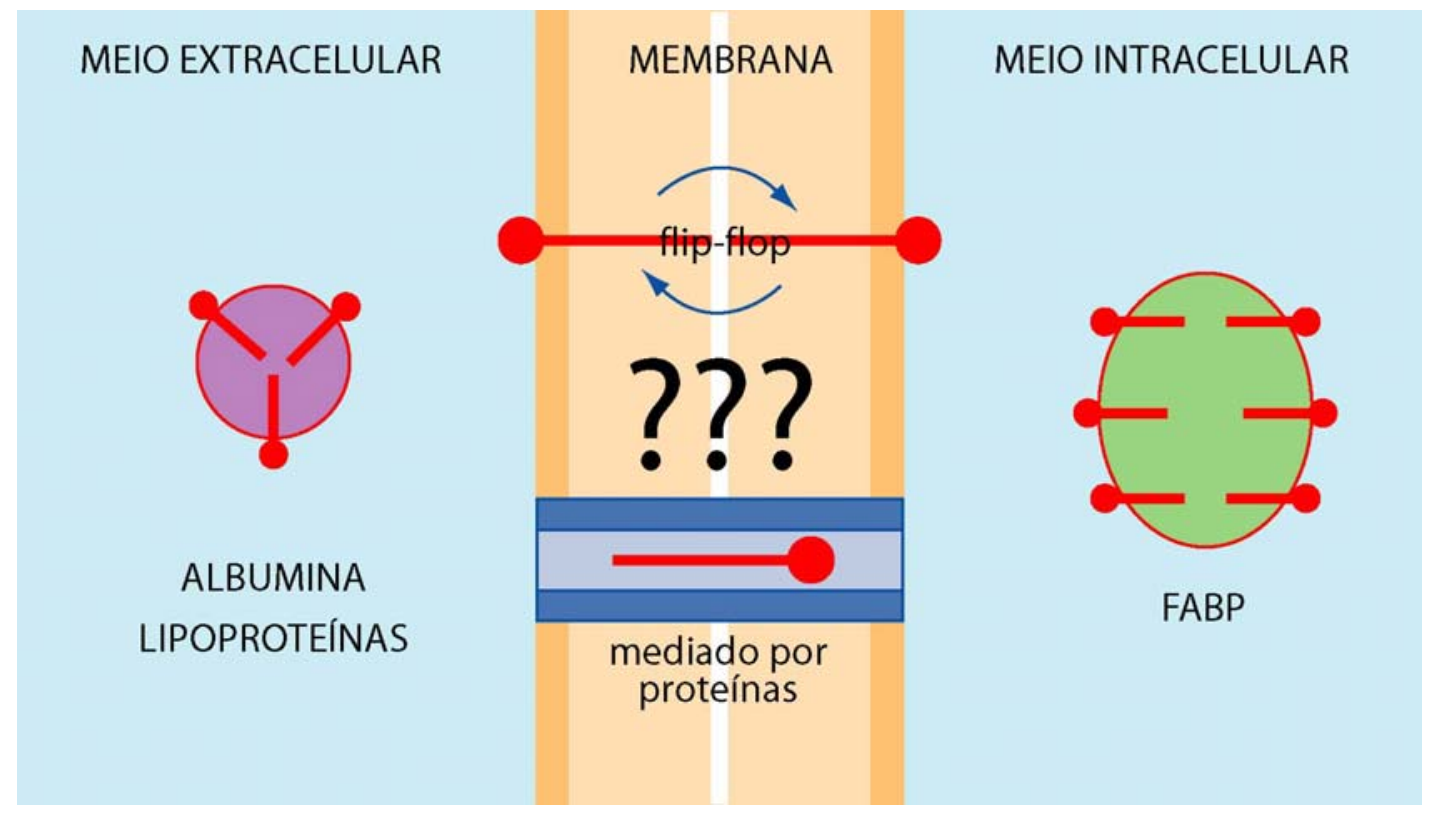

Figura 2: Modelos propostos para a captação celular de ácidos graxos. No meio extracelular os ácidos graxos são transportados pela albumina e/ou lipoproteínas plasmáticas (transportadores inespecíficos de moléculas lipofílicas). O mecanismo pelo qual os ácidos graxos se translocam através de membranas é desconhecido, sendo duas correntes de investigação propostas: fluxo difusional simples ou fluxo mediado por proteínas de membrana (descrição mais detalhada destes mecanismos é feita no texto). No meio intracelular, os ácidos graxos se ligam a proteínas citoplasmáticas (FABPs) ou são rapidamente metabolizados. 
Atualmente, o transporte de ácidos graxos através da membrana, ou seja, as etapas (2), (3) e (4), é motivo de controvérsia, apresentando duas correntes antagônicas que propõem, alternativamente: difusão simples ou transporte mediado por proteínas de membrana.

A primeira etapa no transporte dos ácidos graxos através da membrana é sua inserção (ou adsorção, como é comumente utilizado na literatura especializada). Como os ácidos graxos são transportados no plasma ligados a albumina ou a lipoproteínas, há um consenso na literatura de que a que a constante de velocidade de inserção $\left(k_{o n}\right)$ é determinada apenas pela concentração de ácidos graxos livres, e não pela concentração total de ácidos graxos, que incluiria os ácidos graxos ligados a albumina (ABUMRAD et al., 1998; BERK \& STUMP, 1999). HAMILTON (1998), em estudos com vesículas unilamelares pequenas (SUV) de dimiristoilfosfatidilcolina mostrou que o $k_{o n}$ de ácidos graxos é extremamente grande.

O flip-flop é a etapa mais controversa na translocação dos ácidos graxos através da membrana, sendo que alguns autores postulam ser necessária a existência de proteínas transportadoras de ácidos graxos, para o processo da translocação.

As possíveis proteínas que parecem ter algum tipo de relação com a translocação de ácidos graxos são:

(a) UCP (Uncoupling protein): as UCPs são as mais estudadas e seriam ativadas por ácidos graxos livres, atuando diretamente no transporte de prótons ou no transporte da forma aniônica dos ácidos graxos (BREEN et al., 2006);

(b) FABPpm (Fatty acid binding protein pm): admite-se ser uma proteína citoplasmática que auxiliaria na desorção dos ácidos graxos e, consequentemente, no transporte de ácidos graxos através do meio aquoso intracelular (CÓRSICO et al., 2005);

(c) FATP (Fatty acid transporter protein): demonstrou-se que as proteínas dessa família têm apenas um segmento transmembrana e a maior parte da estrutura da molécula parece estar associada ao hemifolheto interno da membrana (STAHL et al., 2001). Evidências sugerem uma possível regulação por níveis de ATP intracelular. (POHL, 2004);

(d) FAT/CD36 (Fatty acid translocase/CD36): a estrutura proposta seria formada por dois segmentos transmembrana com curtos terminais $\mathrm{N}$ e $\mathrm{C}$ citoplasmáticos, formando uma grande alça protéica no extracelular. Atuaria facilitando o transporte por diminuir a energia de ativação para a translocação da forma aniônica dos ácidos graxos (ABUMRAD et al., 1999).

A hipótese de transporte mediado baseia-se nos seguintes argumentos (ABUMRAD et al., 1998): (i) em adipócitos a cinética de captação celular de ácidos graxos apresentaria um mecanismo saturável, além de ocorrer competição entre os ácidos graxos de cadeia longa; (ii) alterações na captação celular de ácidos graxos ocorriam após modificação específica em 
certas regiões de algumas proteínas da membrana plasmática; e (iii) a captação celular de ácidos graxos seria aumentada com o aumento da expressão de certas proteínas como a FATP. No entanto, contra-argumentos são sugeridos por autores defensores do mecanismo difusional (HAMILTON, 1998): (i) as observações de cinética de saturação não são evidências suficientes para o transporte mediado e podem estar refletindo o particionamento de ácidos graxos entre a membrana fosfolipídica e a albumina; (ii) experimentos que modificam proteínas e mostram inibição da captação celular de ácidos graxos podem interferir com enzimas envolvidas no metabolismo lipídico ou podem alterar a estrutura da membrana interferindo no particionamento dos ácidos graxos; e (iii) a expressão de FATP realmente pode aumentar a internalização de ácidos graxos em células de adipócitos, no entanto, os mecanismos envolvidos neste processo de internalização ainda são pouco esclarecidos.

Dessa forma e, contrariando a hipótese de transporte mediado, existem evidências experimentais de que a constante de velocidade de flip-flop $\left(k_{f f}\right)$ é muito alta devido a maior parte dos ácidos graxos presentes na membrana estarem na forma neutra, ou seja, protonada (KAMP et al., 1995; HAMILTON \& KAMP, 1999). Estudos de fluorescência realizados em vesículas unilamelares, usando sonda fluorescente (piranina) sensível ao $\mathrm{pH}$ do meio intravesicular, mostraram que a taxa de flip-flop era extremamente grande.

Além disso, POHL et al. (2000) descrevem assimetrias de potencial de superfície geradas pela acidificação unilateral de bicamadas lipídicas planas de difitanoilfosfatidilcolina que já continham ácidos graxos, mostrando que este pode se inserir à membrana e, posteriormente, sofrer flip-flop.

Por conseguinte, baseando-se nos estudos de captação de ácidos graxos realizados em vesículas, células de adipócitos e em células $\beta$-pancreáticas, diversos autores (ABUMRAD, 1998; STUMP et al., 2001; SCHAFFER, 2002) vêem consideram importantes tanto o fluxo difusional simples de ácidos graxos como o fluxo mediado por proteínas. Assim, em concentrações basais de ácidos graxos livres (ou seja, não ligados à albumina ou lipoproteínas) sua translocação através da membrana seria preferencialmente mediada por proteínas; porém, em concentrações elevadas, o fluxo difusional torna-se predominante.

A desorção é a passagem da molécula de ácido graxo do hemifolheto interno para o citosol. A desorção dos ácidos graxos geralmente tem sido medida indiretamente pela monitoração da transferência da molécula de ácido graxo de uma vesícula doadora para outra receptora ou albumina. ZHANG et al. (1996), em estudo com SUVs monitorou a cinética de desorção por fluorescência (probe de piranina) e espectroscopia de NMR, sugerindo ser a desorção é a etapa limitante do transporte de ácidos graxos através da membrana. 


\subsection{O transporte de prótons e sua importância biológica}

Desde a teoria quimiosmótica de MITCHELL (1961) vários estudos vêm mostrando a importância da energia derivada do gradiente de concentração de prótons gerado pela cadeia transportadora de elétrons para o metabolismo celular. Através da membrana interna da mitocôndria, a energia gerada pela ação da força próton-motriz, é armazenada e utilizada para a síntese de ATP (processo chamado de fosforilação oxidativa).

Nas soluções biológicas existe uma estreita associação entre a água e o próton, pois na água coexistem as formas $\mathrm{H}_{2} \mathrm{O}, \mathrm{H}_{3} \mathrm{O}^{+}, \mathrm{OH}^{-}$e $\mathrm{H}^{+}$(DECOURSEY, 2003). No entanto, a movimentação da forma $\mathrm{H}^{+}$não requer a translocação física de cada próton, podendo ocorrer pela troca de elétrons através de proton-wire (Figura 3) (HILLE, 2001; VOET \& VOET, 1995). Atualmente, diversos mecanismos são postulados para explicar a translocação de $\mathrm{H}^{+}$ em membranas biológicas:

(a) mecanismos difusionais: defeitos flutuacionais de densidade de membrana (DEAMER \& NICHOLLS, 1989), proton-jump, proton-wire (NAGLE, 1987; HOCH, 1998), cluster-contact mechanism (HAINES, 2001);

(b) mecanismos mediados por transportadores: ácidos graxos intrínsecos (DEAMER \& NICHOLLS, 1989) e ácidos graxos extrínsecos (DEAMER \& NICHOLLS, 1989; KAMP \& HAMILTON, 1993; KAMP et al., 1995 e ZHANG et al., 1996);

(c) canais para prótons: canal para prótons dependente de voltagem (RAMSEY et al., 2006).

No entanto, dois aspectos ainda não esclarecidos sobre a translocação de prótons e a permeabilidade intrínseca de membranas fosfolipídicas contrastam com a necessidade da célula em manter e utilizar gradientes de prótons em inúmeras funções celulares (DECOURSEY, 2003):

1) a permeabilidade a prótons $\left(10^{-4}-10^{-2} \mathrm{~cm} \mathrm{~s}^{-1}\right)$ é muitas ordens de magnitude maior do que a permeabilidade a outros cátions $\left(10^{-12}-10^{-10} \mathrm{~cm} \mathrm{~s}^{-1}\right)$. Além disso, GUTKNECHT (1987) em estudo com bicamadas lipídicas planas reportou ser a permeabilidade a prótons cerca de 5 vezes maior do que a de íons alcalinos.

2) a condutância a prótons de membranas fosfolipídicas é praticamente independente do $\mathrm{pH}$ do meio, ou seja, da concentração de $\mathrm{H}^{+}$. De acordo com a equação de eletrodifusão clássica (equação 1), seria de se esperar que a condutância a prótons aumentasse com a diminuição do $\mathrm{pH}$ na fase aquosa: 


$$
G_{H^{+}}=\frac{z \times F^{2}}{R \times T} \times P_{H^{+}} \times C_{H^{+}} \quad(e q .1)
$$

onde: $\mathrm{P}_{\mathrm{H}}{ }^{+}$- permeabilidade ao próton, $\mathrm{C}_{\mathrm{H}}{ }^{+}$- concentração de prótons na solução, $\mathrm{R}$ - constante geral dos gases, $\mathrm{T}$ - temperatura absoluta, $\mathrm{F}$ - constante de Faraday e $\mathrm{z}$ - valência do íon $\mathrm{H}^{+}$.

No entanto, GUTKNECHT (1988) e DEAMER \& NICHOLS (1989) mostram um aumento pouco expressivo da condutância a prótons com diminuição do $\mathrm{pH}$ da solução. Uma explicação para este comportamento é que o aumento da concentração de prótons levaria a uma diminuição da permeabilidade da membrana ao próton.

A permeabilidade $\left(P_{i}\right)$ da membrana a um íon genérico $i$ é dada por:

$$
P_{i}=\frac{D_{i} \times \beta_{i}}{d} \quad(\text { eq.2) }
$$

onde: $D_{i}$ - coeficiente de difusão do íon i, $\beta_{i}$ - coeficiente de partição do íon i e $d$ - espessura da membrana.

Assim, uma investigação dos mecanismos moduladores da permeabilidade implica em entender como os coeficientes da equação 2 são afetados isoladamente.

A diminuição da permeabilidade com a concentração, observada com o próton, foge ao comportamento eletrodifusional simples, sugerindo que o coeficiente de difusão do próton diminui com a concentração, uma vez que não há evidências de que o coeficiente de partição dependa de modo importante da concentração. 
A WATER WIRE

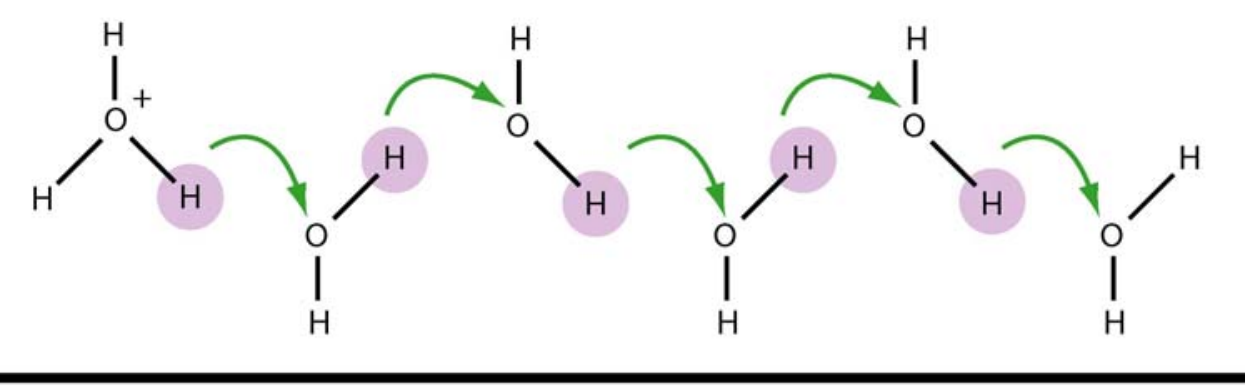

B $\quad$ H HYDROGEN BOND CHAIN (tHBC)

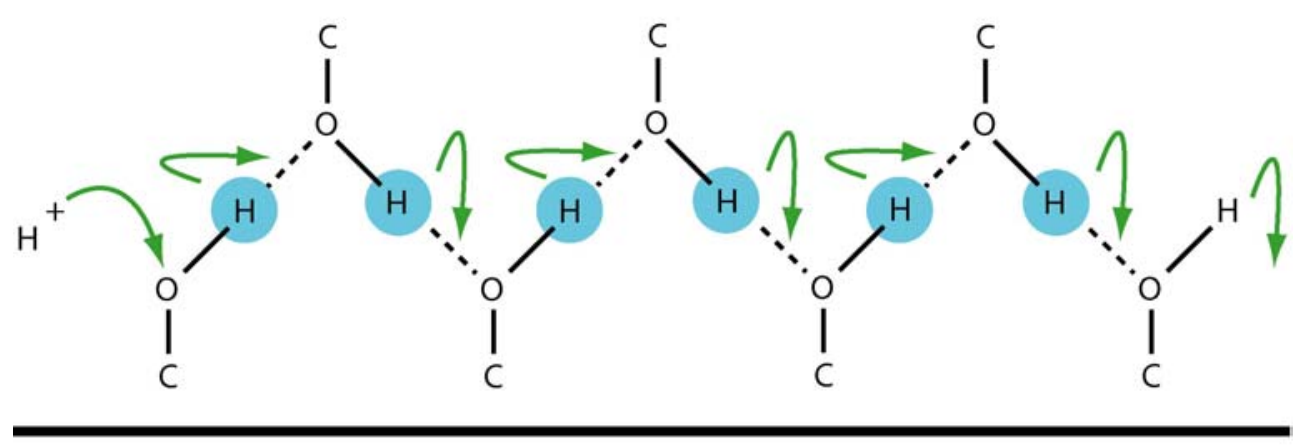

C CLUSTER-CONTACT MECHANISM

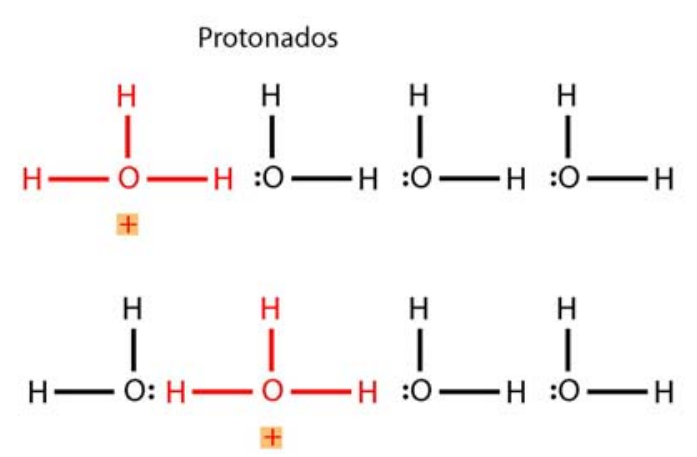

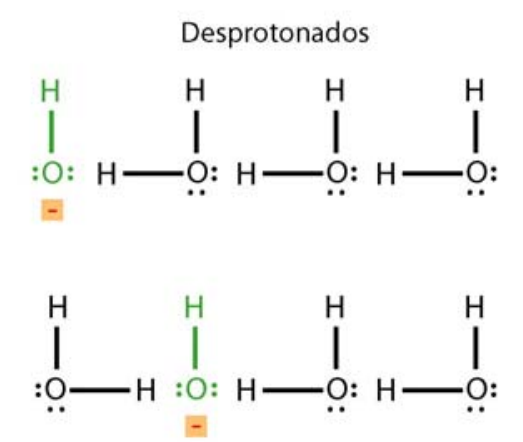

Figura 3: Possíveis mecanismos difusionais de prótons em membranas biológicas. A: water wire, adaptado de DECOURSEY (2003). B: tHBC ( $t$ Hydrogen Bond Chain), adaptado de DECOURSEY (2003). C: cluster-contact mechanism, adaptado de HAINES (2001).

\subsection{Os ácidos graxos como transportadores de prótons}

No início da década de 90, KAMP e HAMILTON (Department of Physiology and Biophysics - University of Boston), ao estudarem a translocação de ácidos graxos em vesículas unilamelares que continham encapsuladas um probe fluorescente de piranina solúvel em água e sensível ao $\mathrm{pH}$ do meio, observaram que a adição de ácidos graxos livres a solução externa ou mesmo a formação de vesículas com ácidos graxos livres incorporados promovia um decaimento da fluorescência devido à diminuição do pH intravesicular. Essa diminuição 
ocorria de forma rápida (em menos de 10 segundos ocorria um decaimento de cerca de 0.22 unidades de $\mathrm{pH}$ ) e foi atribuída a rápida transferência (flip-flop) da forma protonada (i.e., não ionizada) dos ácidos graxos. Subseqüentemente, com a adição de albumina a solução externa, foi observada uma elevação do $\mathrm{pH}$ intravesicular, que foi atribuída a retirada de ácidos graxos da membrana pela albumina. Posteriormente, usando fluorescência do tipo "stopped-flow", os mesmos autores mostram que o decaimento do $\mathrm{pH}$ pode ocorrer ainda mais rapidamente, na escala de tempo de milisecundos, sem diferenças entre os diversos ácidos graxos. Achados semelhantes foram encontrados em células $\beta$-pancreáticas e adipócitos (KAMP \& HAMILTON, 1992, 1993; HAMILTON et al., 1994; KAMP et al., 1995; CIVELEK et al., 1996).

Baseando-se nestes achados, HAMILTON \& KAMP (1998), propuseram um modelo para o transporte de prótons através da membrana acoplado ao transporte de ácidos graxos. Este modelo é constituído pelas seguintes etapas (Figura 4):

(1) associação do próton com a forma aniônica da molécula de ácido graxo, que se encontra localizada no hemifolheto externo da membrana, formando a forma neutra da molécula de ácido graxo;

(2) flip-flop da forma neutra da molécula de ácido graxo do hemifolheto externo para o hemifolheto interno da membrana;

(3) dissociação da forma neutra da molécula de ácido graxo, liberando os prótons para o citosol e regenerando uma molécula de ácido graxo à forma aniônica;

(4) flip-flop da forma aniônica da molécula de ácido graxo do hemifolheto interno para o hemifolheto externo da membrana. No entanto, a translocação da forma aniônica seria lenta por representar a movimentação de uma carga negativa no interior hidrofóbico da membrana.

Dessa forma, atualmente os ácidos graxos são incluídos na classe dos dissipadores de gradientes de prótons (SKULACHEV, 1998). 


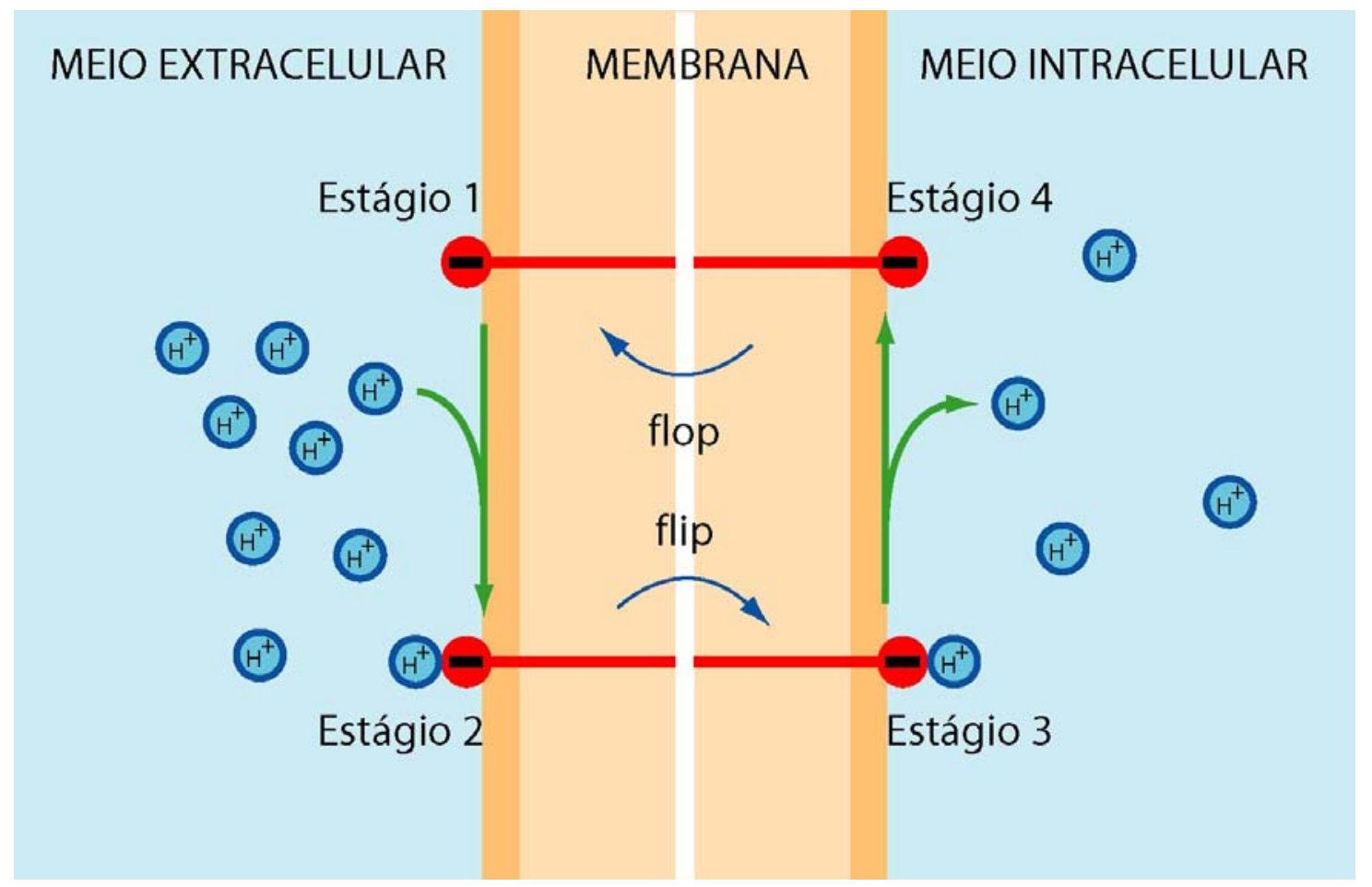

Figura 4: Mecanismo de transporte de prótons por ácidos graxos. Esquematização do transporte de prótons através de uma membrana lipídica pelo mecanismo de flip-flop dos ácidos graxos. Estágio 1: associação do próton com a forma ionizada dos ácidos graxos. Estágio 2: translocação (flip-flop) através da membrana da forma neutra do ácido graxo. Estágio 3: dissociação da forma neutra do ácido graxo, liberando um próton para o citosol e regenerando a forma ionizada do ácido graxo. Estágio 4: translocação (flip-flop) através da membrana da forma ionizada do ácido graxo. Adaptado de HAMILTON \& KAMP (1998).

Contemporaneamente aos estudos de Hamilton e Kamp, GUTKNECHT (1988), utilizando bicamadas lipídicas planas de difitanoilfosfatidilcolina e diferentes ácidos graxos, mostrou que a adição destes às bicamadas fosfolipídicas causa um aumento da condutância a prótons proporcional à concentração de ácidos graxos na solução aquosa ou no interior da membrana (bicamadas formadas por uma mistura de fosfolipídeos e ácidos graxos livres). Ainda, nesse mesmo trabalho, foi estimada a taxa de translocação de ácidos graxos a partir da condutância a prótons e da concentração de ácidos graxos no interior da membrana, supondo ser a etapa limitante do processo o flip-flop da forma ionizada do ácido graxo, devido à sua baixa solubilidade no interior lipídico da membrana. O fluxo da forma ionizada (aniônica) foi então estimado pela seguinte relação:

$$
J_{A}=\frac{R \times T \times G_{H^{+}}}{F^{2}}
$$

que pode ser obtida a partir da equação clássica:

$$
G_{H^{+}}=\frac{F^{2}}{R \times T} \times P_{H^{+}} \times C_{H^{+}} \text {e, fazendo } P_{H^{+}} \times C_{H^{+}}=J_{A}
$$


onde: $\mathrm{R}$ - constante geral dos gases, $\mathrm{T}$ - temperatura absoluta, $\mathrm{G}_{\mathrm{H}}{ }^{+}$- condutância a próton, $\mathrm{F}$ constante de Faraday, $\mathrm{P}_{\mathrm{H}}{ }^{+}$- permeabilidade a próton e $\mathrm{C}_{\mathrm{H}}{ }^{+}$- concentração de prótons no banho.

A constante de flip-flop $\left(k_{f f}\right)$ foi então calculada como:

$$
k_{f f}=\frac{J_{A}}{[\text { ácido graxo }]_{\text {sup erficie }}}
$$

onde: [ácido graxo] $]_{\text {superficie }}$ - concentração superficial da forma ionizada do ácido graxo.

As $k_{f f}$ para os ácidos palmítico, oléico e mirístico foram da ordem de $10^{-4} \mathrm{~s}^{-1}$. Assim, quando os comparamos aos protonóforos clássicos, como por exemplo o FCCP (carbonylcyanide p-trifluoromethoxyphenylhydrazone), os ácidos graxos são considerados transportadores pouco eficientes de prótons; para obter-se uma condutância a prótons de 100 $\mathrm{nS} \mathrm{cm}{ }^{-2}$ é necessário uma concentração de ácido oléico 3 a 4 vezes maior do que a de FCCP (GUTKNECHT, 1988).

A eficiência dos protonóforos em transportar prótons deve-se, em parte, à presença de elétrons $\pi$ (anel aromático), que delocalizam a carga na molécula por ressonância, diminuindo sua polaridade e determinando um aumento em sua solubilidade na região de baixa constante dielétrica da membrana (MCLAUGHLIN \& DILGER, 1980; GUTKNECHT, 1988).

\subsection{Os ácidos graxos e as membranas biológicas}

Tanto nos organismos unicelulares quanto nos pluricelulares o citoplasma está separado do meio extracelular por uma membrana composta basicamente de lipídeos e proteínas. Ainda, as membranas apresentam substancial importância no mecanismo de compartimentalização dos organismos, separando o meio interno das diversas organelas intracelulares do citoplasma.

A principal classe de lipídeos das membranas biológicas é constituída pelos fosfolipídeos, cujos precursores são os ácidos graxos de cadeia longa. Os fosfolipídeos, assim como os ácidos graxos, são moléculas anfifílicas e podem apresentar carga total neutra ou não, dependendo do substituinte na 'cabeça' da molécula. Substituintes eletricamente neutros conferem carga negativa ao fosfolipídeo, enquanto que substituintes com carga positiva fazem com que o fosfolipídeo se torne uma molécula neutra, no entanto polarizada ("zwitterionica").

Apesar do caráter anfifílico, as membranas biológicas não são estruturas totalmente impermeáveis. Moléculas apolares pequenas, como o oxigênio e o óxido nítrico, ao se solubilizarem no interior hidrofóbico da membrana, se difundem livremente. Mesmo algumas 
moléculas polares, como a água e íons (como discutido acima para o transporte passivo de prótons), podem se difundir através da membrana contra uma grande barreira energética - a baixa constante dielétrica da membrana (HAINES, 2001).

As características estruturais dos fosfolipídeos per se ainda podem influenciar na translocação dos ácidos graxos. Estudos em mitocôndrias e vesículas unilamelares mostram que a mobilidade da molécula de ácido graxo no interior hidrofóbico das membranas é otimizada quando o comprimento da molécula do ácido graxo é a metade da espessura da membrana, ou seja, igual ao comprimento de um hemifolheto; assim, a energia de ativação para a translocação do ácido graxo é minimizada (ZENG et al., 1998).

Tem sido reportado que, além dos fosfolipídeos, diversos outros componentes estruturais da membrana podem influenciar a permeabilidade a íons (em especial, prótons) e/ou a translocação de ácidos graxos através da membrana. Os exemplos mais interessantes são o colesterol e a cardiolipina $(\mathrm{HOCH}, 1998)$.

O colesterol (Figura 5), assim como os fosfolipídeos, estruturalmente apresenta duas regiões bem distintas: um grupamento hidroxila $(-\mathbf{O H})$, conferindo um caráter hidrofílico, conectado a uma porção hidrofóbica (grupamento alifático lateral). A porção hidrofóbica é estruturalmente rígida e ao se intercalar com as moléculas dos fosfolipídeos diminui a difusão lateral destes - efeito condensador proposto para o colesterol (VOET \& VOET, 1995). Com isso, as moléculas de colesterol são capazes de alterar propriedades físico-químicas das membranas, como temperatura de transição de fase e nível de hidratação, alterando de modo importante a permeabilidade das membranas a água e outras substâncias. PAPAHADJOPOULOS et al. (1971) mostraram que a permeabilidade a $\mathrm{K}^{+}, \mathrm{Na}^{+}, \mathrm{Cl}^{-}$e glicose de lipossomas é diminuída com o aumento do conteúdo de colesterol. Já STILLWELL et al. (1996) observaram o mesmo efeito para prótons, onde o aumento no conteúdo de colesterol de vesículas unilamelares diminuía consideravelmente a permeabilidade a prótons das mesmas.

A cardiolipina é um fosfolipideo com características estruturais bem peculiares. Encontrada apenas na membrana interna da mitocôndria de eucariotos e em procariotos, sua estrutura apresenta 4 ácidos graxos, 2 grupamentos fosfato e 3 gliceróis (Figura 5). As cadeias acilas podem ser saturadas ou insaturadas, no entanto possuem de 16 a 18 carbonos e não mais que 3 insaturações. Especificamente para a membrana interna da mitocôndria de eucariotos, sua distribuição entre os dois hemifolhetos é assimétrica. Cardiolipinas com cadeias acilas insaturadas ocupam preferencialmente o hemifolheto interno e cardiolipinas com cadeias acilas saturadas o hemifolheto externo. 


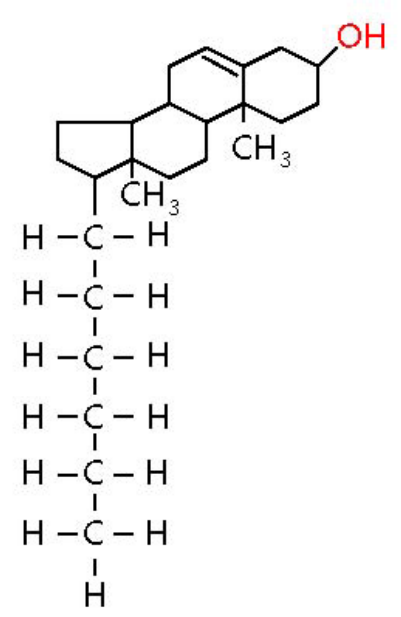

\section{CARDIOLIPINA}

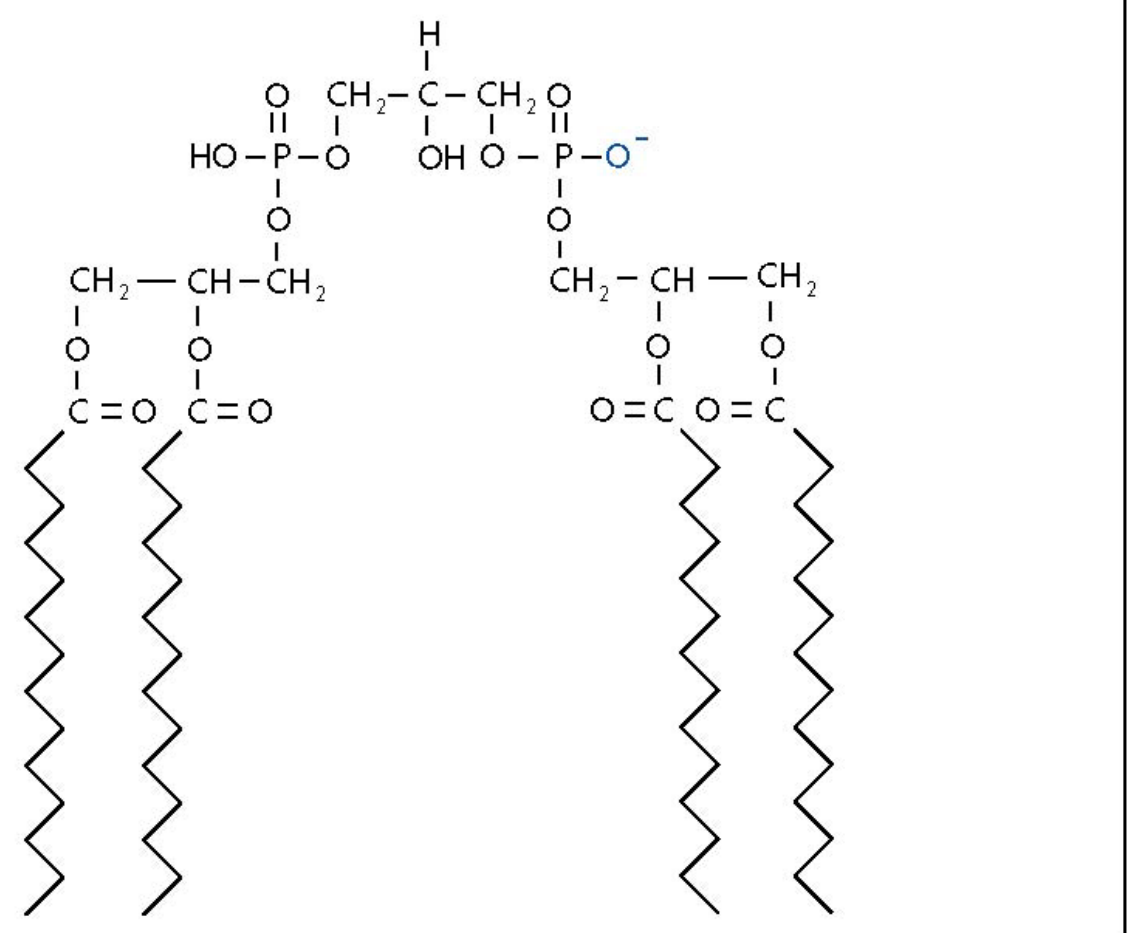

Figura 5: Estrutura molecular do colesterol e da cardiolipina. O colesterol foi utilizado como modelo de modificador da membrana plasmática de eucariotos e a cardiolipina como modelo de modificador da membrana interna da mitocôndria.

HOCH (1998) propôs que as cardiolipinas, em conjunto com outras substâncias, seriam responsáveis pelo vazamento de prótons através da membrana interna da mitocôndria, por um mecanismo denominado "antena" de prótons. Moléculas de cardiolipina localizadas no hemifolheto externo da membrana captariam prótons, transferindo-os para cadeias de 
moléculas de água organizadas ao longo dos fosfolipídeos (transporte passivo de prótons, descrito acima), ou para ácidos graxos livres, ou mesmo para proteínas desacopladoras (UCPs).

Dessa forma, uma vez que as membranas fosfolipídicas e seus outros constituintes interferem tanto com o transporte de moléculas polares como das apolares, se torna necessário entendermos como essas membranas interferem tanto com o mecanismo passivo de prótons como com o mecanismo de acoplamento entre prótons e ácidos graxos. Ao nosso ver, esse conhecimento contribui para melhor entendermos o mecanismo de captação celular dos ácidos graxos e também o mecanismo desacoplador de gradientes de prótons atribuído as essas moléculas. 


\section{OBJETIVOS}

Através de medidas elétricas em bicamadas lipídicas planas, o presente estudo tentou elucidar diversos aspectos do transporte passivo de prótons e do transporte de prótons mediado por ácidos graxos livres, tendo como principais objetivos:

- avaliar o efeito do comprimento da cadeia acila dos ácidos graxos;

- avaliar o efeito da presença e do número de insaturações presentes na cadeia acila dos ácidos graxos;

- avaliar o efeito do tipo de insaturação (cis ou trans) presente na cadeia acila dos ácidos graxos;

- avaliar o efeito da carga de superfície dos fosfolipídeos;

- avaliar o efeito do colesterol; e

- avaliar o efeito da cardiolipina 


\section{MATERIAIS E MÉTODOS}

\subsection{Materiais Usados}

Di-fitanoil-fosfatidil-colina (DPhPC) foi obtida de Avanti Polar Lipids (Birminham, AL, USA). De Sigma (St. Louis, MO, USA) foram obtidos tris-hidroxi-aminometano (Tris), L- $\alpha$-fosfatidilcolina soybean (Asolectina), cardiolipina e os ácidos graxos: caprílico, palmítico, esteárico, oléico, elaídico, linoléico, araquidônico e docosahexaenóico. Colesterol foi obtido de Serva Feinbiochemica (Heidelberg, GER) e de ICN Pharmaceuticals foi obtido n-decano (Plainview, NY, USA).

\subsection{Formação das Membranas}

As membranas, para obtenção de medidas elétricas, foram formadas utilizando a técnica de bicamadas lipídicas planas. As características que as tornam um sistema adequado em estudos eletrofisiológicos são: (a) apresentam raio de curvatura intrínseco muito grande, assemelhando-se mais com a matriz lipídica das membranas naturais do que vesículas unilamelares; (b) são desprovidas de transportadores específicos, podendo estes serem incorporados; (c) apresentam possibilidade de extenso monitoramento elétrico, com alta sensibilidade a pequenas alterações; (d) apresentam possibilidade de monitoramento e modificação do pH bilateralmente; e (e) apresentam possibilidade de troca ou alteração da composição iônica e/ou protéica de ambos os lados (compartimentos) da solução de preenchimento.

As bicamadas lipídicas planas foram formadas pelo método de MUELLER et al. (1963) em um orifício circular ( $\approx 1.0 \mathrm{~mm}$ de diâmetro) formado na parede de um frasco de polipropileno cilíndrico (Wheaton Liquid Scintillation Vials, Millville, NJ, EUA), acoplado a uma câmara de acrílico. Esse sistema define dois compartimentos, designados por cis (anterior) e trans (posterior), como mostra a figura 6. 


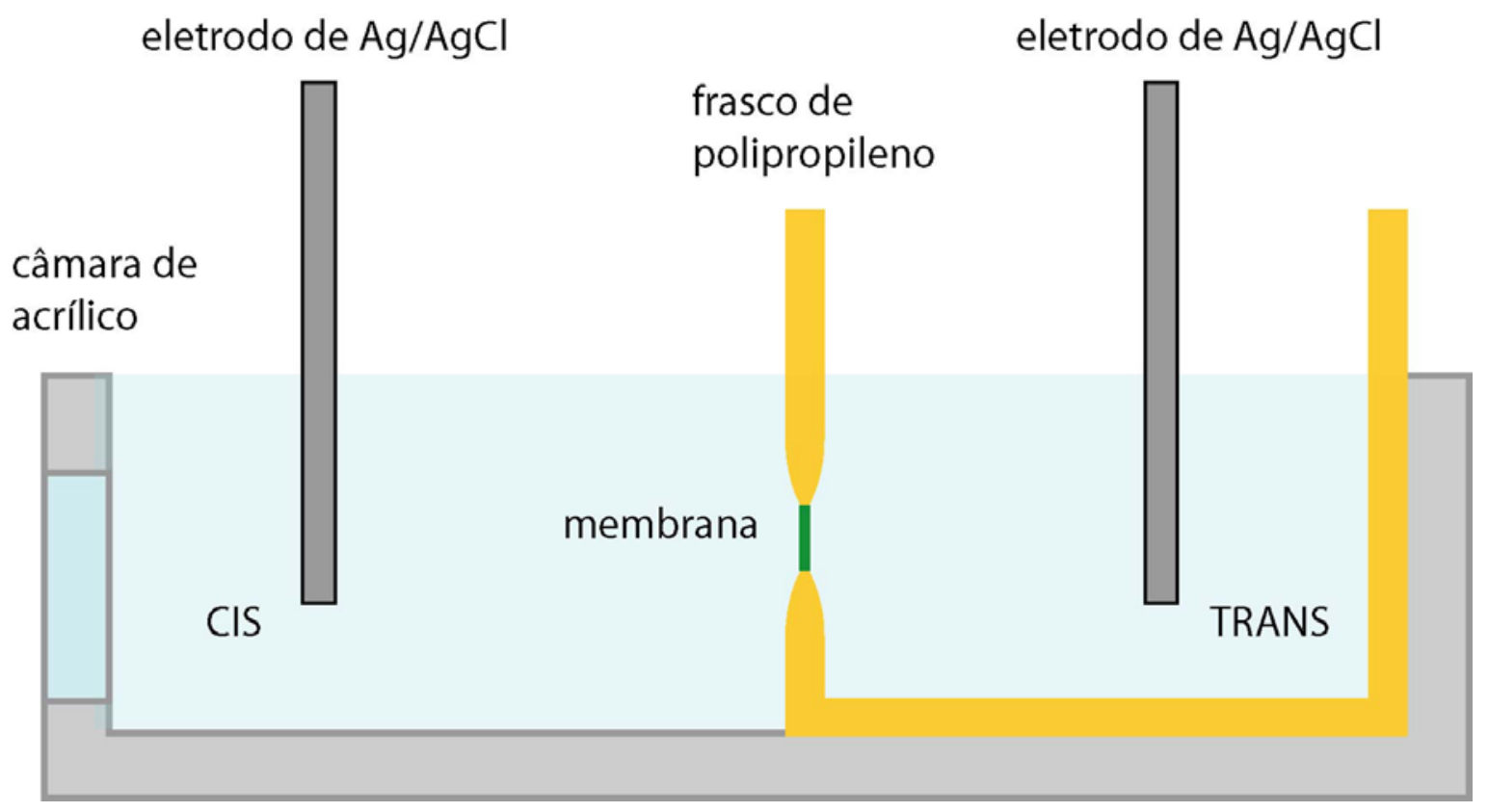

Figura 6: Câmaras utilizadas para a formação de bicamadas lipídicas planas. $O$ acoplamento do frasco de polipropileno com a câmara de acrílico define dois compartimentos: cis (frente) e trans (atrás). Bicamadas lipídicas planas eram formadas em um orifício circular localizado na parede do frasco de poplipropileno. As soluções que preenchiam os compartimentos eram compostas por $\mathrm{KCl}(5 \mathrm{mM})$ e tamponadas com Tris $(5 \mathrm{mM})$ e $\mathrm{KH}_{2} \mathrm{PO}_{4}$. A conexão entre as duas soluções, i.e. entre os dois compartimentos e os equipamentos de medida foi realizada através de um par de eletrodos de $\mathrm{Ag} / \mathrm{AgCl}$.

As bicamadas lipídicas planas foram formadas a partir de soluções estoques em $n$ decano (25 mg mL $\mathrm{mL}^{-1}$ ) dos fosfolipídeos DPhPC ou Azolecitina. Em alguns grupos experimentais, também foram usados $\mathrm{DPhPC}$ com colesterol ou cardiolipina. As características de cada fosfolipídeo e das misturas são mostradas na Tabela 1.

A área (A) das bicamadas foi estimada através das seguintes relações:

Diâmetro da bicamada $=$ diâmetro do orifício $-(2 \times l \arg$ ura do tôrus $)$

Assim,

$$
A=\pi \times R^{2} \quad(e q .6)
$$

onde: R é o raio da bicamada (metade do diâmetro da bicamada).

A área total das bicamadas era controlada, através do aumento ou diminuição do tôrus, e apresentavam valores entre $3-5 \times 10^{-3} \mathrm{~cm}^{2}$. 
Tabela 1: Características gerais dos fosfolipídeos (e respectivas misturas) utilizados para a obtenção de parâmetros elétricos em bicamadas lipídicas planas

\begin{tabular}{|c|c|c|}
\hline Fosfolipídeo & Composição & Características \\
\hline \multirow{4}{*}{ DPhPC } & $100 \% \mathrm{DPhPC}$ & Eletricamente neutra \\
\hline & $83 \% \mathrm{DPhPC}+17 \%$ Colesterol $^{(1)}$ & $\begin{array}{l}\text { Eletricamente neutra. Proporção } \\
\text { fosfolipideo/colesterol semelhante } \\
\text { a encontrada na membrana } \\
\text { plasmática de mamíferos }{ }^{(2)}\end{array}$ \\
\hline & & Carregada negativamente. \\
\hline & $79 \% \mathrm{DPhPC}+21 \%$ Cardiolipina $^{(1)}$ & $\begin{array}{l}\text { Proporção fosfolipídeo/cardiolipina } \\
\text { semelhante a encontrada na } \\
\text { membrana interna da mitocôndria } \\
\text { (2) }\end{array}$ \\
\hline Asolectina & $100 \%$ Asolectina & $\begin{array}{l}\text { Formada por um conjunto de } \\
\text { fosfolipídeos. } \\
\text { negativamente }\end{array}$ \\
\hline \multicolumn{3}{|c|}{${ }^{(1)}$ porcentagem em peso } \\
\hline (2) VOET \& & OET (1995) & \\
\hline
\end{tabular}

\subsection{Solução de Preenchimento}

As soluções aquosas utilizadas para preencher os dois compartimentos (cis e trans) continham $\mathrm{KCl}(5 \mathrm{mM})$ e eram tamponadas com Tris $(5 \mathrm{mM})$ e $\mathrm{KH}_{2} \mathrm{PO}_{4}(5 \mathrm{mM})$. O pH inicial era ajustado a um valor de 7,4, com $\mathrm{HCl}$ ou $\mathrm{KOH}$. Dessa forma, ambos compartimentos eram preenchidos com baixa força iônica total, afim de maximizar os efeitos de carga superficial e minimizar a condutância da via de vazamento.

\section{4. Ácidos Graxos}

Os ácidos graxos eram incorporados às bicamadas lipídicas através da adição de uma alíquota $(\sim 4 \mu \mathrm{L})$ de solução estoque etanólica à fase aquosa de ambos compartimentos, cis e trans. A concentração molar final, ou seja, na solução de preenchimento ficava em torno de $50 \mu \mathrm{M}$.

A representação molecular de cada ácido graxo utilizado é apresentada na Figura 7 

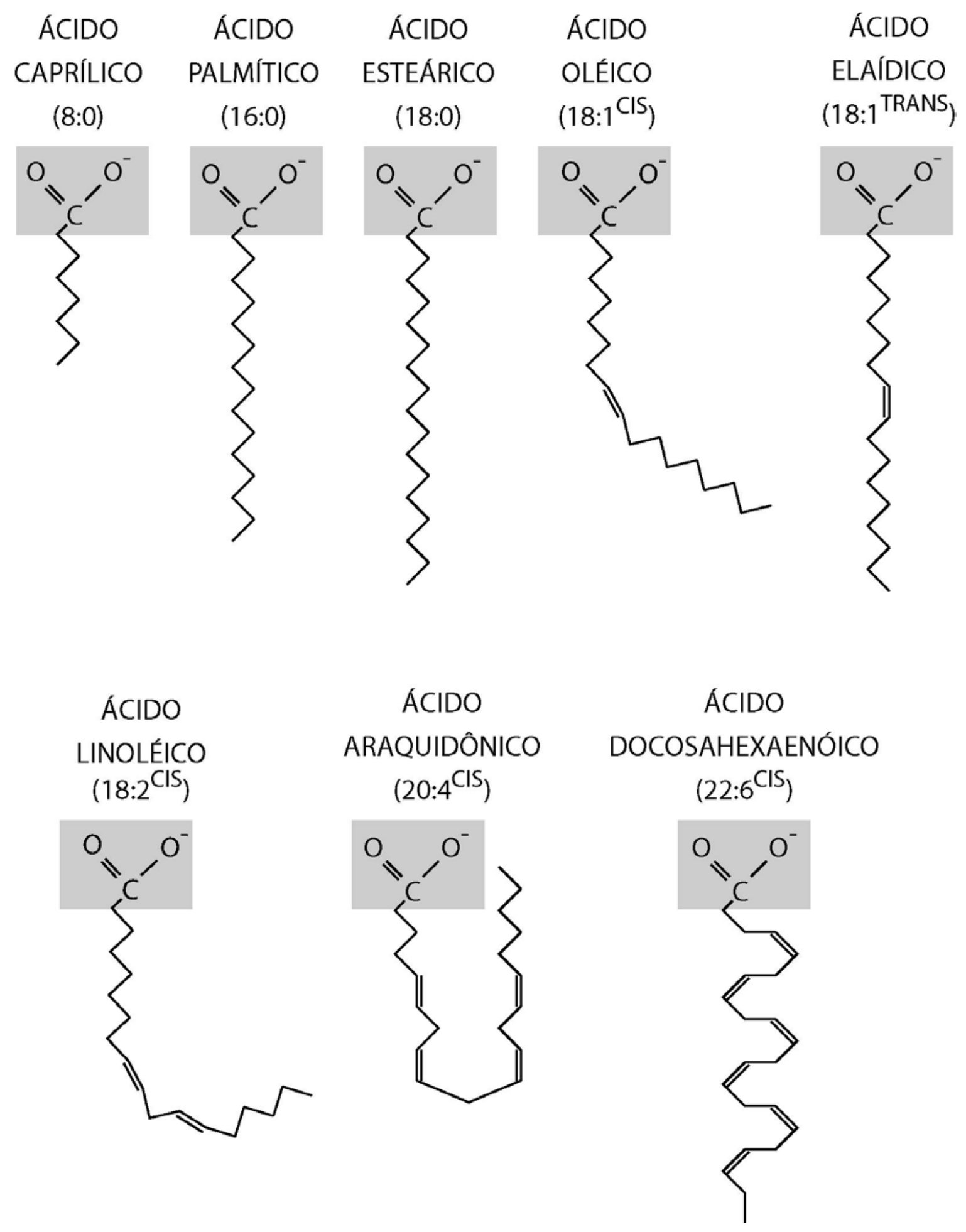

Figura 7: Representação molecular da forma aniônica dos ácidos graxos utilizados. Acima de cada representação é expresso o nome do ácido graxo, o número de carbonos e o número de insaturações, além do tipo de insaturação cis ou trans.

\subsection{Gradientes de Próton}

Os gradientes transmembrana de próton foram obtidos através da adição de alíquotas de $\mathrm{H}_{2} \mathrm{SO}_{4}(0,1 \mathrm{M})$ ao compartimento cis, produzindo deltas de $\mathrm{pH}$ entre 0.5 e 1.0 unidades. Os 
pHs foram medidos ao final de cada experimento através de alíquotas de $200 \mu \mathrm{L}$ retiradas das soluções de preenchimento em um Radiometer Copenhagen ABLP5.

O potencial de equilíbrio para o próton $\left(\mathrm{E}_{\mathrm{H}}{ }^{+}\right)$foi estimado a partir da diferença de $\mathrm{pH}$ $(\Delta \mathrm{pH})$ medida, utilizando a equação de Nernst:

$$
E_{H^{+}}=\frac{R T}{z F} \ln \frac{\left[H^{+}\right]_{c i s}}{\left[H^{+}\right]_{\text {trans }}}=0.059 \times \Delta p H
$$

onde: $\mathrm{R}$ - constante dos gases; $\mathrm{T}$ - temperatura absoluta; $\mathrm{z}$ - valência do íon; F - constante de Faraday.

\subsection{Set-up Experimental}

O conjunto formado pela câmara de acrílico e o frasco de polipropileno era colocado no interior de uma gaiola de Faraday, oferecendo uma blindagem elétrica ao sistema, contra interferências elétricas externas. Além disso, a gaiola de Faraday era colocada sobre uma mesa que continha um sistema anti-vibração, composto por molas e amortecedores de borracha, minimizando vibrações mecânicas externas. A conexão entre as soluções que preenchiam os compartimentos cis e trans e os instrumentos de medida (descritos abaixo) foi feita através de eletrodos de $\mathrm{Ag} / \mathrm{AgCl}$, previamente cloretados por imersão em hipoclorito de sódio. Os eletrodos ficavam imersos na solução, como mostra a figura 6 . O eletrodo de referência ficava imerso no compartimento cis e era terrado, i.e. potencial elétrico igual a 0 (zero) $\mathrm{mV}$; o eletrodo de medida ficava imerso no compartimento trans e era conectado ao instrumento de medida. Previamente à formação da bicamada, o potencial de eletrodo $\left(\mathrm{V}_{\text {eletrodo }}\right)$ existente entre o par de eletrodos era determinado; se este potencial fosse maior que $1 \mathrm{mV}$ o par de eletrodos era cloretado novamente.

Agitações das soluções de preenchimento eram realizadas após a adição tanto de $\mathrm{H}_{2} \mathrm{SO}_{4}$ quanto de ácido graxo, afim de obter homogeneização da mistura. A agitação era feita por meio de fluxo de ar externo obliquamente dirigido a superfície externa da solução, por um período de aproximadamente 5 minutos em cada compartimento.

A visualização das bicamadas foi realizada através de um microscópio estereoscópico com aumento de 20 a $40 \mathrm{X}$. 


\subsection{Medidas Elétricas}

As medidas elétricas foram obtidas através de dois diferentes protocolos, como descritos abaixo:

a) Protocolo 1: Eletrômetro de alta impedância $\left(2 \times 10^{14} \Omega\right)$ - Keithley, modelo 616 (Cleveland, Ohio, USA)

O eletrômetro (anexo 2) foi usado em membranas que apresentavam resistências elétricas tipicamente altas ( $\geq 80 \mathrm{Gohm}$ ) e correntes abaixo de $1 \mathrm{pA}$. Correntes muito baixas e o uso de membranas com áreas relativamente grandes ( $\approx 1 \mathrm{~mm}$ de diâmetro), como as usadas neste projeto, inviabilizavam o uso do amplificador de patch-clamp pela incapacidade deste em medir correntes menores que $1 \mathrm{pA}$ de forma confiável sobre o ruído de fundo dessas membranas. Assim, o eletrômetro foi usado para obtenção dos parâmetros elétricos de membranas modificadas pelos seguintes ácidos graxos: caprílico, palmítico, esteárico e elaídico.

O protocolo utilizado para a obtenção dos parâmetros elétricos com o uso do eletrômetro foi realizada da seguinte forma: formação da bicamada $\rightarrow$ medida dos parâmetros elétricos $\rightarrow$ adição de $\mathrm{H}_{2} \mathrm{SO}_{4}$ ao compartimento cis $\rightarrow$ medida dos parâmetros elétricos $\rightarrow$ adição de ácido graxo aos compartimentos cis e trans, simultaneamente $\rightarrow$ medida dos parâmetros elétricos $\rightarrow$ coleta de solução para medida dos pHs nos compartimentos cis e trans.

O eletrômetro foi utilizado nos modos voltímetro, ohmímetro ou amperímetro, fornecendo, respectivamente, os valores da voltagem através da membrana $\left(\mathrm{V}_{\mathrm{m}}\right)$, resistência elétrica da membrana $\left(\mathrm{R}_{\mathrm{m}}\right)$ e corrente de curto-circuito (CCC).

No modo voltímetro (Figura $8 \mathrm{~A}$ ), o valor de $\mathrm{V}_{\mathrm{m}}$ é lido diretamente. Representando eletricamente a membrana como uma resistência elétrica (por exemplo, $R_{\mathrm{m}}$ de $50 \times 10^{9} \mathrm{ohm}$ ) em série com uma bateria $\left(E_{m}=60 \mathrm{mV}\right)$ e incluindo neste circuito o eletrômetro, cuja resistência interna $\left(\mathrm{R}_{\mathrm{iE}}\right)$ é de $2 \times 10^{14} \mathrm{ohm}$, a corrente circulante (i) é dada por:

$$
i=\frac{E_{m}}{R_{m}+R_{i E}}=\frac{60 \times 10^{-3}}{\left(50 \times 10^{9}\right)+\left(2 \times 10^{14}\right)}=3 \times 10^{-16} p \mathrm{~A}
$$

Assim, podemos calcular $\mathrm{V}_{\mathrm{m}}$ aplicando a $1^{\mathrm{a}}$ Lei de Ohm:

$$
V_{m}=i \times R_{i E}=\left(3 \times 10^{-16}\right) \times\left(2 \times 10^{14}\right)=60 \mathrm{mV}
$$

Portanto, no modo voltímetro o eletrômetro mede fielmente o valor de $\mathrm{V}_{\mathrm{m}}$.

No modo ohmímetro (Figura 8B), o eletrômetro aplica uma corrente ( $i_{\text {injetada }}$ ) determinada (1, 10 ou 100 pA) através da membrana (funcionando como um "current- 
clamp"). Tomando-se como exemplo uma membrana cuja FEM ( $\left.\mathrm{E}_{\mathrm{m}}\right)$ é de $60 \mathrm{mV}$, aplicandose uma corrente de $1 \mathrm{pA}$ e, por exemplo, obtendo-se um $\mathrm{V}_{\mathrm{m}}$ de $110 \mathrm{mV}$, a resistência da membrana $\left(\mathrm{R}_{\mathrm{m}}\right)$ é dada por:

$$
R_{m}=\frac{V_{m}-E_{m}}{i_{\text {injetada }}}=\frac{0.110-0.060}{1 \times 10^{-12}}=5 \times 10^{10}=50 G \Omega
$$

OBS.: note-se que a voltagem obtida antes da aplicação do pulso de corrente, a qual corresponde a voltagem gerada pela bateria $\left(\mathrm{E}_{\mathrm{m}}\right)$, deve ser subtraída da voltagem $\left(\mathrm{V}_{\mathrm{m}}\right)$ obtida com o pulso de corrente.

Os valores de resistência são também convertidos para condutância $\left(G_{m}\right)$, já que: $G_{m}=1 / R_{m}$

No modo amperímetro (Figura 8C), o multiplicador era ajustado até obter-se uma leitura menor que $1 \mathrm{mV}$. Isto eqüivale a reduzir-se a resistência interna do eletrômetro até a obtenção de uma $\mathrm{V}_{\mathrm{m}}$ abaixo de $1 \mathrm{mV}$, produzindo um curto-circuito virtual. Dessa forma, a diferença de voltagem através da resistência interna do eletrômetro é igual ao $V_{m}$ e, novamente através da $1^{\mathrm{a}}$ Lei de Ohm, obtínhamos a corrente que passa pela membrana. Retornando a membrana da Figura 8A (modo voltímetro), cujo $\mathrm{E}_{\mathrm{m}}$ é de $60 \mathrm{mV}$ e $\mathrm{R}_{\mathrm{m}}$ de $50 \mathrm{x}$ $10^{9} \mathrm{ohm}$, teremos um $\mathrm{V}_{\mathrm{m}}$ de $60 \mathrm{mV}$; no entanto, se a resistência interna do eletrômetro for reduzida de $2 \times 10^{14} \mathrm{ohm}$ para $1 \times 10^{8} \mathrm{ohm}$, o novo valor do $\mathrm{V}_{\mathrm{m}}$, obtido através das equações 8 e 9 é de $0.119 \mathrm{mV}$, ou seja, teremos uma condição de curto circuito virtual e a CCC será:

$$
C C C=\frac{V_{m}}{R_{i E}}=\frac{0.000119}{1 \times 10^{8}}=1.19 p A
$$



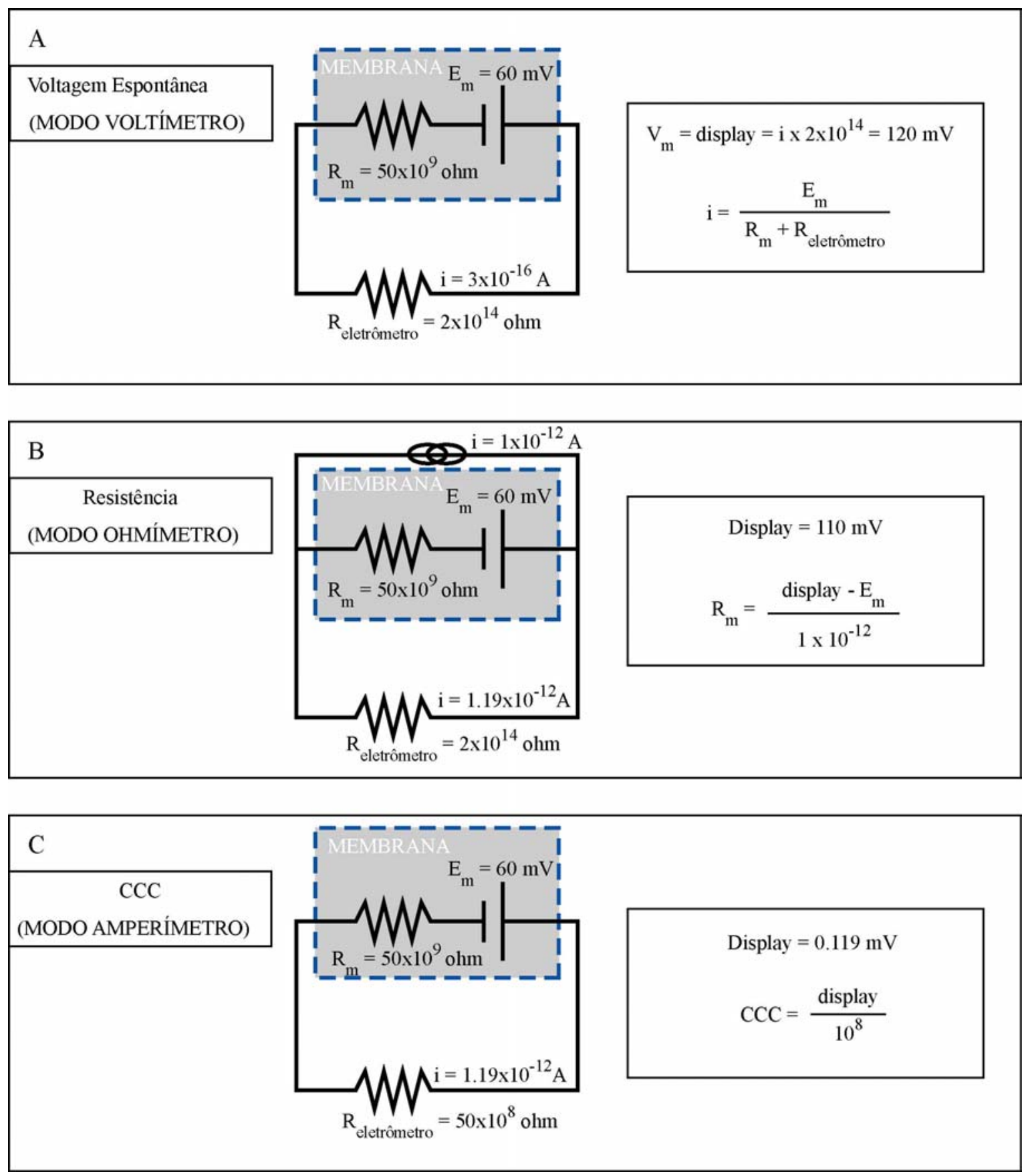

Figura 8: Representação elétrica dos três modos de operação do eletrômetro. (A): Modo amperímetro, utilizado para a medida da voltagem transmembrana $\left(\mathrm{V}_{\mathrm{m}}\right)$; (B): Modo ohmímetro, utilizado para a medida de resistência da membrana $\left(\mathrm{R}_{\mathrm{m}}\right)$ e; (C): Modo amperímetro, utilizado para a medida da corrente de curto-circuito (CCC). Esta técnica foi utilizada com os seguintes ácidos graxos: palmítico, esteárico e elaídico. 
b) Protocolo 2: Amplificador de Patch-clamp (modo Voltage-clamp) - Dagan, modelo 8900 (Minneapolis, MN, USA).

O amplificador de patch-clamp (anexo 3), como mencionado anteriormente, não constituía um sistema compatível para medidas de correntes abaixo de $1 \mathrm{pA}$, por conseguinte, sua utilização se deu com os seguintes ácidos graxos: oléico, linoléico, araquidônico e docosahexaenóico.

O amplificador de patch-clamp, com probe de $10 \mathrm{GOhm}$, foi configurado no modo voltage-clamp e ficava acoplado a um osciloscópio digital - Tektronix, modelo TDS340A. Os valores de saída de corrente $\left(\mathrm{I}_{\mathrm{out}}\right)$ do amplificador eram convertidos para a forma digital através de uma interface análogo-digital do tipo Labmaster e adquiridos por um software (Axotape 2.0) por meio de um computador.

No modo voltage-clamp ocorre a fixação da voltagem $\left(\mathrm{V}_{\text {clamp}}\right)$ através da membrana em um valor pré-determinado pelo experimentador, ficando os pontos 1 e 2 (Figura 9A) em um mesmo potencial elétrico. No entanto, na presença de uma diferença de potencial elétrico ou gradiente de concentração iônica tem-se corrente fluindo através da membrana. Esta corrente, chegando ao ponto 4 , faz com que o potencial do ponto 1 fique diferente do potencial do ponto 2. Assim, afim de manter os potenciais nesses dois pontos iguais, o amplificador injeta uma corrente pelo ponto 3, de mesma intensidade da corrente gerada pela membrana $\left(\mathrm{i}_{\mathrm{m}}\right)$, porém de sinal contrário $\left(-\mathrm{i}_{\mathrm{m}}\right)$ e, ao passar pela resistência de feed-back, gera uma voltagem de saída $\left(\mathrm{V}_{\text {out }}\right)$, assim:

$$
V_{\text {out }}=i_{m} \times R_{\text {feed-back }}
$$

Dessa forma, o amplificador de patch-clamp, no modo voltage-clamp, funciona como um conversor de corrente para voltagem. 


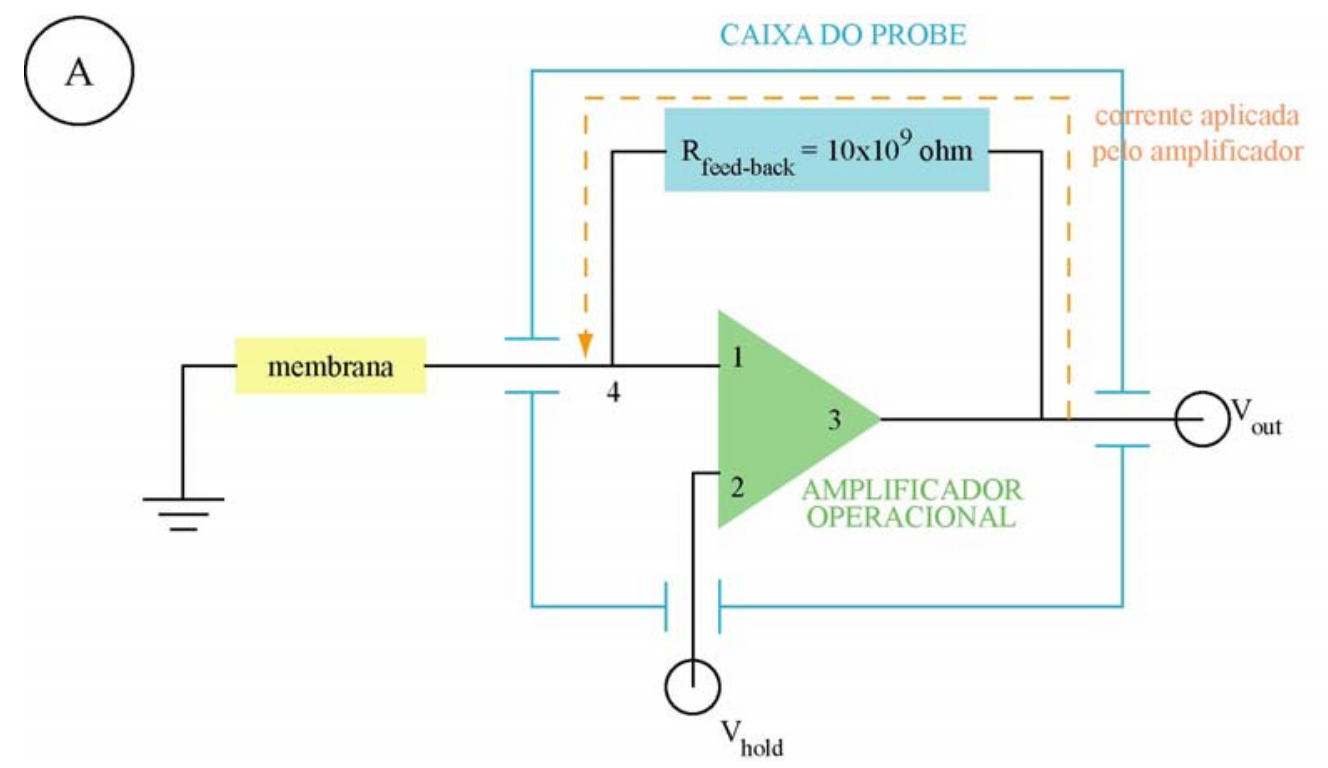

(B)

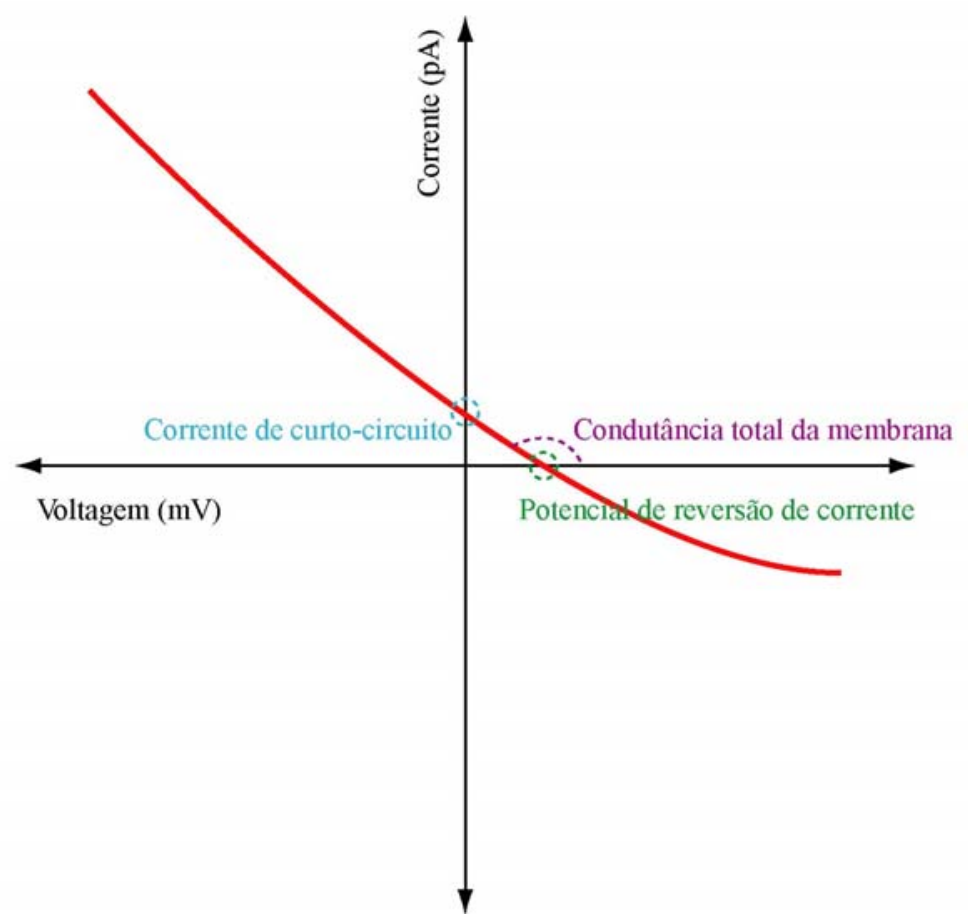

Figura 9: A) Representação esquemática do probe da técnica de patch-clamp com a membrana e seu respectivo funcionamento no modo voltage-clamp e B) parâmetros elétricos obtidos a partir de relações I-V. Descrição mais detalhada é feita no texto. Relações I-V foram obtidas com o Amplificador de patch-clamp no modo voltage-clamp. Esta técnica foi utilizada com os seguintes ácidos graxos: oléico, linoléico, araquidônico e docosahexaeníco.

Para avaliarmos os efeitos de ácidos graxos nos parâmetros elétricos de bicamadas lipídicas relações corrente versus voltagem (relações I x V) foram obtidas através da aplicação 
de pulsos de voltagem entre -120 e $+120 \mathrm{mV}$, em intervalos de $20 \mathrm{mV}$. Os parâmetros obtidos das relações I x V foram (Figura 9B):

- o potencial de reversão de corrente $\left(\mathbf{V}_{\text {rev }}\right)$, que corresponde ao potencial de membrana com zero de corrente;

- a corrente de curto-circuito (CCC), que corresponde a corrente com zero de voltagem; e

- a condutância total da membrana $\left(\mathbf{G}_{\mathbf{m}}\right)$, que corresponde ao coeficiente angular da reta obtida a partir da curva I x V no intervalo voltagem entre $-20 \mathrm{mV}$ e $+20 \mathrm{mV}$.

Algumas modificações, em relação ao protocolo utilizado com o eletrômetro, foram realizadas quando este protocolo (voltage-clamp) foi usado. A adição de ácidos graxos monoinsaturados (exceto ácido elaídico) ou poliinsaturados produziam membranas altamente condutivas, viabilizando o uso do amplificador de patch-clamp e, consequentemente, a obtenção de relações I x V. A seqüência de realização deste protocolo foi: formação da bicamada $\rightarrow$ medida dos parâmetros elétricos $\rightarrow$ adição de ácido graxo nos compartimentos

cis e trans, simultaneamente $\rightarrow$ medida dos parâmetros elétricos $\rightarrow$ adição de $\mathrm{H}_{2} \mathrm{SO}_{4}$ ao compartimento cis $\rightarrow$ medida dos parâmetros elétricos $\rightarrow$ coleta de solução para medida dos pHs nos compartimentos cis e trans.

\subsection{Cálculo da condutância a prótons}

Para o cálculo da condutância da membrana, formulamos um modelo baseado em condutâncias paralelas e independentes (o circuito elétrico equivalente é mostrado na Figura 10). Assim, considerando a condutância total da membrana $\left(G_{m}\right)$ formada por uma via seletiva a prótons, denominada de condutância a prótons $\left(\mathrm{G}_{\mathrm{H}}{ }^{+}\right)$, e uma via de vazamento inespecífica, denominada de condutância de vazamento $\left(\mathrm{G}_{\text {leak }}\right)$, temos:

$$
G_{m}=G_{H^{+}}+G_{\text {leak }}
$$

O potencial de equilíbrio da membrana $\left(\mathrm{E}_{\mathrm{m}}\right)$ é dado por:

$$
E_{m}=\frac{\left(E_{H^{+}} \times G_{H^{+}}\right)+\left(E_{\text {leak }} \times G_{\text {leak }}\right)}{G_{H^{+}}+G_{\text {leak }}}
$$

$\mathrm{G}_{\text {leak }}$ não apresenta força eletromotriz associada $\left(\mathrm{E}_{\text {leak }}=0\right)$ e não gera voltagem, sendo constituída por todas as vias de vazamento de corrente, incluindo o selamento de borda. Diferentemente, a via protônica apresenta uma força eletromotriz $\left(\mathrm{E}_{\mathrm{H}}^{+}\right)$associada, dada por:

$$
E_{H^{+}}=0.059 \times \Delta p H
$$


Assim, a membrana pode ser reduzida a um circuito equivalente contendo apenas uma força eletromotriz (igual a $E_{m}$ ), em série com uma resistência total da membrana $\left(R_{m}\right)$. Nesse caso, a voltagem espontânea da membrana $\left(\mathrm{V}_{\mathrm{m}}\right)$ é dada por:

$$
V_{m}=\frac{E_{H^{+}} \times G_{H^{+}}}{G_{H^{+}}+G_{\text {leak }}}
$$

Além disso, e baseando-se em nossos protocolos experimentais, o único gradiente de concentração presente era o de ácido sulfúrico $\left(\mathrm{H}_{2} \mathrm{SO}_{4}\right)$. Assumindo ser a membrana impermeável ao ânion sulfato $\left(\mathrm{SO}_{4}{ }^{-}\right)$, a corrente de curto-circuito (CCC) também pode ser expressa por:

$$
C C C=E_{H^{+}} \times G_{H^{+}}
$$

No entanto, como esses valores são calculados a partir dos dados experimentais? Para isso, consideramos dois casos: (OBS.: estando a membrana totalmente desconectada de qualquer instrumento de medida, sua voltagem $\left(\mathrm{V}_{\mathrm{m}}\right)$ é exatamente igual a $\mathrm{E}_{\mathrm{m}}$, porém não pode ser medida).

Caso 1 - medidas obtidas com o uso do eletrômetro: ao conectarmos o eletrômetro as soluções banhantes, ocorrerá um vazamento de corrente através do mesmo, o valor desta corrente depende da resistência interna do eletrômetro $\left(\mathrm{R}_{\mathrm{iE}}\right)$, que varia de $2 \times 10^{14}$ até $10^{7} \mathrm{ohm}$ (o valor de $\mathrm{R}_{\mathrm{iE}}$ é determinada manualmente pelo experimentador). No entanto, qualquer que seja $\mathrm{R}_{\mathrm{iE}}$, a corrente $\left(\mathrm{i}_{\mathrm{E}}\right)$ que passa por ele é dada por:

$$
i_{E}=\frac{E_{m}}{R_{m}+R_{i E}}
$$

Essa corrente polariza a resistência do eletrômetro com uma voltagem igual a leitura do display. Assim, temos:

$$
\text { Display }=i_{E} \times R_{i E}
$$

E, o potencial de membrana $\left(\mathrm{V}_{\mathrm{m}}\right)$ pode ser expresso como:

$$
V_{m}=E_{m}-\left(i_{E} \times R_{m}\right)
$$

Assim, a medida que diminuímos $\mathrm{R}_{\mathrm{iE}}$, a corrente circulante aumenta e, ao passar pela $\mathrm{R}_{\mathrm{m}}$, ocorre uma despolarização maior da membrana, fazendo com que o potencial de membrana caia. Observe que, em um certo valor de $\mathrm{R}_{\mathrm{iE}}\left(\sim 1 \times 10^{9} \mathrm{ohm}\right)$, a leitura cai abaixo de $1 \mathrm{mV}$, não mudando mais; isto ocorre quando $\mathrm{R}_{\mathrm{iE}}$ é da ordem de $\mathrm{R}_{\mathrm{m}}$.

Baseando-se nesses fatores, vemos que existe apenas um par de valores de $\mathrm{G}_{\mathrm{H}}{ }^{+} \mathrm{e}$ $\mathrm{G}_{\text {leak }}$ que, pela equação 16 , satisfaz os valores de $\mathrm{V}_{\mathrm{m}}$ e CCC medidos experimentalmente. Um programa desenvolvido pelo Prof. Dr. Joaquim Procopio em linguagem Microsoft 
QuickBasic, denominado Chnew.bas; analisa, por tentativa e erro, pares de valores de $\mathrm{G}_{\mathrm{H}}{ }^{+} \mathrm{e}$ $\mathrm{G}_{\text {leak }}$ que satisfaçam esses valores. No apêndice 1 é apresentado uma listagem exemplo deste programa.

Caso 2 - medidas obtidas com o amplificador de patch-clamp: considerando a condutância total medida da membrana $\left(\mathrm{G}_{\mathrm{m}}\right)$ como igual a soma das condutâncias das vias protônica e de vazamento e obtendo $\mathrm{G}_{\mathrm{H}}{ }^{+}$pela equação 17 , obtínhamos $\mathrm{G}_{\text {leak }}$ por:

$$
G_{\text {leak }}=G_{m}-G_{H^{+}}
$$

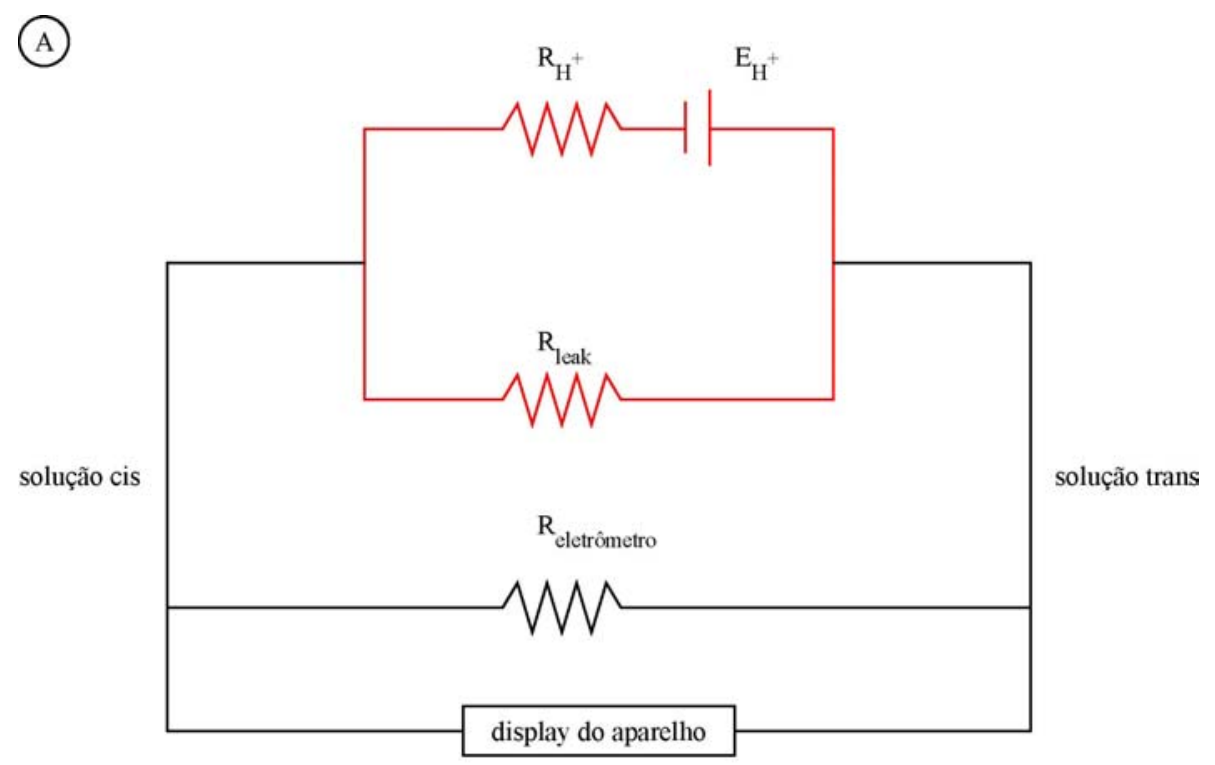

(B)

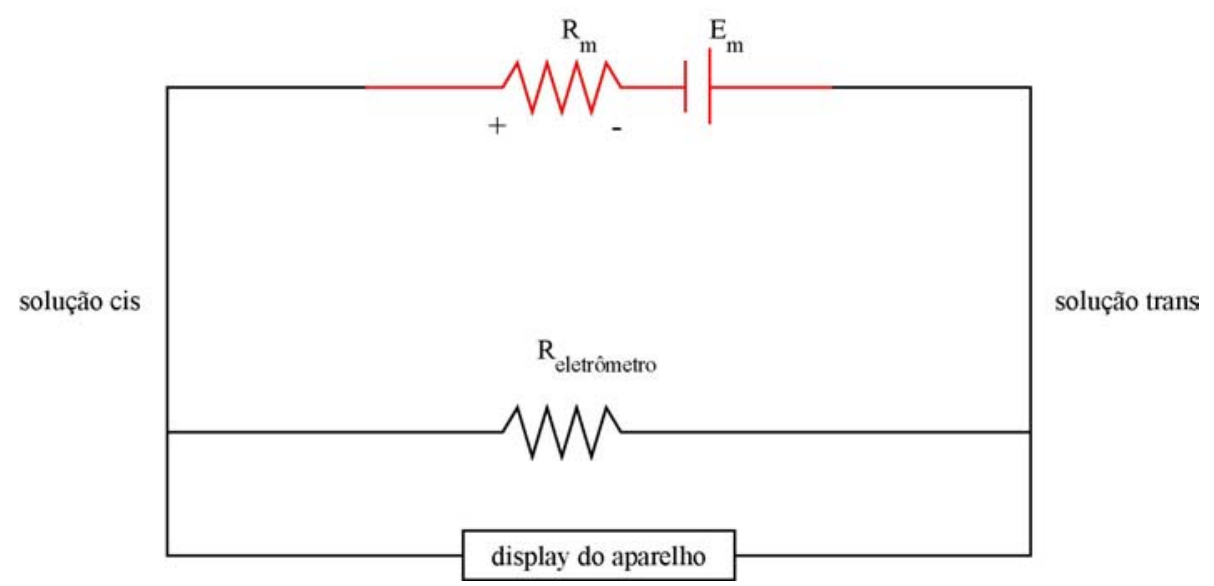

Figura 10: Representação elétrica do modelo de condutâncias paralelas e sua conexão com o eletrômetro. Este modelo foi utilizado para a obtenção dos valores individuais da comdutância a prótons $\left(\mathrm{G}_{\mathrm{H}}{ }^{+}\right)$e da condutância de vazamento $\left(\mathrm{G}_{\text {leak }}\right)$. Uma descrição destalhada das porções A e B desta figura é apresentada no texto. 


\subsection{Cálculo da Permeabilidade a Prótons}

A permeabilidade a prótons $\left(\mathrm{P}_{\mathrm{H}}{ }^{+}\right)$foi obtida indiretamente a partir dos valores da CCC tanto para o eletrômetro quanto para o amplificador de patch-clamp.

Considerando uma condição de curto-circuito elétrico através da membrana, o fluxo de prótons $\left(\mathrm{J}_{\mathrm{H}}{ }^{+}\right)$pode ser determinado a partir da CCC:

$$
C C C=J_{H^{+}} \times F
$$

onde: F é a constate de Faraday (96500 $\left.\mathrm{C} \mathrm{mol}^{-1}\right)$

No entanto, o $\mathrm{J}_{\mathrm{H}}^{+}$é dado por:

$$
J_{H^{+}}=P_{H^{+}} \times \Delta\left[H^{+}\right]
$$

Multiplicando-se ambos os lados da equação acima pela constante de Faraday temos:

$$
F \times J_{H^{+}}=P_{H^{+}} \times \Delta\left[H^{+}\right] \times F \quad \text { ou } \quad C C C=P_{H^{+}} \times \Delta\left[H^{+}\right] \times F
$$

Assim, a permeabilidade ao próton $\left(\mathrm{P}_{\mathrm{H}}{ }^{+}\right)$é:

$$
P_{H^{+}}=\frac{C C C}{F \times \Delta\left[H^{+}\right]}
$$

\subsection{Temperatura}

Os experimentos foram realizados a temperatura ambiente, que variou entre $22-25^{\circ}$ C (medidas realizadas através de um termômetro simples acoplado a parte interior da gaiola de Faraday).

\subsection{Análise Estatística}

Os dados obtidos experimentalmente foram analisados estatisticamente pelo programa GraphPad Software Prism 4 (GraphPad Software, Inc., CA). As médias foram analisadas através do One-way ANOVA (and nonparametric)-Bonferroni's Multiple Comparison Test. O intervalo de significância considerado foi de $95 \%$, ou seja, as médias eram significativamente diferentes se $\mathrm{p}<0,05$.

Os dados são expressos em termos da área das membranas, permitindo a comparação de dados obtidos em membranas com áreas diferentes; sendo apresentados na forma de média \pm erro padrão. 


\section{RESULTADOS}

No tópico destinado a introdução, descrevemos as evidências atuais que fundamentam os ácidos graxos como transportadores de prótons através de membranas fosfolipídicas. Essas evidências se baseiam, principalmente, em estudos com células e vesículas fosfolipídicas obtidas com o uso de marcadores fluorescentes. Com isso, são raras as evidências elétricas e principalmente estruturais de que possa existir um mecanismo de transporte acoplado $\mathrm{H}^{+}$ácidos graxos. Para isso, desenvolvemos uma série de experimentos de medidas elétricas em bicamadas lipidicas planas com o objetivo de elucidar o efeito da estrutura dos ácidos graxos e de outros componentes de membranas no mecanismo acoplador $\mathrm{H}^{+}$-ácidos graxos. Além disso, nos protocolos com diferentes componentes de membrana, vimos à necessidade de analisarmos o efeito destes componentes nos mecanismos passivos (i.e., não acoplado ao transporte de ácidos graxos) de transporte de prótons através de membranas. As principais evidências encontradas são mostradas nos tópicos a seguir.

\subsection{Efeito de ácidos graxos saturados e cis insaturados nas propriedades elétricas de membranas de DPhPC}

Os ácidos graxos saturados e os ácidos graxos cis insaturados apresentam o mesmo efeito no transporte de prótons? Para responder esta questão, a condutância total da membrana $\left(\mathrm{G}_{\mathrm{m}}\right)$, a condutância a prótons $\left(\mathrm{G}_{\mathrm{H}}{ }^{+}\right)$e a condutância de vazamento inespecífica $\left(\mathrm{G}_{\text {leak }}\right)$ de membranas de DPhPC foram obtidas na presença de um gradiente de prótons $\left(\mathrm{pH}_{\text {cis }}<\mathrm{pH}_{\text {trans }}\right)$, para uma série de ácidos graxos com diferentes comprimentos e número de insaturações na cadeia carbônica. As condutâncias do grupo controle (i.e, sem a adição de ácidos graxos no banho) e dos grupos com os ácidos graxos caprílico, palmítico e esteárico foram obtidas com o uso do eletrômetro (protocolo 1 - ver Materiais e Métodos). Já as condutâncias dos grupos com os ácidos graxos oléico, linoléico, araquidônico e docosahexaenóico foram obtidas com o uso do amplificador de patch-clamp (protocolo 2 - ver Materiais e Métodos), por meio de relações I x V.

A condutância total $\left(\mathrm{G}_{\mathrm{m}}\right)$ (Figura 11) de membranas de DPhPC não foram alteradas com a adição de $\mathrm{AC}$ e AP às soluções de preenchimento. No entanto, a adição de AS, AO, $\mathrm{AL}, \mathrm{AA}$ e DHA promoviam um aumento substancial de $\mathrm{G}_{\mathrm{m}}$. Interessante notar que o aumento de $\mathrm{G}_{\mathrm{m}}$ era dependente do comprimento da cadeia acila e do número de insaturações dos ácidos graxos; por exemplo, membranas modificadas por AS (18:0) eram cerca de 1,5 vezes mais 
condutivas do que membranas modificadas por AP (16:0) e, membranas modificadas por AL (18:2) eram cerca de 3,5 vezes mais condutivas que as membranas modificadas por AS.

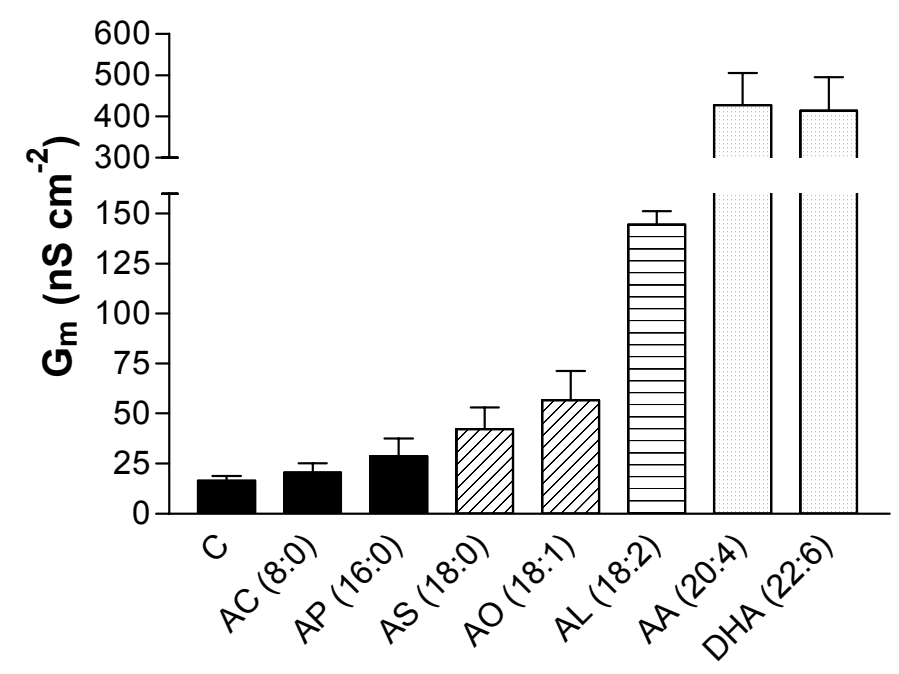

Figura 11: Efeito de ácidos graxos saturados e cis insaturados na condutância total $\left(G_{m}\right)$ de membranas de DPhPC puras. C - controle, AC - ácido caprílico, AP - ácido palmítico, $\mathrm{AS}$ - ácidos esteárico, AO - ácido oléico, AL - ácido linoléico, AA - ácido araquidônico e DHA - ácido docosahexaenóico. $(\mathrm{C}, \mathrm{n}=15 ; \mathrm{AC}, \mathrm{n}=6 ; \mathrm{AP}, \mathrm{n}=10 ; \mathrm{AS}, \mathrm{n}=7 ; \mathrm{AO}, \mathrm{n}=8 ; \mathrm{AL}$, $\mathrm{n}=8$; AA, $\mathrm{n}=6$; DHA, $\mathrm{n}=6$ ). Preenchimentos diferentes das barras representam grupos estatisticamente diferentes.

As Figuras 12 e 13 mostram, respectivamente, o efeito dos ácidos graxos saturados e cis insaturados sobre as condutâncias da via de prótons $\left(\mathrm{G}_{\mathrm{H}}{ }^{+}\right)$e de vazamento inespecífica $\left(\mathrm{G}_{\text {leak }}\right)$ em membranas de DPhPC. As $\mathrm{G}_{\mathrm{H}}{ }^{+}$e $\mathrm{G}_{\text {leak }}$ dos grupos controle e dos grupos com os ácidos caprílico, palmítico e esteárico foram calculadas através do programa Chnew.bas (anexo 1) e $\mathrm{G}_{\mathrm{H}}{ }^{+}$e $\mathrm{G}_{\text {leak }}$ dos grupos com os ácidos graxos oléico, linoléico, araquidônico e docosahexaenóico através da equação 17 (protocolo 2 - ver Materiais e Métodos).

Como mostrado na Figura 12, a incorporação de AC e AP as soluções de preenchimento não alterou $\mathrm{G}_{\mathrm{H}}{ }^{+}$. No entanto, a adição dos outros ácidos graxos promoveu um aumento progressivo da $\mathrm{G}_{\mathrm{H}}{ }^{+}$, onde $\mathbf{A S}<\mathbf{A O} \leq \mathbf{A L}<\mathbf{A A} \leq \mathbf{D H A}$. Novamente, é interessante notarmos que o aumento da $\mathrm{G}_{\mathrm{H}}{ }^{+}$está relacionado com o comprimento da cadeia acila e/ou com o número de insaturações na estrutura molecular dos ácidos graxos. Já, como mostrado na Figura 13, nenhum ácido graxo estudado foi eficaz (i.e., forma estatisticamente nenhuma alteração significativa foi observada) em promover alterações da $G_{\text {leak }}$. Esta ineficiência independe da estrutura do ácido graxo, ou seja, comprimento da cadeia acila ou mesmo do número de insaturações presente. 


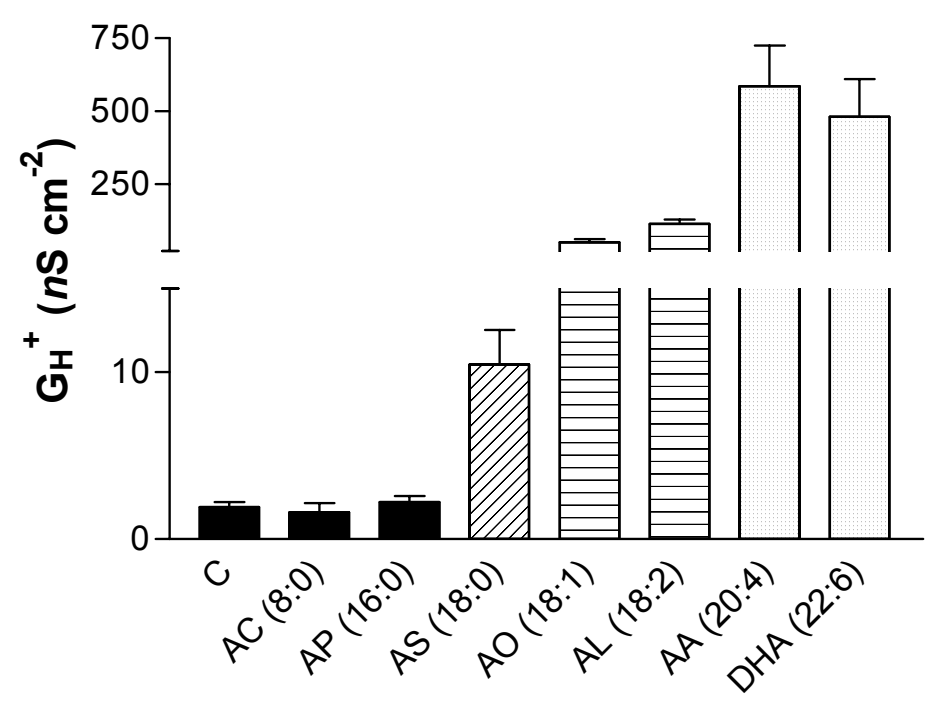

Figura 12: Efeito de ácidos graxos saturados e cis insaturados na condutância a prótons $\left(\mathrm{G}_{\mathbf{H}}{ }^{+}\right)$de membranas de DPhPC. C - controle, AC - ácido caprílico, AP - ácido palmítico, $\mathrm{AS}$ - ácidos esteárico, AO - ácido oléico, AL - ácido linoléico, AA - ácido araquidônico e DHA - ácido docosahexaenóico. $(\mathrm{C}, \mathrm{n}=15 ; \mathrm{AC}, \mathrm{n}=7 ; \mathrm{AP}, \mathrm{n}=11 ; \mathrm{AS}, \mathrm{n}=7 ; \mathrm{AO}, \mathrm{n}=6$; $\mathrm{AL}$, $\mathrm{n}=7$; AA, $\mathrm{n}=6$; DHA, $\mathrm{n}=6$ ). Preenchimentos diferentes das barras representam grupos estatisticamente diferentes.

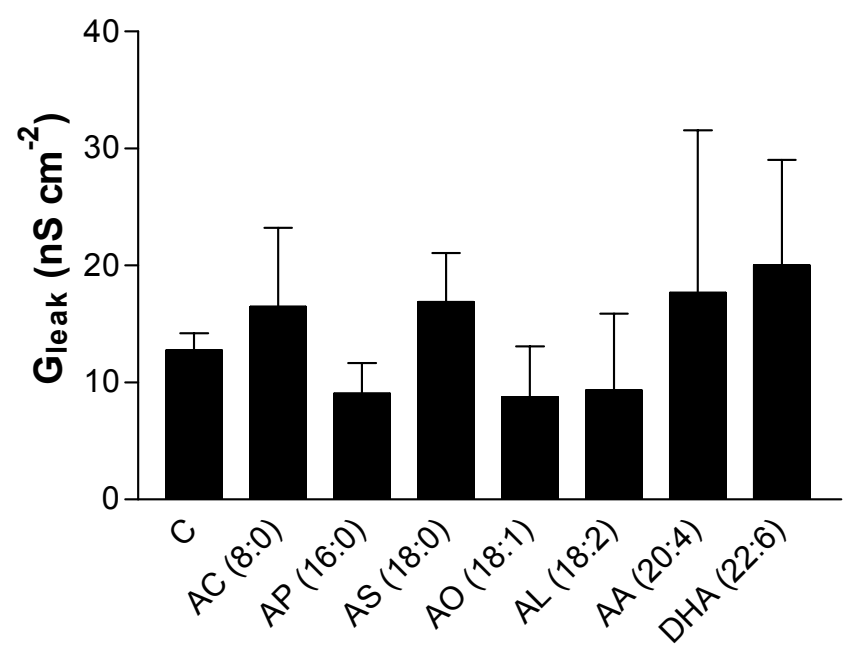

Figura 13: Efeito de ácidos graxos saturados e cis insaturados na condutância de vazamento inespecífica $\left(G_{\text {leak}}\right)$ de membranas de DPhPC. C - controle, AC - ácido caprílico, AP - ácido palmítico, AS - ácidos esteárico, AO - ácido oléico, AL - ácido linoléico, $\mathrm{AA}$ - ácido araquidônico e DHA - ácido docosahexaenóico. $(\mathrm{C}, \mathrm{n}=15 ; \mathrm{AC}, \mathrm{n}=7 ; \mathrm{AP}, \mathrm{n}=11$; $\mathrm{AS}, \mathrm{n}=7$; $\mathrm{AO}, \mathrm{n}=6$; $\mathrm{AL}, \mathrm{n}=7$; $\mathrm{AA}, \mathrm{n}=6$; DHA, $\mathrm{n}=6$ ). 
Assim, o aumento observado na condutância total da membrana $\left(\mathrm{G}_{\mathrm{m}}\right)$ (Figura 11) é devido um aumento na condutividade a prótons (aumento na $\mathrm{G}_{\mathrm{H}}{ }^{+}$) e não por um aumento na condutância da via de vazamento inespecífica $\left(\mathrm{G}_{\text {leak }}\right)$.

A Figura 14 mostra o efeito dos ácidos graxos saturados e cis insaturados na contribuição de $\mathrm{G}_{\mathrm{H}}{ }^{+}$e $\mathrm{G}_{\text {leak }}$ para a $\mathrm{G}_{\mathrm{m}}$ de membranas de DPhPC puras, submetidas a um gradiente de $\mathrm{pH}\left(\mathrm{pH}_{\mathrm{cis}}<\mathrm{pH}_{\text {trans }}\right)$. Vemos, através do grupo controle (C), que a relação $\mathrm{G}_{\text {leak }} / \mathrm{G}_{\mathrm{m}}$ em membranas não modificadas por ácidos graxos é maior que a relação $\mathrm{G}_{\mathrm{H}}{ }^{+} / \mathrm{G}_{\mathrm{m}}$, indicando que em tais membranas a $\mathrm{G}_{\mathrm{m}}$ era quase exclusivamente determinada por $\mathrm{G}_{\text {leak }}$. A adição de AC e AP pouco modificou estas relações. No entanto, a adição de AS, AO, AL, AA e DHA promoveram um aumento na contribuição de $\mathrm{G}_{\mathrm{H}}{ }^{+}$para $a \mathrm{G}_{\mathrm{m}}$ dessas membranas; sendo praticamente total a contribuição da $\mathrm{G}_{\mathrm{H}}{ }^{+}$para a $\mathrm{G}_{\mathrm{m}}$ (relação $\mathrm{G}_{\mathrm{H}}{ }^{+} / \mathrm{G}_{\mathrm{m}}$ igual a 1 ) quando os ácidos graxos poliinsaturados foram adicionados as soluções de preenchimento.

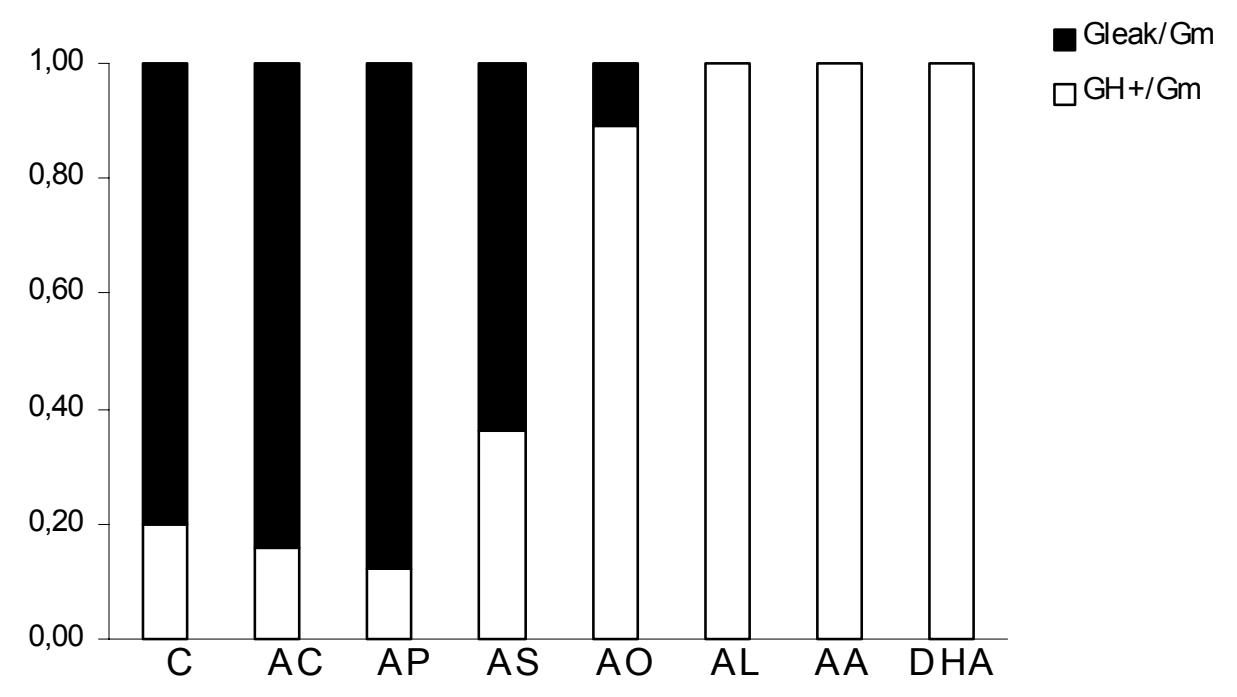

Figura 14: Contribuição das condutâncias a prótons $\left(\mathrm{G}_{\mathrm{H}}{ }^{+}\right)$e de vazamento inespecífica $\left(G_{\text {leak}}\right)$ para a condutância total $\left(G_{m}\right)$ de membranas de DPhPC. Comparações entra as relações $\mathrm{G}_{\mathrm{H}}{ }^{+} / \mathrm{G}_{\mathrm{m}}$ e $\mathrm{G}_{\text {leak }} / \mathrm{G}_{\mathrm{m}}$.

Para analisarmos os efeitos dos ácidos graxos saturados e cis insaturados no potencial expontâneo $\left(\mathrm{E}_{\mathrm{m}}\right)$ das bicamadas devemos ressaltar dois aspectos:

$1^{\mathrm{o}}$ - os valores de $\mathrm{E}_{\mathrm{m}}$ são analisados em razão do potencial de equilíbrio do próton $\left(\mathrm{E}_{\mathrm{H}}{ }^{+}\right.$, calculado através da equação 15) tornando possível a comparação entre grupos de membranas submetidas a diferentes gradientes de $\mathrm{pH}$.

$2^{o}$ - os dados obtidos de $\mathrm{E}_{\mathrm{m}}$ devem ser analisados em conjunto com os dados de condutância dessas membranas; segundo a equação 16, alterações do $\mathrm{E}_{\mathrm{m}}$ podem indicar alterações na condutância a prótons $\left(\mathrm{G}_{\mathrm{H}}{ }^{+}\right)$e/ou na condutância da via de vazamento 
inespecífica $\left(\mathrm{G}_{\text {leak }}\right)$. Com isso, se o valor da condutância a prótons $\left(\mathrm{G}_{\mathrm{H}}{ }^{+}\right)$tender ao valor da condutância total membrana $\left(\mathrm{G}_{\mathrm{m}}\right)$, o valor da razão $\mathrm{E}_{\mathrm{m}} / \mathrm{E}_{\mathrm{H}}{ }^{+}$tende a ser 1 .

A Figura 15 mostra a razão entre os valores de $\mathrm{E}_{\mathrm{m}}$ e $\mathrm{E}_{\mathrm{H}}{ }^{+}\left(\mathrm{E}_{\mathrm{m}} / \mathrm{E}_{\mathrm{H}}{ }^{+}\right)$para membranas de DPhPC pura em duas situações distintas: sem AG (grupo controle, com gradiente de $\mathrm{pH}$ ), onde $\mathrm{pH}_{\text {cis }}<\mathrm{pH}$ trans e com ácido graxo (AC, AP, AO, AS, AL, AA e DHA) em ambos compartimentos (cis e trans). O $\mathrm{E}_{\mathrm{m}}$ dos grupos controle e com os AC, AP e AS foram obtidos com o eletrômetro no modo voltímetro (protocolo 1 - Materiais e Métodos) e o $\mathrm{E}_{\mathrm{m}}$ dos grupos com os AO, AL, AA e DHA (protocolo 2 - Materiais e Métodos) corresponde ao potencial de reversão de corrente, ou seja, a voltagem obtida com 0 (zero) de corrente; este valor era obtido das curvas I x V.

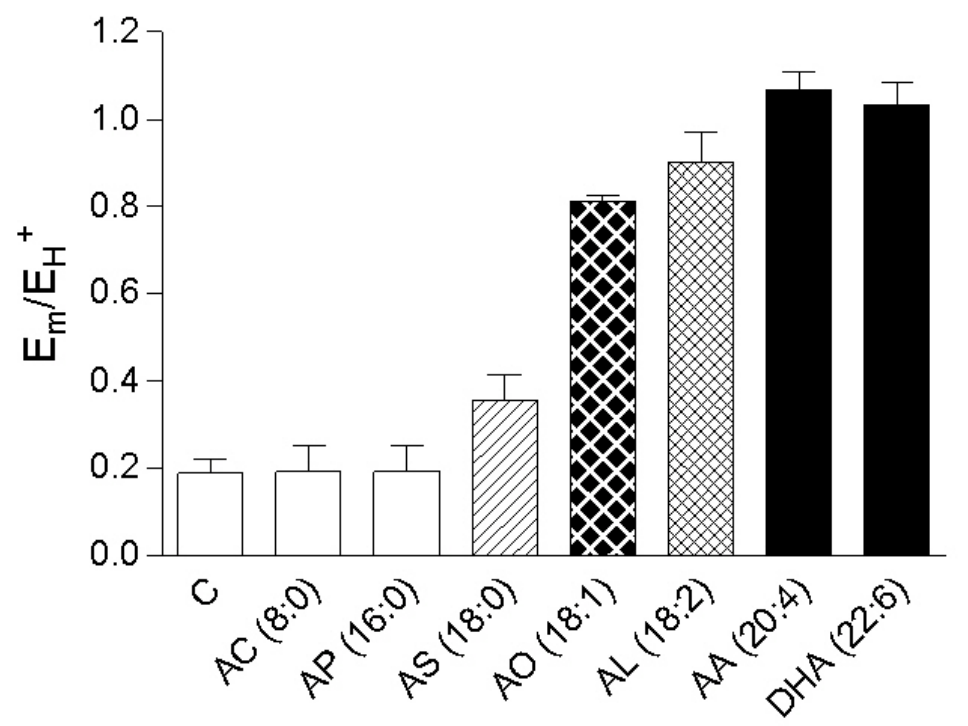

Figura 15: Efeito de ácidos graxos saturados e cis insaturados na relação $E_{m} / E_{H}^{+}$de membranas de DPhPC puras. C - controle, AC - ácido caprílico, AP - ácido palmítico, AS ácidos esteárico, $\mathrm{AO}$ - ácido oléico, $\mathrm{AL}$ - ácido linoléico, AA - ácido araquidônico e DHA ácido docosahexaenóico. $(\mathrm{C}, \mathrm{n}=15 ; \mathrm{AC}, \mathrm{n}=7 ; \mathrm{AP}, \mathrm{n}=11 ; \mathrm{AS}, \mathrm{n}=7 ; \mathrm{AO}, \mathrm{n}=6 ; \mathrm{AL}, \mathrm{n}=7$; $\mathrm{AA}, \mathrm{n}=6$; DHA, $\mathrm{n}=6$. Preenchimentos diferentes das barras representam grupos estatisticamente diferentes.

Como mostrado na Figura 15, em membranas de DPhPC e não modificadas por ácidos graxos (i.e., grupo controle - C), $\mathrm{E}_{\mathrm{m}}$ é menor que $\mathrm{E}_{\mathrm{H}}{ }^{+}\left(\mathrm{E}_{\mathrm{m}} / \mathrm{E}_{\mathrm{H}}{ }^{+}<0,30\right)$, certamente por uma alta condutância da via de vazamento inespecífica.

$\mathrm{A}$ incorporação tanto de $\mathrm{AC}$ quanto de $\mathrm{AP}$ às soluções de preenchimento não alterou a razão $\mathrm{E}_{\mathrm{m}} / \mathrm{E}_{\mathrm{H}}{ }^{+}$dessas membranas. Já a incorporação de AS, AO, AL, AA e DHA promoveu um aumento da razão $\mathrm{E}_{\mathrm{m}} / \mathrm{E}_{\mathrm{H}}{ }^{+}$dessas membranas, com tendência ao valor 1. Esse efeito 
ocorreu de forma mais acentuada para os ácidos graxos insaturados, corroborando os dados das Figuras 12 e 14, onde membranas modificadas por ácidos graxos insaturados são quase que totalmente seletivas a prótons.

A tabela II mostra valores típicos de correntes de curto-circuito (CCC) e permeabilidades a prótons $\left(\mathrm{P}_{\mathrm{H}}^{+}\right)$de membranas de DPhPC sem ácido graxo (i.e., grupo controle) e com os seguintes ácidos graxos: AC, AP, AS, AO, AL, AA ou DHA. Em ambas situações as membranas estavam submetidas a um gradiente de $\mathrm{pH}$, com $\mathrm{pH}_{\text {cis }}<\mathrm{pH}_{\text {trans. }}$.

As CCCs do grupo controle e dos AC, AP e AS foram obtidas com o uso do eletrômetro (protocolo 1 - ver Materiais e Métodos) e as CCCs dos grupos com os AO, AL, AA e DHA foram obtidas com o amplificador de patch-clamp, através de curvas I x V (protocolo 2 - ver Materiais e Métodos), sendo a CCC obtida quando a voltagem através da membrana era 0 (zero) ou nula. Já a $\mathrm{P}_{\mathrm{H}}{ }^{+}$em todos os grupos foi obtida indiretamente a partir dos valores das CCCs, de acordo com a equação 18.

$\mathrm{Na}$ presença de uma diferença de $\mathrm{pH}$, as membranas do grupo controle apresentavam uma CCC e uma $\mathrm{P}_{\mathrm{H}}{ }^{+}$basais significativas, corroborando os dados da literatura (Decoursey, 2003) e indicando que as bicamadas apresentam uma via de permeação para prótons, independente da ação de ácidos graxos. A adição tanto de AC quanto de AP às soluções de preenchimento não promovia alterações significativas tanto da $\mathrm{CCC}$ e como da $\mathrm{P}_{\mathrm{H}}{ }^{+}$. No entanto, quando adicionávamos $\mathrm{AS}, \mathrm{AO}, \mathrm{AL}, \mathrm{AA}, \mathrm{DHA}$, tanto a $\mathrm{CCC}$ quanto a $\mathrm{P}_{\mathrm{H}}{ }^{+}$sofriam aumentos substanciais, acompanhando os aumentos observados na $\mathrm{G}_{\mathrm{H}}{ }^{+}$dessas membranas.

Assim como o aumento da $\mathrm{G}_{\mathrm{H}}{ }^{+}$, os aumentos da CCC e da $\mathrm{P}_{\mathrm{H}}{ }^{+}$estão relacionados com a estrutura dos ácidos graxos, onde ácidos graxos com mais insaturações promoveram aumentos mais significativos. Por exemplo, membranas modificadas pelos ácidos graxos poliinsaturados AA ou DHA apresentavam CCC e $\mathrm{P}_{\mathrm{H}}{ }^{+}$cerca de 150 vezes maiores que as membranas controle ou membranas modificadas por AC ou AP. 
Tabela 2: Efeito de ácidos graxos saturados e cis insaturados na corrente de curtocircuito (CCC) e na permeabilidade $\left(\mathrm{P}_{\mathrm{H}}{ }^{+}\right)$de membranas de DPhPC ${ }^{(1)}$.

\begin{tabular}{|c|c|c|c|}
\hline Ácido Graxo & $\Delta p \mathbf{H}^{(2)}$ & 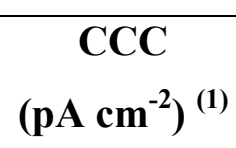 & $\begin{array}{c}\mathbf{P}_{\mathrm{H}}^{+} \\
\left(\mathrm{cm} \mathrm{s}^{-1}\right)^{(1)}\end{array}$ \\
\hline Controle & 0.53 & 100 & $8,6 \times 10^{-6}$ \\
\hline Caprílico & 0.70 & 92 & $2,9 \times 10^{-6}$ \\
\hline Palmítico & 0.53 & 100 & $8,6 \times 10^{-6}$ \\
\hline Esteárico & 0.53 & 423 & $3,1 \times 10^{-5}$ \\
\hline Oléico & 0.51 & 2039 & $1,5 \times 10^{-4}$ \\
\hline Linoléico & 0.42 & 2457 & $3,1 \times 10^{-4}$ \\
\hline Araquidônico & 0.45 & 11987 & $1,4 \times 10^{-3}$ \\
\hline DHA & 0.46 & 21905 & $3,0 \times 10^{-3}$ \\
\hline
\end{tabular}

(1) os valores apresentados são valores típicos de CCC (corrente de curto-circuito) e de $\mathrm{P}_{\mathrm{H}}{ }^{+}$

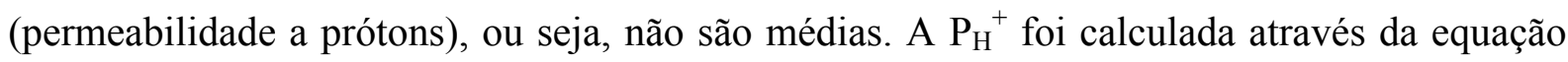
18 (ver materiais e métodos).

${ }^{\text {(2) }} \Delta \mathrm{pH}$ - gradiente de concentração de prótons, onde $\mathrm{pH}_{\text {cis }}<\mathrm{pH}_{\text {trans. }}$.

\subsection{Efeito de ácidos graxos trans nas propriedades elétricas de membranas de DPhPC}

Uma vez que tínhamos determinado a diferença entre ácidos graxos saturados e ácidos graxos cis insaturados com relação a taxa de transporte de prótons, as seguintes questões surgiram: Poderiam ser diferentes as taxas de transporte de prótons determinadas por ácidos graxos com diferentes tipos de insaturações? Qual o efeito, na taxa de transporte de prótons, de insaturações do tipo trans? Assim, para analisarmos os efeitos do tipo de insaturação dos ácidos graxos nas propriedades elétricas de bicamadas lipídicas, comparamos o ácido oléico, que possui uma insaturação do tipo cis no C9, com o ácido elaídico (AE), que também possui apenas uma insaturação no C9, no entanto do tipo trans (ver Figura 7 - Materiais e Métodos) e ambos com o ácido esteárico (AS) que possui o mesmo número de carbonos na cadeia acila dos anteriores (18C), porém é do tipo saturado. O protocolo utilizado foi idêntico ao empregado nos experimentos descritos acima, ou seja, utilizamos membranas de DPhPC e os parâmetros elétricos foram obtidos tanto com o eletrômetro (grupos controle, AE e AS) como com o amplificador de patch-clamp (grupo com AO), em duas situações distintas: sem ácido 
graxo e na presença de ácido graxo nas soluções de preenchimento. Em ambas situações essas membranas eram submetidas a um gradiente de $\mathrm{pH}$, onde $\mathrm{pH}_{\text {cis }}<\mathrm{pH}_{\text {trans. }}$.

A figura 16 compara o efeito do $\mathrm{AS}, \mathrm{AE}$ e do $\mathrm{AO}$ na razão $\mathrm{E}_{\mathrm{m}} / \mathrm{E}_{\mathrm{H}}{ }^{+}$, mostrando que, diferentemente do que ocorre com o $\mathrm{AO}$, a incorporação de $\mathrm{AE}$ às soluções de preenchimento promove alterações menos expressivas na relação $\mathrm{E}_{\mathrm{m}} / \mathrm{E}_{\mathrm{H}}{ }^{+}$quando comparadas tanto com as membranas do grupo controle quanto com as membranas que continham AO. O comportamento do $\mathrm{AE}$ na relação $\mathrm{E}_{\mathrm{m}} / \mathrm{E}_{\mathrm{H}}^{+}$foi parecido com o do $\mathrm{AS}$ (estatisticamente iguais).

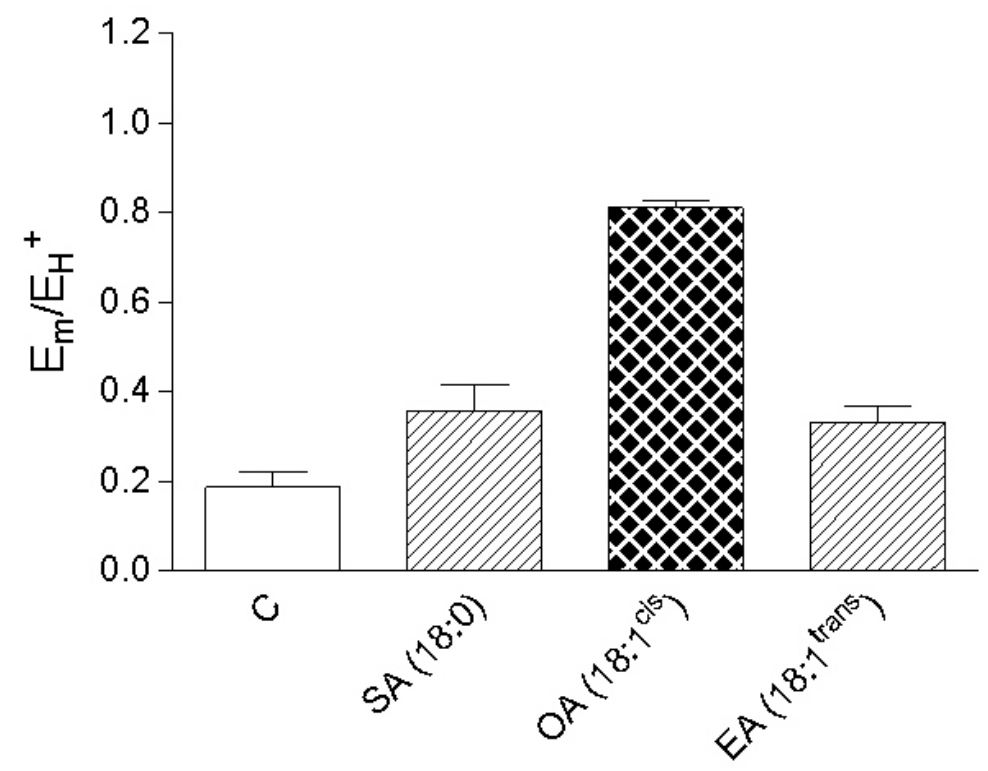

Figura 16: Comparação entre o efeito do ácido graxos cis oléico e do ácido graxo trans elaídico na relação $\mathbf{E}_{\mathbf{m}} / \mathbf{E}_{\mathbf{H}}{ }^{+}$de membranas de DPhPC puras. C - controle, AS - ácido esteárico, $\mathrm{AO}$ - ácido oléico e $\mathrm{AE}$ - ácido elaídico. $(\mathrm{C}, \mathrm{n}=15$; $\mathrm{AS}, \mathrm{n}=7, \mathrm{AO}, \mathrm{n}=8$; $\mathrm{AE}, \mathrm{n}=$ 6). Preenchimentos diferentes das barras representam grupos estatisticamente diferentes.

A Figura 17 compara o efeito do AS, AE e do AO nas condutâncias a prótons $\left(\mathrm{G}_{\mathrm{H}}{ }^{+}\right)$e de vazamento inespecífica $\left(\mathrm{G}_{\text {leak }}\right)$ em membranas de DPhPC puras. Da mesma forma que ocorreu com a razão $\mathrm{E}_{\mathrm{m}} / \mathrm{E}_{\mathrm{H}}{ }^{+}$, o $\mathrm{AE}$ apresentou efeito menos expressivo quando comparado ao AO. Novamente, o comportamento do AE se assemelha ao comportamento do AS. O mesmo padrão foi observado nos valores de CCC e de $\mathrm{P}_{\mathrm{H}}{ }^{+}$(Tabela 3).

Esses resultados, em conjunto, mostram que o AE apresenta características totalmente diferentes quando comparado com os ácidos graxos que apresentam insaturações do tipo cis, principalmente quando comparado ao $\mathrm{AO}$ e, sim, parece comportar-se como os ácidos graxos saturados, principalmente com o ácido esteárico (18:0). 

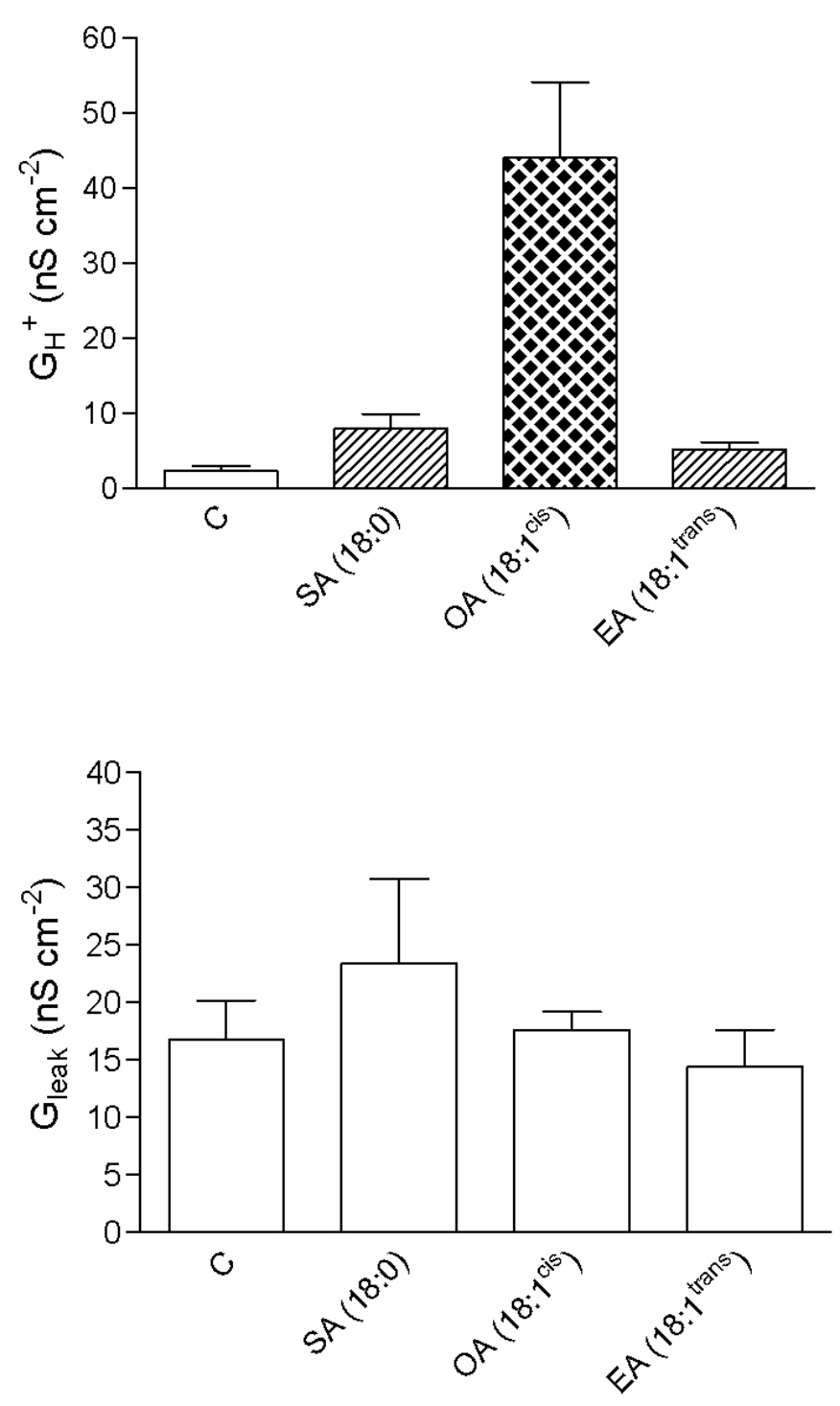

Figura 17: Comparação entre o efeito do ácido graxos cis oléico e do ácido graxo trans elaídico na condutância a prótons $\left(\mathrm{G}_{\mathrm{H}}{ }^{+}\right)$e na condutância da via inespecícica $\left(\mathrm{G}_{\text {leak }}\right)$ de membranas de DPhPC puras. C - controle, AS - ácido esteárico, $\mathrm{AO}$ - ácido oléico e $\mathrm{AE}$ ácido elaídico. $(\mathrm{C}, \mathrm{n}=15$; $\mathrm{AS}, \mathrm{n}=7, \mathrm{AO}, \mathrm{n}=8$; $\mathrm{AE}, \mathrm{n}=6)$. Preenchimentos diferentes das barras representam grupos estatisticamente diferentes. 
Tabela 3: Compara o efeito do ácido elaídico com os efeitos dos ácidos oléico e esteárico na corrente de curto-circuito $(\mathrm{CCC})$ e na permeabilidade $\left(\mathrm{P}_{\mathrm{H}}{ }^{+}\right)$de membranas de $\operatorname{DPhPC}^{(1)}$.

\begin{tabular}{|c|c|c|c|}
\hline Ácido Graxo & $\Delta p H^{(2)}$ & 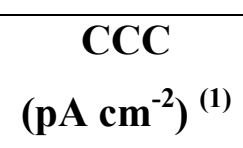 & $\begin{array}{c}\mathbf{P}_{\mathrm{H}}^{+} \\
\left(\mathrm{cm} \mathrm{s}^{-1}\right)^{(1)}\end{array}$ \\
\hline Controle & 0.53 & 100 & $8,6 \times 10^{-6}$ \\
\hline Esteárico (18:0) & 0.53 & 423 & $3,1 \times 10^{-5}$ \\
\hline Oléico (18:1 $\left.{ }^{\text {cis }}\right)$ & 0.51 & 2039 & $1,5 \times 10^{-4}$ \\
\hline Elaídico $\left(18: 1^{\text {trans }}\right)$ & 0.57 & 170 & $1,0 \times 10^{-5}$ \\
\hline
\end{tabular}

(1) os valores apresentados são valores típicos de CCC (corrente de curto-circuito) e de $\mathrm{P}_{\mathrm{H}}{ }^{+}$ (permeabilidade a prótons), ou seja, não são médias. $\mathrm{A}_{\mathrm{H}^{+}}{ }^{+}$foi calculada através da equação18 (ver materiais e métodos).

${ }^{(2)} \Delta \mathrm{pH}$ - gradiente de concentração de prótons, onde $\mathrm{pH}_{\text {cis }}<\mathrm{pH}_{\text {trans. }}$

\subsection{Efeito da composição da membrana no transporte de prótons por ácidos graxos}

Para analisarmos o efeito da composição lipídica da membrana nas alterações induzidas por ácidos graxos três diferentes grupos de membranas foram usados, conforme mostrado abaixo:

- Grupo 1: membranas de DPhPC;

- Grupo 2: membranas de DPhPC-colesterol, 83:17 w/w - mimetizando a membrana plasmática de mamíferos; e

- Grupo 3: membranas de DPhPC-cardiolipina, 79:21 w/w - mimetizando a membrana interna da mitocôndria.

Para estes experimentos utilizamos apenas o ácido oléico. Sua escolha baseou-se no fato de que este ácido graxo apresenta valores de $\mathrm{E}_{\mathrm{m}} / \mathrm{E}_{\mathrm{H}}{ }^{+}, \mathrm{G}_{\mathrm{H}}{ }^{+}, \mathrm{CCC}$ e $\mathrm{P}_{\mathrm{H}}{ }^{+}$intermediários quando comparado aos outros ácidos graxos. Assim, caso houvesse aumento ou diminuição dos parâmetros elétricos, estes seriam facilmente observados, fato que poderia não ocorrer caso utilizássemos, por exemplo, o AP (pouco ou nenhum efeito) ou DHA (efeito extremo). Para a realização desses experimentos usamos apenas o amplificador de patch-clamp (protocolo 2), como descrito em Materiais e Métodos. 
No entanto, para entendermos os efeitos de diferentes componentes de membrana no mecanismo de transporte acoplado $\mathrm{H}^{+}$-ácido graxo, tornou-se essencial sabermos como estes outros componentes interferiam nos mecanismos passivos de transporte de prótons.

Com isso, uma série de experimentos de membranas de DPhPC ou DPhPC-colesterol ou DPhPC-cardiolipina, submetidas a um gradiente de prótons $\left(\mathrm{pH}_{\mathrm{cis}}<\mathrm{pH}_{\text {trans }}\right)$, foram realizados.

A Figura 18 mostra $\mathrm{E}_{\mathrm{m}} / \mathrm{E}_{\mathrm{H}}{ }^{+}, \mathrm{G}_{\mathrm{H}}{ }^{+}$e $\mathrm{G}_{\text {leak }}$ de membranas de DPhPC, DPhPC-colesterol, $\mathrm{DPhPC}$-cardiolipina não modificadas por ácidos graxos. Igualmente ao que mostramos anteriormente para as membranas de $\mathrm{DPhPC}$, as membranas com colesterol ou cardiolipina apresentam $\mathrm{E}_{\mathrm{m}}$ muito menores que $\mathrm{E}_{\mathrm{H}}{ }^{+}$, indicando que a condutância da via de vazamento inespecífica, contribui para a maior parte da condutância total dessas membranas.

A incorporação de colesterol promoveu um aumento da relação $\mathrm{E}_{\mathrm{m}} / \mathrm{E}_{\mathrm{H}}{ }^{+}$, enquanto que a incorporação de cardiolipina as membranas de DPhPC não alterou esta relação. Para o colesterol, esse aumento é possivelmente devido a uma diminuição de $\mathrm{G}_{\text {leak }}$, pois $\mathrm{G}_{\mathrm{H}}{ }^{+}$parece não ser influenciado pela presença de colesterol. Já para a cardiolipina, a manutenção de $\mathrm{E}_{\mathrm{m}} / \mathrm{E}_{\mathrm{H}}^{+}$em um mesmo patamar que as membranas controle (DPhPC) seria dado por uma diminuição tanto de $\mathrm{G}_{\mathrm{H}}^{+}$como de $\mathrm{G}_{\text {leak }}$. A princípio, este efeito da cardiolipina nas condutâncias contradiz o proposto por Hoch (1998), de que as cardiolipinas agiriam como moléculas captadoras de prótons. 

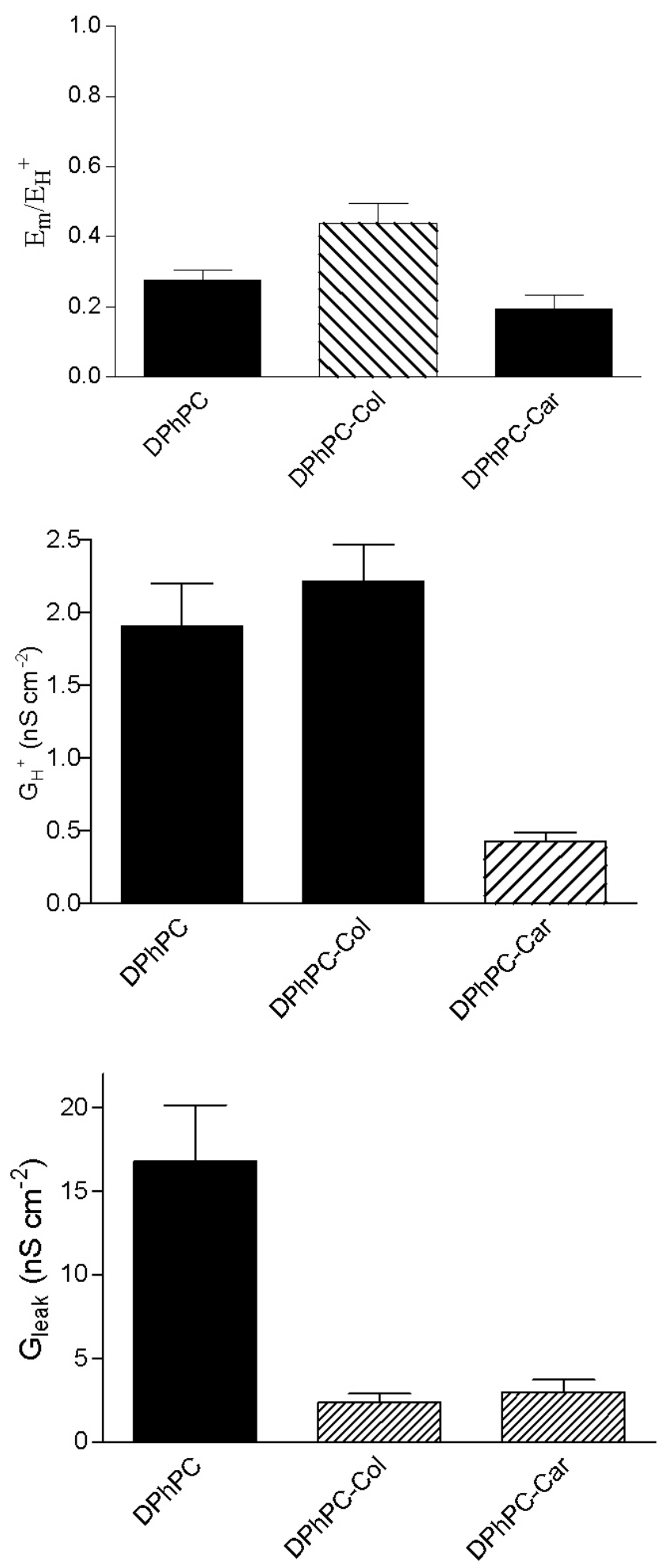

Figura 18: Parâmetros elétricos de membranas fosfolipídicas não modificadas por ácidos graxos. Os dados foram obtidos em uma situação de gradiente de $\mathrm{pH}$ (pHcis $<$ pHtrans), como descrito em Materiais e Métodos. Preenchimentos diferentes das barras representam grupos estatisticamente diferentes. Cada barra corresponde a um $\mathrm{n}$ de no mínimo 5 experimentos 
Como mostra a Tabela 4, os mesmos perfis obtidos para $\mathrm{G}_{\mathrm{H}}{ }^{+}$, quando os comparamos com a composição da membrana, foram encontrados para os valores de CCC e $\mathrm{P}_{\mathrm{H}}{ }^{+}$.

Tabela 4: Efeito da composição da membrana na corrente de curto-circuito (CCC) e na permeabilidade $\left(\mathrm{P}_{\mathrm{H}}{ }^{+}\right)$basal de membranas de DPhPC pura, DPhPC-colesterol, DPhPCcardiolipina $^{(1)}$

\begin{tabular}{|c|c|c|c|}
\hline Membrana & $\Delta \mathbf{p} \mathbf{H}^{(2)}$ & 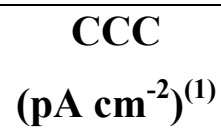 & $\begin{array}{c}\mathbf{P}_{\mathbf{H}}^{+} \\
\left(\mathrm{cm} \mathrm{s}^{-1}\right)^{(1)}\end{array}$ \\
\hline DPhPC pura & 0,53 & 100 & $8,8,1 \times 10^{-6}$ \\
\hline DPhPC-colesterol & 0,66 & 100 & $6,4 \times 10^{-6}$ \\
\hline DPhPC-cardiolipina & 0,78 & 20 & $6,8 \times 10^{-7}$ \\
\hline
\end{tabular}

(1) os valores apresentados são valores típicos de CCC (corrente de curto-circuito) e de $\mathrm{P}_{\mathrm{H}}{ }^{+}$ (permeabilidade a prótons), ou seja, não são médias. $\mathrm{A}_{\mathrm{P}_{\mathrm{H}}}{ }^{+}$foi calculada através da equação18 (ver materiais e métodos).

${ }^{\text {(2) }} \Delta \mathrm{pH}$ - gradiente de concentração de prótons, onde $\mathrm{pH}_{\text {cis }}<\mathrm{pH}_{\text {trans. }}$.

No entanto, nosso principal objetivo nesta série de experimentos era verificar como o mecanismo de transporte de prótons por ácidos graxos poderia ser influenciado tanto pelo colesterol quanto pela cardiolipina. Assim, a Figura 19 mostra a razão entre $\mathrm{G}_{\mathrm{H}}^{+}$de membranas de DPhPC, DPhPC-colesterol e DPhPC-cardiolipina não modificadas (experimentos controle) e modificadas por AO. A cardiolipina produziu um considerável aumento na razão $\mathrm{G}_{\mathrm{H}}{ }^{+}$(AO, DPhPC-cariolipina) $/ \mathrm{G}_{\mathrm{H}}{ }^{+}$(DPhPC-cardiolipina) quando comparado com as membranas de DPhPC pura (i.e., sem a incorporação de outro tipo de lipídeo). O mesmo não foi observado em membranas que continham colesterol.

$\mathrm{Na}$ verdade, membranas de DPhPC que continham cardiolipina eram cerca de 3 vezes mais seletivas a prótons que membranas puras de DPhPC, quando ambos os grupos eram modificados por ácido oléico. 


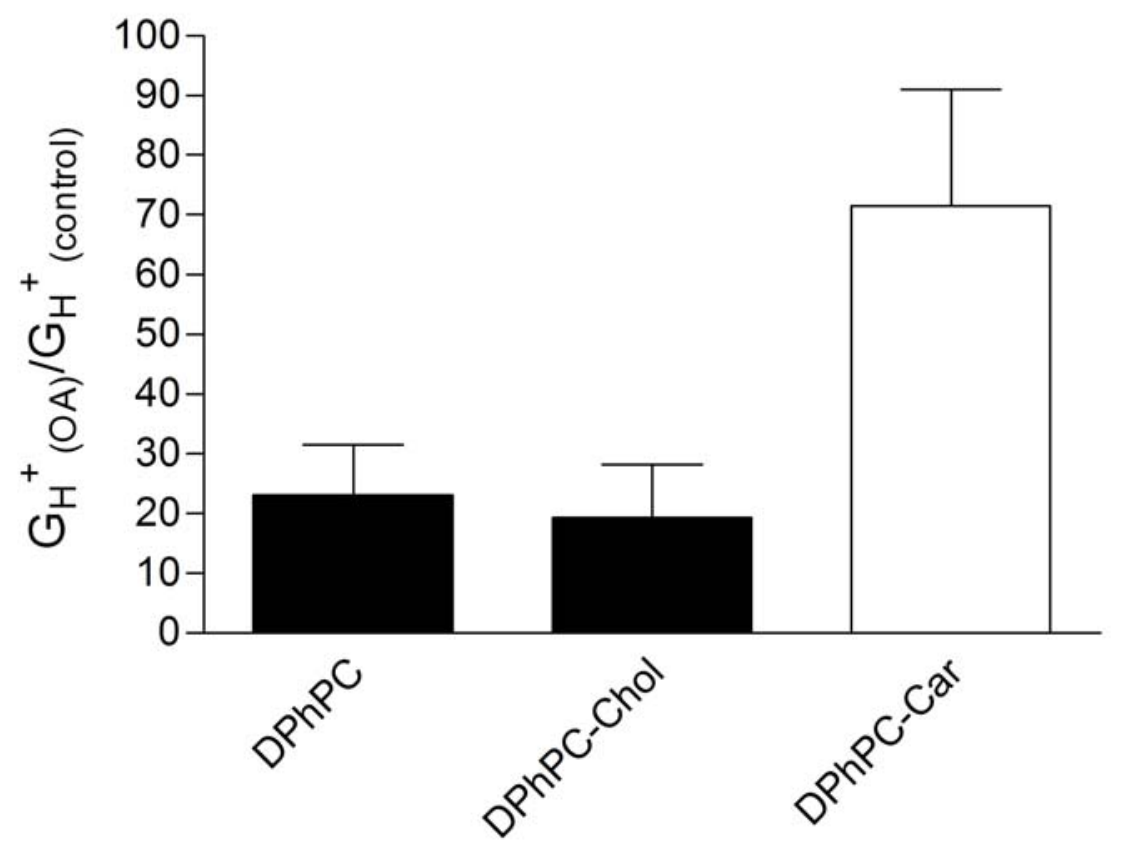

Figura 19: Efeito do colesterol e da cardiolipina na condutância a prótons determinada pelo ácido oléico. DPhPC-Col e DPhPC-Car correspondem, respectivamente, a uma mistura de DPhPC e colesterol $(17 \% \mathrm{w} / \mathrm{w})$ ou DPhPC e cardilipina $(21 \% \mathrm{w} / \mathrm{w})$. Preenchimentos diferentes das barras representam grupos estatisticamente diferentes.

Dando continuidade ao estudo do efeito da composição lipídica no mecanismo de transporte de prótons por ácidos graxos, a seguinte dúvida surgiu "Uma mistura de fosfolipídeos com diferentes comprimentos na cadeia acila poderia influenciar este mecanismo?" Com o objetivo de responder esta questão uma série de experimentos foram realizados usando Azolectina, uma mistura de fosfolipídeos com cadeias acilas de diferentes tamanhos. Os ácidos graxos utilizados foram o AP (saturado), o AO (monoinsaturado) e o AA (poliinsaturado).

A Figura 20 mostra o efeito destes ácidos graxos no $\left(\mathrm{E}_{\mathrm{m}} / \mathrm{E}_{\mathrm{H}}{ }^{+}\right)$. Como nas membranas de DPhPC, em membranas de Asolectina não modificadas por ácidos graxos (grupo controle), $\mathrm{E}_{\mathrm{m}}$ foi sempre maior que $\mathrm{E}_{\mathrm{H}}{ }^{+}$, também devido a alta condutância da via de vazamento $\left(\mathrm{G}_{\text {leak }}\right)$ em comparação com a via específica a prótons $\left(\mathrm{G}_{\mathrm{H}}{ }^{+}\right)$.

Ácido palmítico, adicionado ao banho, aumentou o $\mathrm{E}_{\mathrm{m}}$ de membranas de Asolectina, porém o valor de $\mathrm{E}_{\mathrm{m}}$ ainda se manteve significativamente menor que $\mathrm{E}_{\mathrm{H}}{ }^{+}$. Por outro lado, a adição de ácidos graxos insaturados ao banho, tanto o ácido oléico como o ácido araquidônico, aumentaram $\mathrm{E}_{\mathrm{m}}$ de forma significativa, aproximando-o do valor de $\mathrm{E}_{\mathrm{H}}^{+}$. 
A Figura 20 ainda mostra o efeito dos ácidos palmítico, oléico e araquidônico sobre as condutâncias da via específica de prótons $\left(\mathrm{G}_{\mathrm{H}}{ }^{+}\right)$e da via de vazamento inespecífica $\left(\mathrm{G}_{\text {leak }}\right)$. $\mathrm{G}_{\mathrm{H}}{ }^{+}$e $\mathrm{G}_{\text {leak }}$ dos grupos controle (sem ácido graxo e com gradiente de prótons) foram obtidos utilizando-se o eletrômetro (protocolo 1 - ver Materiais e Métodos). Já $\mathrm{G}_{\mathrm{H}}{ }^{+}$e $\mathrm{G}_{\text {leak }}$ dos grupos com ácidos oléico e araquidônico formam calculados a partir dos parâmetros elétricos obtidos com o amplificador de patch-clamp no modo voltage-clamp (protocolo 2 - ver Materiais e Métodos). A adição de ácido graxo ao banho, em geral, produziu um aumento de $\mathrm{G}_{\mathrm{H}}{ }^{+}$na seguinte ordem: controle < ácido palmítico < ácido oléico < ácido araquidônico, coincidindo com o grau de insaturação dos ácidos graxos, seguindo um padrão semelhante ao observado em membranas de DPhPC. No entanto, diferentemente das membranas de DPhPC, observou-se um aumento significativo de $\mathrm{G}_{\mathrm{H}}{ }^{+}$após a adição de ácido palmítico ao banho.

Por outro lado, ácidos graxos insaturados, independente do fosfolipídeo utilizado (DPhPC ou Azolectina) promoveram um aumento muito maior de $\mathrm{G}_{\mathrm{H}}{ }^{+}$do que o ácido palmítico (saturado).

Ainda, na Figura 20 vemos que o ácido palmítico não modificou a $\mathrm{G}_{\text {leak }}$ de membranas de Azolectina. Por outro lado, membranas de Azolectina tratadas com ácidos graxos insaturados experimentam aumentos significativos na $\mathrm{G}_{\text {leak }}$, refletindo, provavelmente, uma possível redução no empacotamento dos fosfolipídeos, o que poderia levar a um no número de defeitos na matriz lipídica. 

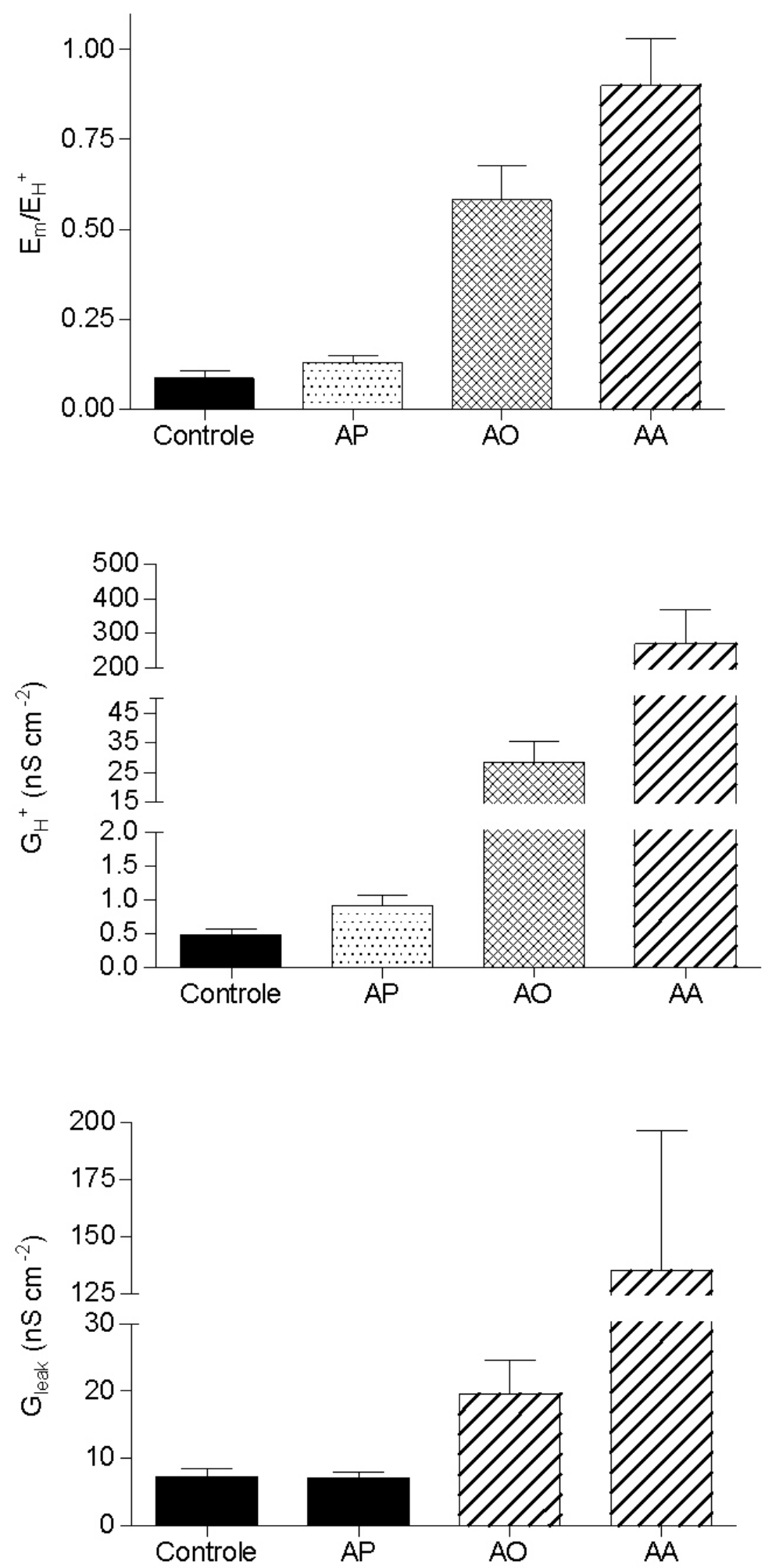

Figura 20: Efeito dos ácidos graxos palmítico, oléico e araquidônico nos parâmetros elétricos de membranas de Azolectina. $\mathrm{C}$ - controle, AP - ácido palmítico, AO - ácido oléico e AA - ácido araquidônico $(\mathrm{C}, \mathrm{n}=12 ; \mathrm{AP}, \mathrm{n}=11 ; \mathrm{AO}, \mathrm{n}=6$; $\mathrm{AA}, \mathrm{n}=6)$. Preenchimentos diferentes das barras representam grupos estatisticamente diferentes. 
A Tabela 5 mostra o efeito destes ácidos graxos sobre a corrente de curto-circuito (CCC) e permeabilidade a prótons $\left(\mathrm{P}_{\mathrm{H}}{ }^{+}\right)$de membranas de Azolectina. Em geral, a adição de ácidos graxos ao banho produziu um aumento da CCC e da $\mathrm{P}_{\mathrm{H}}{ }^{+}$de membranas de Azolectina na seguinte ordem: controle < ácidos palmítico < ácido oléico < ácido araquidônico, acompanhando o aumento observado de $\mathrm{G}_{\mathrm{H}}{ }^{+}$. $\mathrm{O}$ aumento concomitante da CCC, do $\mathrm{G}_{\mathrm{H}}{ }^{+}$e da $\mathrm{P}_{\mathrm{H}}^{+}$pode indicar a ativação, por ácidos graxos, de uma via seletiva a prótons.

Tabela 5: Efeito dos ácidos graxos palmítico, oléico e araquidônico na corrente de curtocircuito (CCC) e na permeabilidade $\left(\mathrm{P}_{\mathrm{H}}{ }^{+}\right)$de membranas de Azolectina ${ }^{(1)}$.

\begin{tabular}{|c|c|c|c|}
\hline Ácido Graxo & $\Delta p H^{(2)}$ & 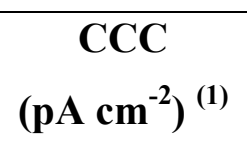 & $\begin{array}{c}\mathbf{P}_{\mathbf{H}}^{+} \\
\left(\mathrm{cm} \mathrm{s}^{-1}\right)^{(1)}\end{array}$ \\
\hline Controle & 0.77 & 14 & $6,8 \times 10^{-7}$ \\
\hline Palmítico & 0.77 & 33 & $1,6 \times 10^{-6}$ \\
\hline Oléico & 0.74 & 1375 & $4,0 \times 10^{-5}$ \\
\hline Araquidônico & 0.40 & 9046 & $9,8 \times 10^{-4}$ \\
\hline
\end{tabular}

(1) os valores apresentados são valores típicos de CCC (corrente de curto-circuito) e de $\mathrm{P}_{\mathrm{H}}{ }^{+}$ (permeabilidade a prótons), ou seja, não são médias. $\mathrm{A}_{\mathrm{H}_{\mathrm{H}}}{ }^{+}$foi calculada através da equação18 (ver materiais e métodos).

${ }^{(2)} \Delta \mathrm{pH}$ - gradiente de concentração de prótons, onde $\mathrm{pH}_{\text {cis }}<\mathrm{pH}_{\text {trans. }}$. 


\section{DISCUSSÃO}

Nossos resultados mostram que membranas, não modificadas, constituídas de DPhPC, DPhPC-colesterol, DPhPC-cardiolipina e Asolectina apresentam uma seletividade parcial ao próton. A seletividade parcial destas membranas se fundamenta no fato de que, em gradiente de $\mathrm{pH}$, a voltagem espontânea $\left(\mathrm{E}_{\mathrm{m}}\right)$ é sempre menor que o potencial de equilíbrio do próton $\left(\mathrm{E}_{\mathrm{H}}{ }^{+}\right.$), i.e. $\mathrm{E}_{\mathrm{m}} / \mathrm{E}_{\mathrm{H}}{ }^{+}<1$ (Figuras 15,18 e 20), indicando a coexistência de uma via de vazamento inespecífica paralela a uma via seletiva a prótons.

Somando-se a esta seletividade basal a prótons, a adição de ácidos graxos as soluções banhantes tornam estas membranas mais condutivas a prótons, indicando um aumento da permeabilidade a prótons (Figuras 12, 19 e 20).

Assim, de forma geral, nossos resultados sugerem que o transporte de prótons através de bicamadas fosfolipídicas dá-se por duas vias distintas (Figura 21): uma determinada pelo fluxo difusional simples de prótons e outra via determinada pela influencia de ácidos graxos. Por sua vez, a via protônica ativada por ácidos graxos pode subdividir-se em uma via de acoplamento $\mathrm{H}^{+}$-ácidos graxos e uma via difusional induzida por ácido graxo. No entanto, estas vias não são independentes, ou seja, a via determinada pelos ácidos graxos pode interferir no fluxo difusional simples e, vice-versa.

Além disso, as duas vias que determinam o transporte de prótons podem ser influenciadas tanto pela composição das membranas como por diferenças estruturais dos ácidos graxos. 

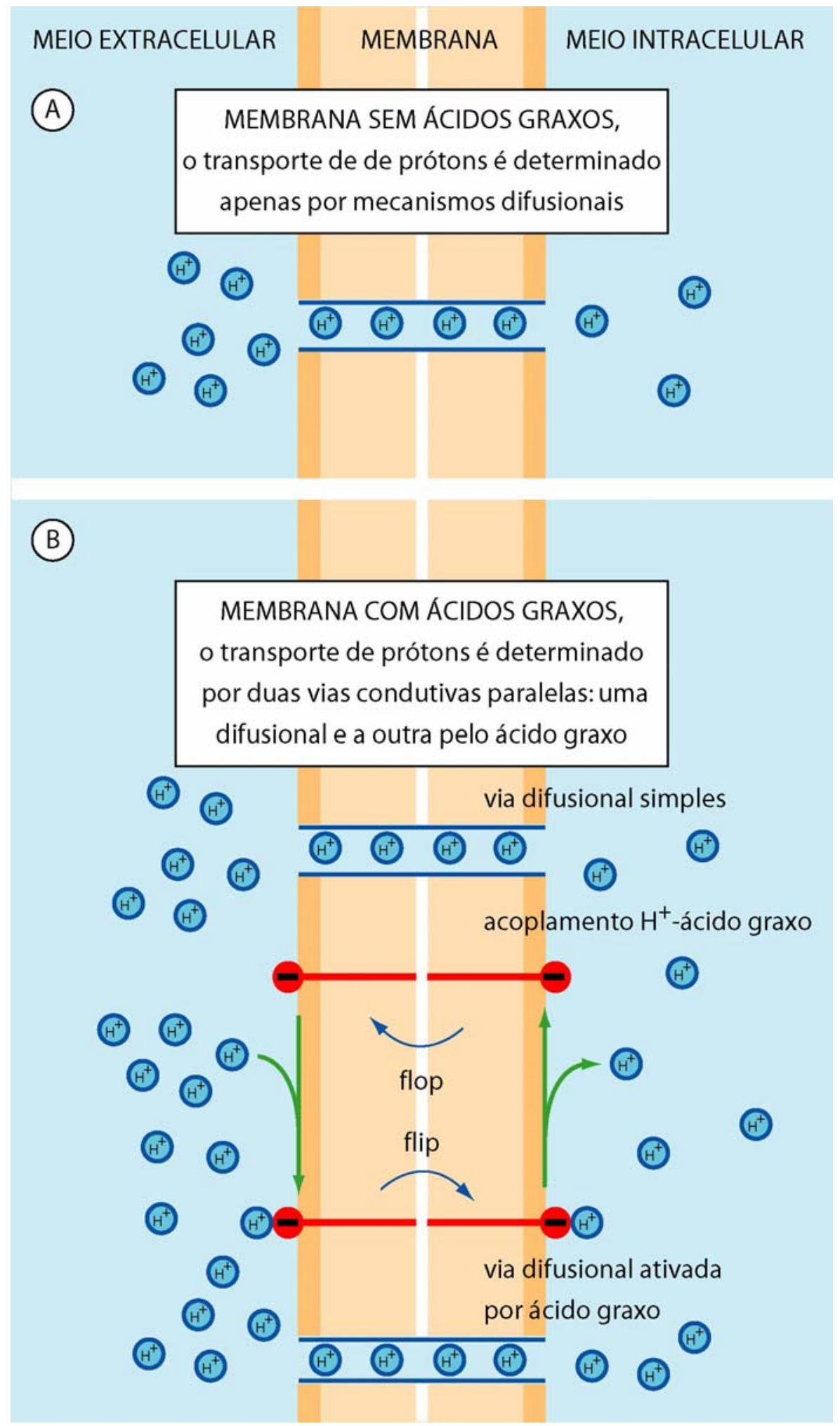

Figura 21: Esquematiza os mecanismos de transporte de prótons em bicamadas lipídicas. (A): Exemplifica os mecanismos difusionais de transporte de prótons em membranas não modificadas por ácidos graxos. Os mecanismos difusionais de prótons através de membranas fosfolipídicas são apresentados no tópico destinado a introdução. (B): Mostra os mecanismos de transporte de prótons em membranas modificadas por ácidos graxos; neste estágio há a coexistência dos dois mecanismos de transporte de prótons: mecanismo difusional e o mecanismo acoplado $\mathrm{H}^{+}$-ácido graxo. 


\subsection{Fluxo difusional simples de prótons através de bicamadas fosfolipídicas}

Há muito se sabe que a passagem de íons por membranas fosfolipídicas, desprovidas de canais ou transportadores específicos, dá-se pelo mecanismo de difusão simples. A difusão de um íon através da membrana envolve uma série de etapas: 1) particionamento do íon em um lado (hemifolheto) da membrana, a partir da solução aquosa banhante; 2) difusão através do core hidrofóbico da membrana e; 3 ) dissociação da membrana (hemifolheto oposto) para a solução aquosa oposta. Neste processo, considera-se que a passagem do íon pelo core hidrofóbico da membrana é a etapa limitante da permeação do íon, dificultada pela baixa constante dielétrica $(\sim 2)$ deste ambiente (HILLE, 2001). No entanto, no caso específico para prótons, à existência de uma quantidade considerável de moléculas de água no interior da membrana (i.e, no core hidrofóbico) cria um ambiente propício para uma alta mobilidade do próton. Na verdade, sabe-se que a permeabilidade de membranas fosfolipídicas ao próton é anomalamente alta (da ordem de $10^{-4}$ a $10^{-2} \mathrm{~cm} \mathrm{~s}^{-1}$ ) quando comparada a outros cátions (que é da ordem de $10^{-12}$ a $10^{-10} \mathrm{~cm} \mathrm{~s}^{-1}$ ) (DECOURSEY, 2003).

Os mecanismos de difusão simples de prótons em bicamada lipídicas mais aceitos na literatura são os defeitos flutuacionais de densidade (DEAMER \& NICHOLLS, 1989) e as “water-wires" (HOCH, 1998). No entanto, recentemente, HAINES (2001) propôs outro modelo para o transporte de prótons nas bicamadas, denominado de “cluster-contact mechanism". Cada cluster é formado pela associação de 3 ou 4 moléculas de água que podem estar protonadas ou não. Com isso, o transporte de prótons através da membrana dar-se-ia pelo contato de um cluster carregado positivamente localizado em um hemifolheto da membrana com outro cluster carregado negativamente e localizado no hemifolheto oposto da membrana.

Assim, a CCC e a $\mathrm{P}_{\mathrm{H}}^{+}$basais observadas (Tabelas 2, 4 e 5), em resposta a um gradiente de $\mathrm{pH}$, nas membranas de DPhPC, DPhPC-colesterol, DPhPC-cardiolipina e Azolectina não modificadas por ácidos graxos deve-se ao fluxo de prótons associado a algum desses mecanismos difusionais, ou mesmo, através da associação entre eles.

Nossos resultados, de forma interessante, ainda mostram que as membranas de DPhPC apresentam uma maior $\mathrm{G}_{\mathrm{H}}{ }^{+}$e $\mathrm{G}_{\text {leak }}$ quando comparadas com as membranas de Azolectina, ambas não modificadas por ácidos graxos. Uma explicação plausível para este fato tem como base na composição lipídica encontrada nessas membranas. A Azolectina é formada por uma 
mistura de fosfolipídeos, com cadeias saturadas e insaturadas ${ }^{1}$. Por outro lado, as membranas de DPhPC são formadas por um único tipo de fosfolipídeo, que apresenta cadeia saturada com ramificações; essas ramificações impossibilitam o perfeito empacotamento lateral das cadeias acilas adjacentes, resultando em certo grau de desordem na configuração da cadeia (HUNG et al., 2000).

Assim, as membranas de DPhPC estão sujeitas a um maior número de "defeitos" no core hidrofóbico. Estes defeitos, ocorrendo de forma desorganizada, podem constituir rotas de vazamento inespecíficas, o que intensificaria a $\mathrm{G}_{\text {leak }}$ dessas membranas. No entanto, se dois ou mais defeitos do core hidrofóbico de hemifolhetos opostos estiverem alinhados; ao conterem água e estarem dispostos em toda a extensão da membrana (i.e., a extensão dos dois hemifolhetos) constituiriam uma rota de difusão de prótons ("cluster contact" ou proton wire), tornando mais elevada $\mathrm{a}_{\mathrm{H}}{ }^{+}$dessas membranas.

Ainda, com base na diferença de estrutura entre as membranas de DPhPC (neutra) e Azolectina (carregada negativamente), devemos considerar o efeito da carga de superfície sobre os mecanismos passivos de transporte de prótons. Sendo carregada negativamente, a Azolectina geraria um potencial de superfície local, atraindo uma maior quantidade de prótons para a região próxima a superfície da membrana, ou seja, a $\left[\mathrm{H}^{+}\right]$na superfície da membrana seria maior que a $\left[\mathrm{H}^{+}\right]$no cerne da solução (McLAUGHLIN et al., 1971), favorecendo o fluxo de prótons através da membrana. Já, em membranas de DPhPC (neutra) a $\left[\mathrm{H}^{+}\right]$na superfície da membrana e no cerne da solução é a mesma. No entanto, como mencionado acima, nossos resultados mostram que membranas de Azolectina são menos condutivas a prótons quando comparadas as membranas de DPhPC. Ou seja, isto demonstra claramente que a simples aproximação dos íons a superfície da membrana não assegura uma maior taxa de transporte, caso a membrana não disponha de mecanismos adequados para realizar o transporte. Sendo as membranas de Azolectina mais "empacotadas", menor é a quantidade de "defeitos" no core hidrofófico, ou seja, menor é a quantidade de mecanismos difusionais disponíveis para o transporte de prótons.

\subsection{Como o colesterol e a cardiolipina podem interferem no fluxo difusional de prótons?}

Nossos resultados mostram que a incorporação de colesterol ou cardiolipina as membranas de DPhPC promove uma redução da $\mathrm{G}_{\text {leak }}$ (Figura 18), sugerindo um efeito

\footnotetext{
${ }^{1}$ A composição aproximada da Azolecitina é: 29\% - fosfatidil colina (PC), 30\% - fosfatidil etanolamina (PE), $26 \%$ - fosfadidil inositol (PI), 14\% - ácidos fosfatidico (PA) e 1\% - fosfatidil serina (PS) (Tilcock, 1986).
} 
"selador" tanto para o colesterol quanto para a cardiolipina. Este efeito, claramente, é independente da carga superficial da membrana, porém está intimamente relacionado com a estrutura molecular dessas substâncias e sua conseqüente interação com as membranas fosfolipídicas.

A interação entre as moléculas de colesterol e as moléculas de fosfolipídeos das membranas ocorre através de pontes de hidrogênio entre o grupo hidroxila do colesterol e os grupamentos ésteres dos fosfolipídeos (Figura 22) (BHATTACHARYA \& HALDAR, 2000). Com isso, a interação do anel esteróide rígido do colesterol com as moléculas de fosfolipídeo reduz a difusão lateral dos fosfolipídeos, diminuindo a probabilidade de formação de defeitos no core hidrofóbico da membrana, por onde água e solutos poderiam se difundir - "efeito selador" (VOET \& VOET, 1995). Portanto, a redução da $\mathrm{G}_{\text {leak }}$ em membranas de DPhPC com colesterol pode ser atribuída a este efeito "selador". Esse achado corrobora com os estudos de HAINES (2001), que atribui, ao colesterol, uma função condensadora de fosfolipídeos, diminuindo a permeabilidade da membrana a não eletrólitos, como a água.

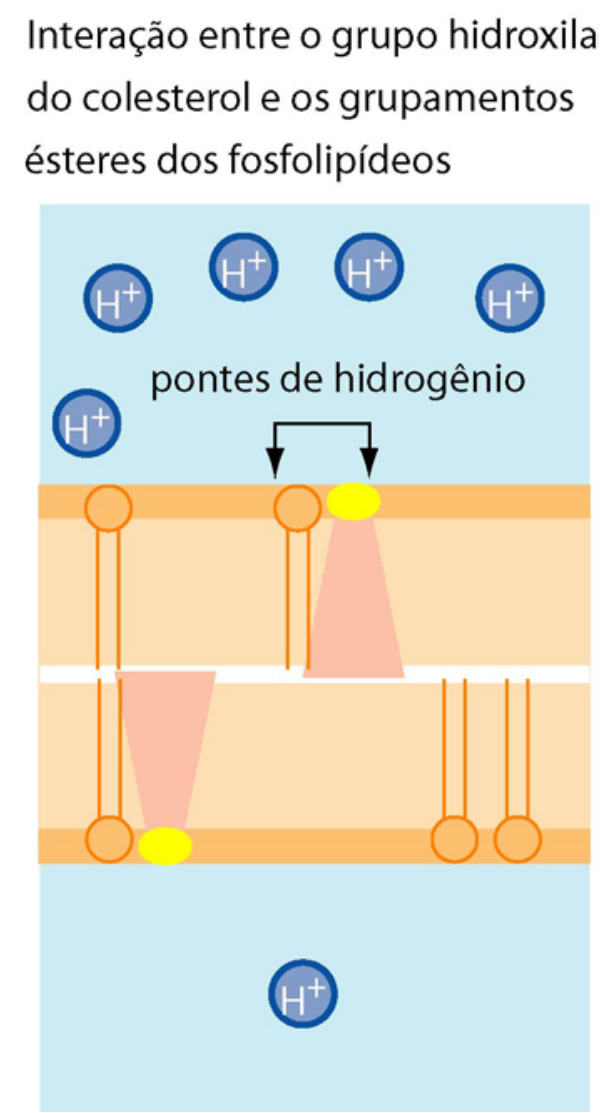

Figura 22. Mostra a interação entre as moléculas de colesterol e de fosfolipídeos.

As moléculas de cardiolipina são formadas pela ligação de dois fosfatos, três gliceróis e quatro cadeias de ácidos graxos e quando incorporadas as membranas de $\mathrm{DPhPC}$, conferem 
carga superficial negativa a estas membranas (HAINES \& DENCHER, 2002). HOCH (1998) propôs que as cardiolipinas atuariam na superfície das membranas como "antenas de prótons", captando-os e transferindo-os para agentes protonóforos. Duas moléculas de cardiolipina adjacentes formariam um microdomínio de cardiolipina, no qual o grupamento polar de uma das cardiolipinas se ligaria as moléculas de água por pontes de hidrogênio. No microdomínio, um grupamento fosfato de cada molécula de cardiolipina pode ligar-se a prótons e, posteriormente, transferi-los a agentes protonóforos.

Porém, nossos resultados, de forma surpreendente, mostram que além da diminuição da $\mathrm{G}_{\text {leak }}$, que pode ser explicada pelo mesmo efeito selador observado para o colesterol, a incorporação de cardiolipina as membranas de DPhPC também diminui a $\mathrm{G}_{\mathrm{H}}{ }^{+}$, contradizendo, pelo menos em parte, o mecanismo de antenas de prótons sugerido por Hoch. No entanto, outros autores (SHIBATA et al., 1994; CHEN \& LI, 2001; NICHOLS-SMITH et al., 2004) sugerem três grandes efeitos da cardiolipina sobre as propriedades físicas de membranas fosfolipídicas (Figura 23): (i) aumentam a quantidade de moléculas de água ligadas na interface lipídeo-água, o que poderia diminuir a energia de ativação de entrada dos íons na bicamada, aumentando a permeabilidade a prótons; (ii) aumentam a interação lateral de cadeias acilas de fosfolipídeos adjacentes localizados no mesmo hemifolheto da membrana, causando significante diminuição da permeabilidade a água; e (iii) diminuem as forças coesivas existentes entre os dois hemifolhetos da membrana, aumentando a separação entre eles. Ou seja, isto sugere que, mesmo as cardiolipinas agindo como antenas de prótons, as alterações causadas no empacotamento dos fosfolipídeos e mesmo no empacotamento dos dois hemifolhetos da membrana, tornam estas membranas desprovidas de mecanismos apropriados para o transporte de prótons (mecanismos passivos), justificando a concomitante diminuição de $\mathrm{G}_{\mathrm{H}}{ }^{+}$e $\mathrm{G}_{\text {leak }}$ observada nestas membranas. 


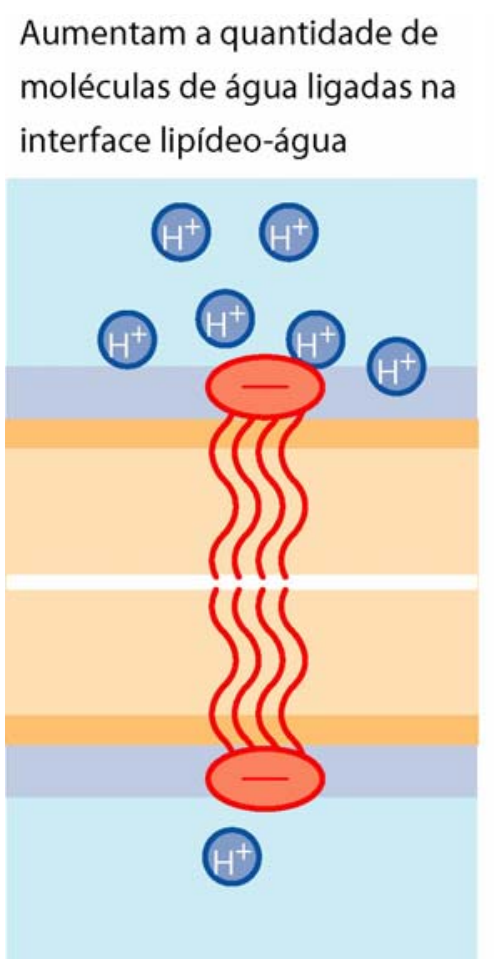

Aumentam a interação lateral entre as moléculas de fosfolipídeos de um mesmo hemifolheto

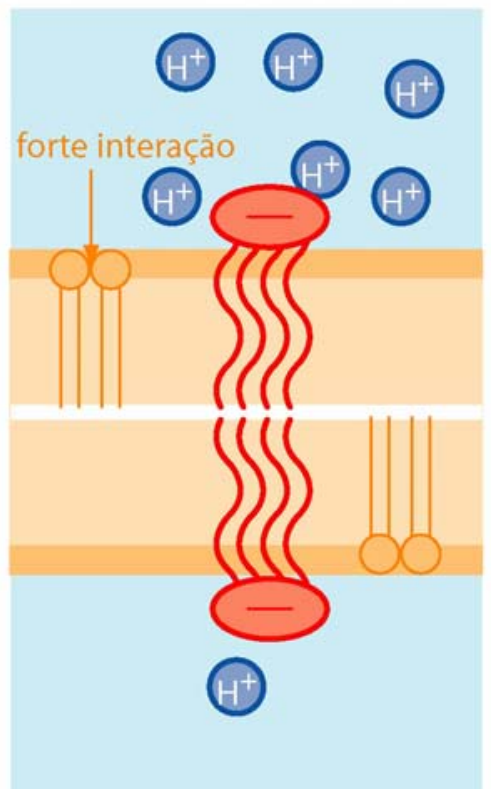

Diminuem as forças coesivas entre os dois hemilhetos, aumentando a separação entre eles

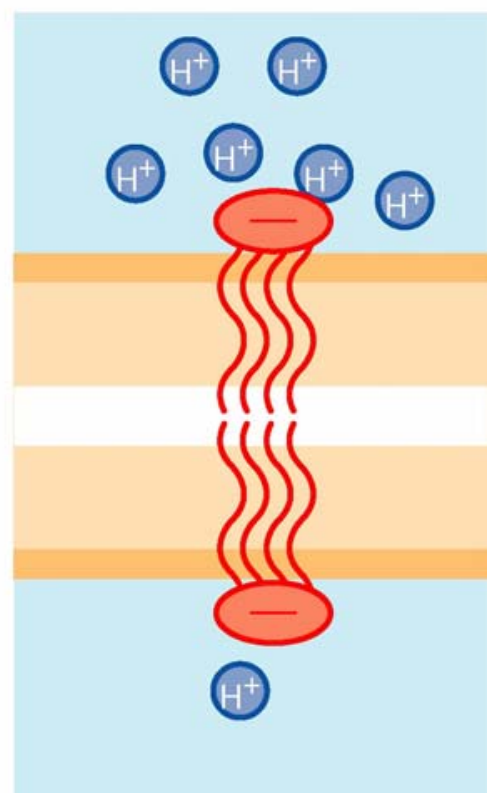

Figura 23. Efeitos da incorporação de cardiolipina em membranas fosfolipídicas.

\subsection{O transporte de prótons por ácidos graxos}

Nossos resultados com membranas de DPhPC indicam que os ácidos esteárico, oléico, linoléico, araquidônico e docosahexaenóico, quando adicionados as soluções de preenchimento e submetidos a um gradiente de concentração de prótons, promovem um aumento substancial da seletividade a prótons dessas membranas, aumentando a contribuição da via seletiva a prótons. Esse achado é observado por uma elevação dos seguintes parâmetros: relação Em/ $\mathrm{E}_{\mathrm{H}}{ }^{+}$(Figura 15), $\mathrm{G}_{\mathrm{H}}{ }^{+}$(Figuras 12 e 14), CCC (Tabela 2) e $\mathrm{P}_{\mathrm{H}}{ }^{+}$(Tabela 2).

Nossos achados ainda corroboram os estudos do início da década de 90 de KAMP \& HAMILTON (1993; 1995). Esses autores demonstraram a eficiência de ácidos graxos em aumentar a taxa de acidificação de vesículas fosfolipídicas, após a adição de ácido oléico a solução banhante. Nessa ocasião, estes autores propuseram um modelo, no qual os ácidos graxos funcionariam como transportadores de prótons.

Baseando-se nesse modelo e extrapolando-o para bicamadas lipídicas planas em uma condição de curto-circuito elétrico, a análise do fluxo de prótons acoplado aos ácidos graxos $\left(\mathrm{H}^{+}\right.$-ácido graxo) ocorre através das seguintes etapas (Figura 24): 
1 - inicialmente, o ânion de ácido graxo, adicionado as soluções de preenchimento dos compartimentos cis e trans, particiona-se facilmente na membrana fosfolipídica (etapa 1);

2 - a interação dos ânions de ácido graxo com prótons gera uma molécula neutra de ácido graxo no hemifolheto cis (etapa 2);

3 - com a criação de uma diferença de concentração de moléculas neutras de ácido graxo entre os dois hemifolhetos da membrana, os ácidos graxos protonados fluem do hemifolheto cis para o hemifolheto trans (flip-flop) (etapa 3);

4 - no hemifolheto trans ocorre a dissociação da molécula neutra de ácido graxo, com o próton desligando-se do ânion de ácido graxo indo para a solução trans. Um ânion de ácido graxo é regenerado, realizando o movimento de flip-flop para o hemifolheto cis (etapa 4). Fechando o ciclo.

Um aspecto de importância neste modelo é que a translocação física do ânion de ácido graxo do hemifolheto trans para o hemifolheto cis dá origem a uma corrente de cargas negativas direcionada de trans para cis, que corresponde a uma corrente elétrica de cargas positivas de cis para trans (também esquematizado na Figura 24). Este fluxo de ácido graxo no sentido trans $\rightarrow$ cis é movido pelo gradiente de concentração de ácidos graxos carregados estabelecido entre os dois hemifolhetos.

Este modelo prioriza essencialmente o transporte de prótons, uma vez que os ácidos graxos ficam acondicionados no ambiente hidrofóbico da membrana. No entanto, estudos prévios com fluxo isotópico de ácidos graxos marcados realizados em nosso laboratório, mostraram que em uma escala temporal maior (de vários dias) pode ocorrer a desorção de ácidos graxos, quando na presença de um gradiente de concentração de ácidos graxos transmembrana (ROMANO-FONTES et al., 2000). No entanto, para o tempo de duração dos nossos experimentos ( 3 horas) podemos considerar que a concentração de ácidos graxos nas soluções banhantes é constante e, como a quantidade de ácido graxo está acima do limite de solubilidade a concentração de ácido graxo livre é constante e igual ao limite de solubilidade.

O mecanismo acima é corroborado por outros autores, em diferentes sistemas biomiméticos (HAMILTON \& KAMP, 1999). O retorno do ânion de ácido graxo ao hemifolheto cis seria, em princípio, a etapa limitante do processo, uma vez que requer a translocação de carga através da região hidrofóbica da membrana. Um mecanismo para explicar o retorno do ânion de ácido graxos na membrana interna da mitocôndria foi proposto por SKULACHEV (1998) e JEZEK (1999), usando proteínas desacopladoras (UCPs uncoupling proteins. Por este mecanismo, o retorno do ânion de ácido graxo seria propiciado por sua ligação a um grupo catiônico da UCP. 


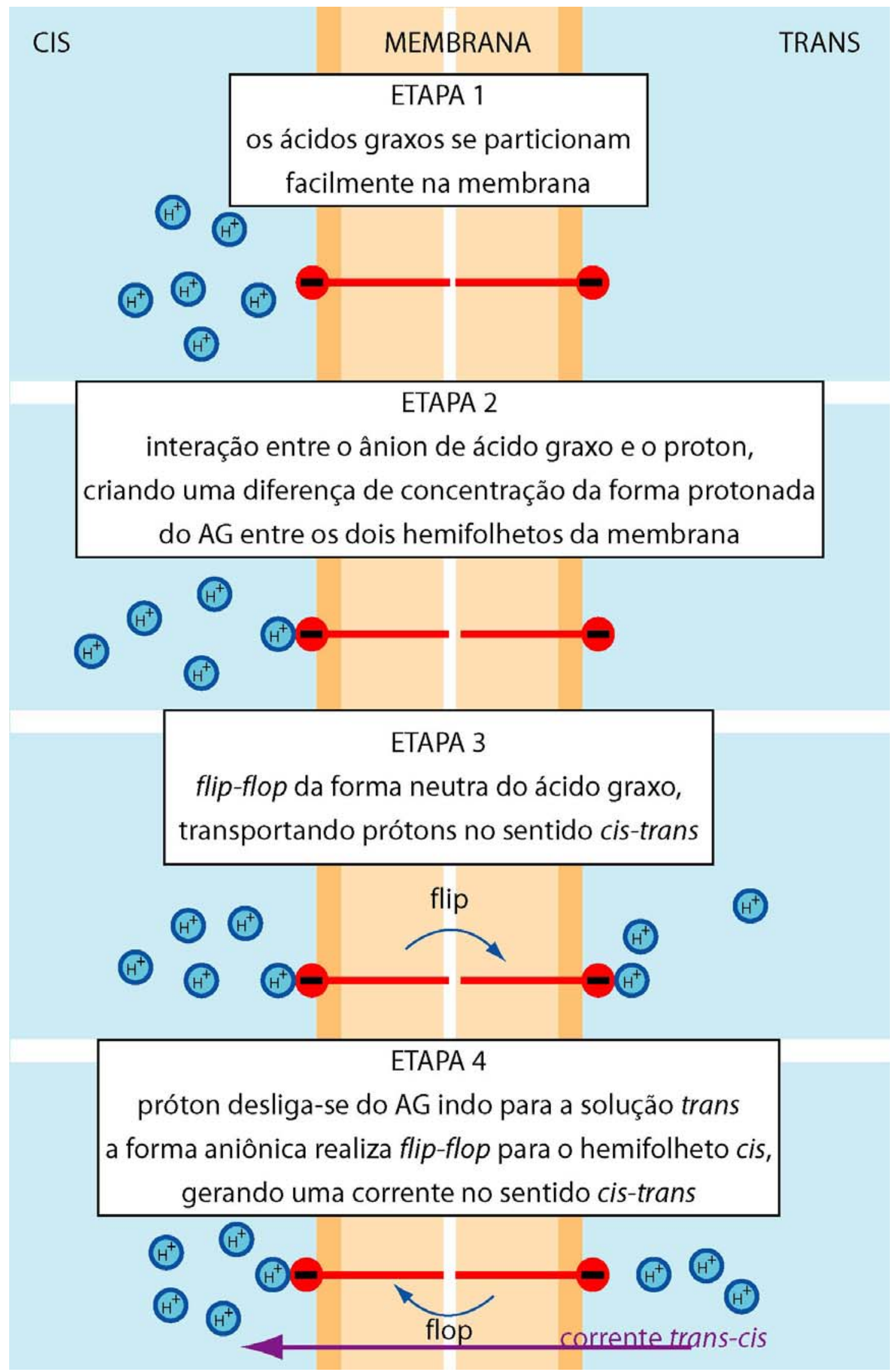

Figura 24: Representação cinética do transporte de prótons por ácidos graxos em membranas fosfolipídicas. Modelo de Kamp \& Hamilton (1998) adaptado para as bicamadas lipídicas planas. Para maiores detalhes são apresentados no texto (tópico 4.3.) 
Nossos resultados ainda mostram uma dependência substancial da seletividade de membranas de DPhPC a prótons com a estrutura molecular dos ácidos graxos, sendo influenciada pelo comprimento da cadeia acila e pelo número de insaturações. A seletividade a prótons de membranas tratadas com ácidos graxos seguia a seguinte ordem: ácido docosahexaenóico $(22: 6) \geq$ ácido araquidônico $(20: 4) \geq$ ácido linoléico (18:2) > ácido oléico (18:1) > ácido esteárico (18:0). Os ácidos graxos caprílico (8:0) e palmítico (16:0) parecem não influenciar a seletividade a prótons dessas membranas.

KLEINFELD et al. (1997) e ZENG et al. (1998), em estudos com vesículas unilamelares, mostraram uma relação inversa entre o tamanho do ácido graxo e sua taxa de translocação (flip-flop) através da membrana. Esta relação é explicada pela necessidade do flip-flop do ácido graxo em gerar um espaço livre na matriz lipídica capaz de englobar por inteiro a molécula de ácido graxo, onde a energia de ativação associada a este mecanismo seria maior quanto maior for a molécula do ácido graxo. Ainda nestes estudos, e corroborado por outros autores em estudos com mitocôndrias (BERNARDI et al., 2002), os autores mostraram que a taxa de flip-flop é otimizada quando o comprimento da cadeia acila dos ácidos graxos é próxima a metade da espessura da membrana, ou seja, do comprimento de um hemifolheto.

Baseando-se nesses estudos, seria de se esperar que ácidos graxos longos e/ou poliinsaturados determinassem uma seletividade a prótons menor às membranas de DPhPC que, por exemplo, o ácido palmítico. No entanto, isto não foi observado em nossos experimentos. Então, como estes ácidos graxos poderiam estar atuando? Para respondermos esta questão devemos considerar dois aspectos:

$1^{\circ}$ - como mostrado na Figura 7 (ver Materiais e Métodos), os ácidos graxos saturados apresentam um estrutura linear, enquanto que os ácidos graxos insaturados possuem dobramentos da cadeia acila, devido a angulação de $30^{\circ}$ das duplas ligações do tipo cis; esses dobramentos acabam por reduzir o comprimento da cadeia acila desses ácidos graxos, podendo otimizar o comprimento das cadeias acilas dos ácidos graxos e dos fosfolipídeos;

$2^{\circ}$ - os ácidos graxos insaturados, por apresentarem dobramentos na cadeia acila, poderiam causar alterações na organização estrutural de membranas fosfolipídicas, o que formaria cavidades na estrutura das membranas facilitando o flip-flop dos ácidos graxos.

Assim, os ácidos graxos insaturados e poliinsaturados devem diminuir o grau de empacotamento dos fosfolipídeos, determinando um aumento do espaço livre entre os mesmos, que poderia de certa forma facilitar tanto o seu flip-flop quanto o mecanismo difusional de prótons e, assim, eventualmente dissipar gradientes de $\mathrm{pH}$ (Figura 25). $\mathrm{Na}$ 
verdade, KLAUSNER et al. (1980) em estudos de polarização de fluorescência em vesículas unilamelares mostraram que a simples intercalação de ácidos graxos livres com as moléculas de fosfolipídeos diminui o parâmetro de ordem da membrana como um todo.

Por outro lado, a estrutura linear dos ácidos graxos saturados e do ácido elaídico, possuidor de uma dupla ligação do tipo trans, facilitaria tanto a interação destes ácidos graxos com as cadeias acila dos fosfolipídeos quanto o empacotamento das mesmas, diminuindo espaços livres e a mobilidade dos ácidos graxos no ambiente hidrofóbico das membranas (Figura 25). Porém, estudos de ácidos graxos livres com duplas ligações do tipo trans são escassos na literatura, sendo realizados principalmente em estudos com ácidos graxos esterificados modificando membranas fosfolipídicas. Esses estudos mostraram que ácidos graxos como o ácido elaídico não alteram as propriedades físico-químicas de membranas fosfolipídicas (FUNARI et al., 2003).

Nossos resultados ainda mostram que em membranas de Azolectina (Figura 20), todos os ácidos graxos testados (palmítico, oléico e araquidônico), são efetivos em aumentar a seletividade a prótons. Este efeito, especificamente, não foi encontrado para o ácido palmítico em membranas de DPhPC. Como mencionado acima, a membrana de Azolectina é formada por uma mistura de fosfolipídeos com diferentes comprimentos. Isso poderia criar microregiões na qual existe uma perfeita associação entre o comprimento do ácido palmítico e o comprimento das moléculas de fosfolipídeo, permitindo a realização de flip-flop da molécula de ácido palmítico (Figura 25). 


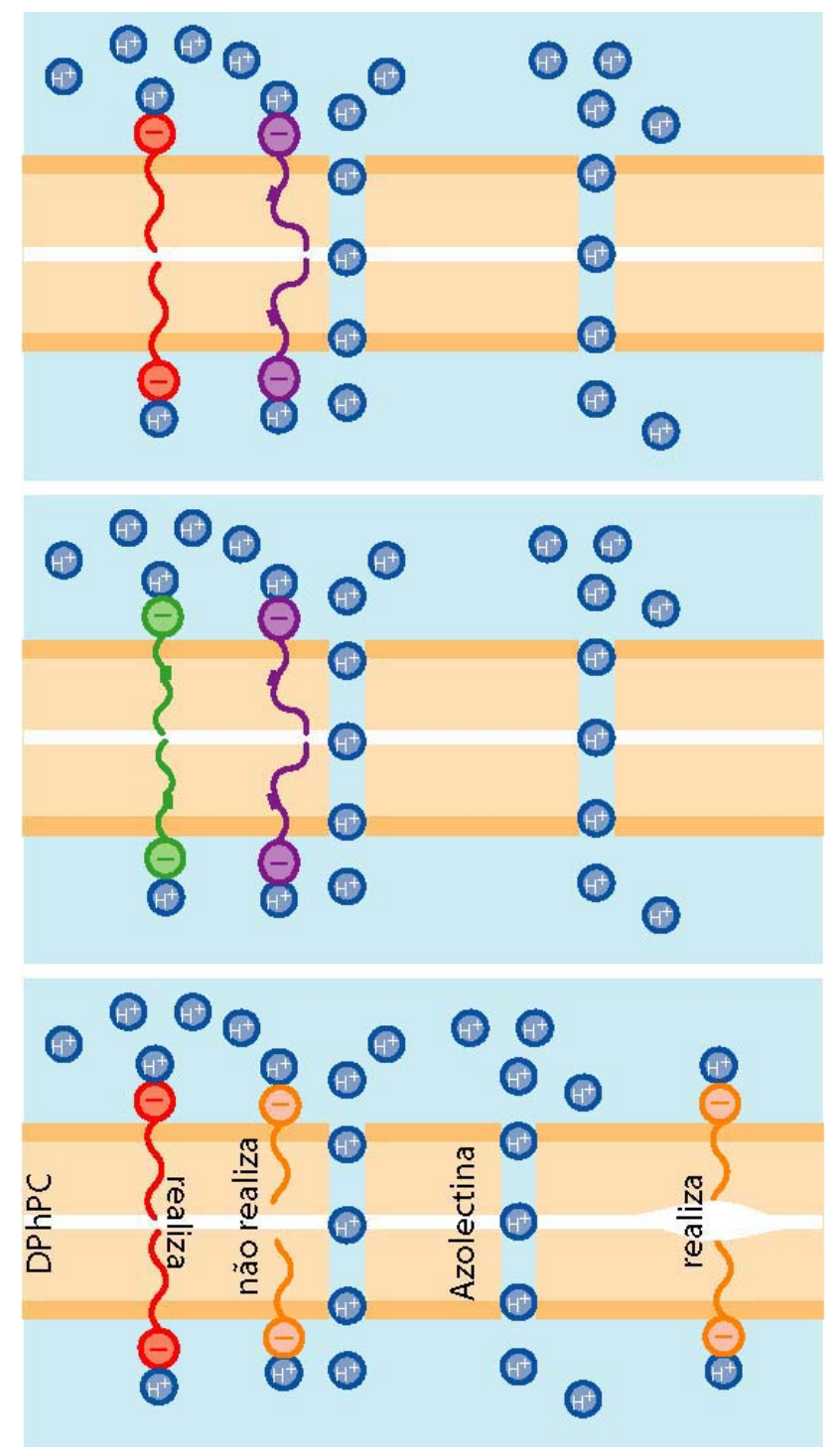

\section{SATURADO vs. INSATURADO}

Diferentemente dos AGs saturados, os AGs insaturados desorganizam a membrana, criando novas rotas aquosas para o transporte de prótons

cis-INSATURADOS vs. trans-INSATURADOS

Os AGs trans-Insaturados por apresentarem estrutura linear, agem de forma parecida aos AGs saturados

\section{DPhPC vs. AZOLECTINA}

A translocação do AG (flip-flop) depende de uma perfeita associação entre o comprimento das moléculas de AG e fosfolipídeo.

Figura 25. Representação dos efeitos dos diferentes ácidos graxos em membranas de DPhPC e Azolectina.

\subsection{Efeito do colesterol e da cardiolipina no transporte de prótons por ácidos graxos}

Para testar o efeito de agentes modificadores do ambiente lipídico de membranas no fluxo de prótons acoplado ao transporte de ácidos graxos, usamos como modelo o colesterol e a cardiolipina, além do ácido graxo insaturado oléico.

O colesterol foi incorporado as membranas de DPhPC em uma concentração equivalente a $17 \%$ do peso total em massa, simulando a proporção entre colesterol e fosfolipídeo encontrada na maioria das membranas plasmáticas (VOET \& VOET, 1995). Contrariando nossas expectativas que se baseavam no efeito condensador do colesterol em 
membranas fosfolipídicas, a incorporação de colesterol as membranas de DPhPC não alterou a seletividade a prótons mediada pelo ácido oléico, como mostrado na Figura 19. No entanto, MESHULAM et al. (2006) vêm mostrando uma fase adicional, chamada de fase lenta, no decréscimo do $\mathrm{pH}$ intracelular induzido por ácidos graxos em células HEK 293. Este lento decréscimo foi atribuído a associação das moléculas de ácidos graxos com regiões da membrana contendo 'rafts' de colesterol e caveolina-1. Assim, a importância do colesterol na translocação de moléculas de ácidos graxos através de membranas fosfolipídicas parece estar relacionada a presença de micro-regiões específicas na membrana celular, como os 'lipid rafts'.

A cardiolipina foi incorporada às membranas de DPhPC com o objetivo de testar a hipótese de "antena de prótons" na superfície de membranas, onde a cardiolipina atuaria captando prótons na superfície e transferindo-os a agentes protonóforos (que no nosso caso seria o ácido oléico), como proposto por HOCH (1998). Estes experimentos foram realizados com membranas de DPhPC com cardiolipina a $21 \%$ em relação a massa total, que é a concentração encontrada na membrana interna da mitocôndria (VOET \& VOET, 1995). Como mostrado na Figura 19, a incorporação de cardiolipina a estas membranas produziu um aumento substancial na condutância a prótons determinada pelo ácido oléico, sendo a condutância a prótons de membranas de DPhPC com cardiolipina cerca de 3 vezes maior que as membranas de DPhPC, quando ambas são modificadas por ácido oléico. Também, como discutido acima, em membranas de DPhPC com cardiliopina e não modificadas por ácidos graxos, as moléculas de cardiolipina são capazes de reduzir a energia de ativação para a adsorção de íons na membrana (CHEN \& LI, 2001). Com isso, o tratamento dessas membranas com AO cria uma via adicional seletiva a prótons através da membrana. Neste sistema, as moléculas de cardiolipina provavelmente agem coletando prótons e doando-os especificamente para o AO (Figura 26), o que sugere existir o mecanismo de antena de prótons proposto por Hoch. Este mecanismo causa um aumento na permeabilidade a prótons especificamente através do acoplamento com ácidos graxos $\left(\mathrm{H}^{+}\right.$-ácido oléico). 


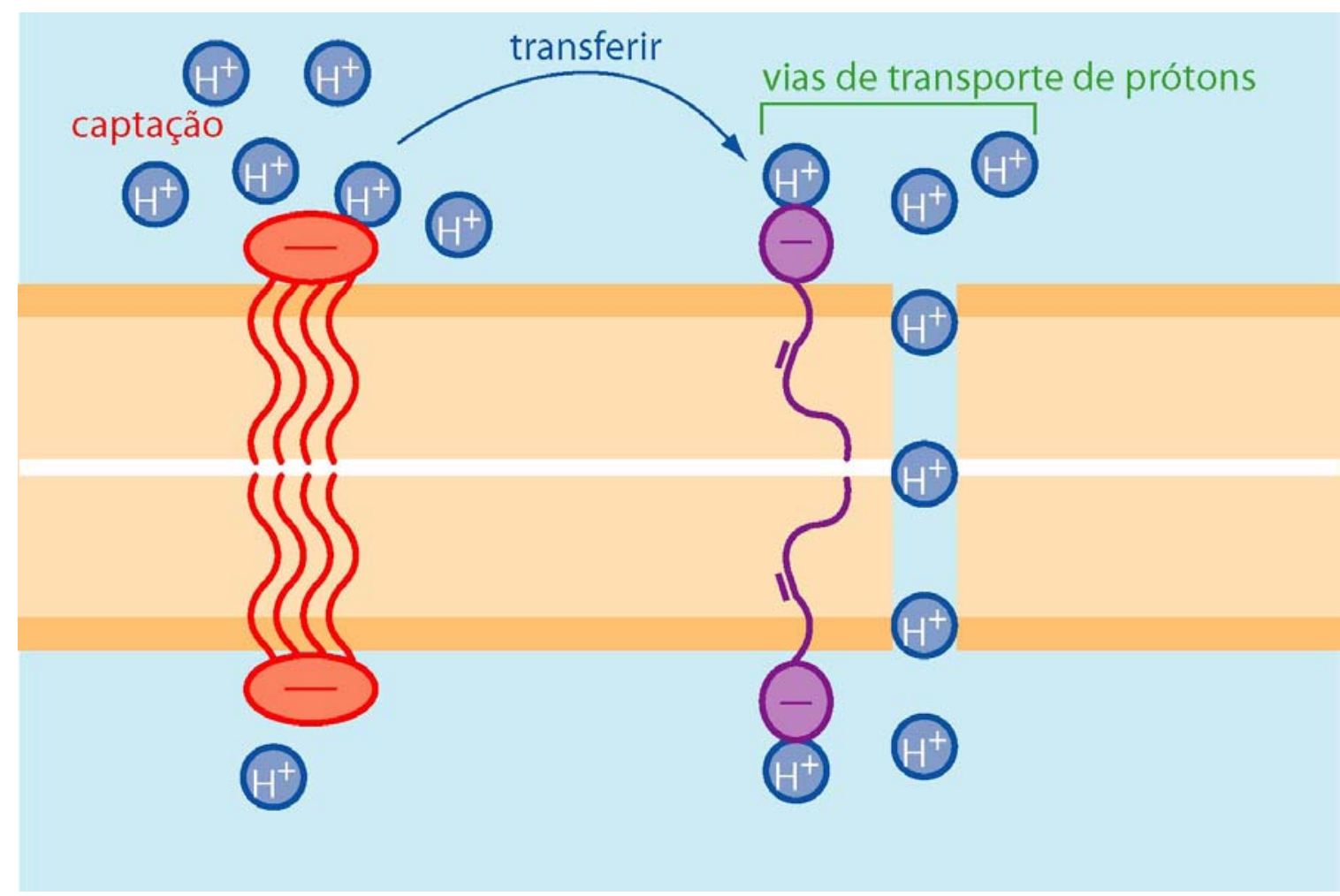

Figura 26. Efeito da cardiolipina em membranas modificadas por ácido oléico. As moléculas de cardiolipina agiriam captando prótons e tranferindo-os especificamente para as moléculas de ácido oléico.

A função das moléculas de cardiolipina assim como das proteínas desacopladores (UCPs) na atividade da membrana interna da mitocôndria (MMI) ainda é motivo de controvérsia.

Para as cardiolipinas há duas correntes antagônicas que propõem: na primeira, defendida principalmente por $\mathrm{HOCH}$ (1998), as cardiolipinas agiriam como antenas de prótons no hemifolheto externo da MMI, captando e transferindo prótons para a matriz lipídica (dissipando o gradiente de prótons gerado pela cadeia transportadora de elétrons) e/ou para a ATP sintase (aumentando a produção de ATP). E na segunda, HAINES \& DENCHER (2002) propõem que a função das cardiolipinas na MMI estaria associada a proteínas envolvidas no processo de fosforilação oxidativa, principalmente com a ATP sintase, onde as cardiolipinas por serem fosfolipídeos carregados negativamente atuariam como um reservatório de prótons, atraindo uma maior quantidade de prótons para a região próxima a entrada da ATP sintase, impedindo o vazamento de prótons e aumentando a produção de ATP.

Já, para as UCPs, URBANKOVÁ et al. (2003) defendem a hipótese de que essas proteínas seriam transportadores de prótons e os ácidos graxos agiriam apenas como 
ativadores específicos dessas proteínas. Contrariando, SKULACHEV et al. (1998) e mais recentemente BREEN et al. (2006) defendem que as UCPs presentes na MMI agem mediando o flip-flop da forma aniônica dos ácidos graxos, fechando o ciclo para a ação desacopladora dos ácidos graxos.

Com isso, nossos resultados com o AO corroboram a proposta de Hoch quanto a de Skurachev, relacionando a atividade desacopladora de gradientes de prótons dos ácidos graxos com as atividades da cardiolipina e das UCPs na MMI.

\subsection{Importância para o transporte de ácidos graxos nas células}

Nossos resultados sugerem que o transporte de ácidos graxos através de membranas fosfolipídicas, incluindo as membranas celulares e de organelas intracelulares, pode ocorrer por um mecanismo acoplado ao transporte de prótons, ou seja, sem a necessidade de proteínas transportadoras específicas (transporte mediado). Ainda, em maior ou menor escala e dependendo de fatores estruturais, os ácidos graxos podem agir como moléculas dissipadoras de gradientes de prótons, atuando diretamente em diversas funções metabólicas, como manutenção ou não do pH intracelular, produção ou não de ATP e termogênese.

No entanto, nossos achados não excluem a possibilidade de haver, em paralelo, um processo mediado por proteínas, principalmente em células ou situações (como exercício físico) de grande exigência metabólica de ácidos graxos. Na verdade, atualmente, há uma necessidade de se reconhecer tanto o mecanismo de flip-flop acoplado a $\mathrm{H}^{+}$quanto o mecanismo mediado por proteínas, onde tais mecanismos poderiam contribuir em maior ou menor grau. Como mencionado na introdução, STUMP et al. (2001) consideram que, em situações basais, a captação celular de ácidos graxos é principalmente mediada por proteínas de membrana enquanto que em situações de elevada concentração de ácidos graxos, a contribuição do mecanismo de flip-flop é predominante.

Em especial, na membrana interna da mitocôndria, a associação entre os mecanismos determinados pela cardiolipina (“antena de prótons”), pelas proteínas desacopladores - UCPs (transporte de forma ionizada do ácido graxo) e pelos ácidos graxos podem agir diretamente na termogênese do organismo. Este efeito na termogênese têm especial importância na musculatura esquelética durante a atividade física. Por exemplo, HIRABARA et al. (2006) vêm propondo substancial importância para ácidos graxos na transição do metabolismo anaeróbico para o aeróbico. 
Por conseguinte, vemos que o mecanismo de transporte de prótons por ácidos graxos tem elevada importância para a fisiologia dos ácidos graxos e do organismo como um todo. Por sua vez, as bicamadas lipídicas planas constituem um sistema adequado para se avaliar a importância de fatores estruturais dos ácidos graxos, de membranas fosfolipídicas e outros componentes como colesterol ou cardiolipina, mimetizando as membranas biológicas. 


\section{CONCLUSÕES}

- o transporte de prótons através de bicamadas fosfolpídicas pode ocorrer por um mecanismo acoplado ao transporte de ácidos graxos;

- o transporte de prótons se dá por duas vias: uma passiva (inicial ou induzida por ácidos graxos) e outra pelo acoplamento prótons-ácidos graxos;

- ácidos graxos cis insaturados são mais efetivos em transportar prótons quando comparados aos ácidos graxos saturados;

- ácidos graxos trans insaturados se comportam como ácidos graxos saturados, provavelmente por causa características estruturais semelhantes;

- a efetividade de um ácido graxo em transportar prótons também é dependente de uma perfeita associação entre o comprimento das moléculas de ácido graxo e de fosfolipídeo, minimizando a energia de ativação para o transporte;

- o colesterol pouco interfere com os mecanismos de transporte de prótons através da membrana (passivos ou acoplado a ácidos graxos), alterando de forma considerável a condutância de vazamento inespecífica - efeito selador;

- a cardiolipina interfere com os mecanismos passivos de transporte de prótons e com a condutância de vazamento inespecífica de membranas não modificadas por ácidos graxos, provavelmente por alterar propriedades estruturais de membrana;

- a cardiolipina intensifica a atividade transportadora de prótons do ácido oléico, provavelmente pelo mecanismo de antena de prótons. 


\section{REFERÊNCIAS}

Abumrad, N.; Harmon, C.; Ibrahimi, A. Membrane transport of long-chain fatty acids: evidence for a facilitated process. J. Lipid Res., v. 39, p. 2309-2318, 1998.

Abumrad, N.; Coburn, C.; Ibrahimi, A. Membrane proteins implicated in long-chain fatty acid uptake by mammalian cells: CD36, FATP and FABPm. Biochem. Biophy. Acta., v. 1441, p. 4-13, 1999.

Anel, A.; Richieri, G.V.; Kleinfeld, A.M. Membrane partition of fatty acids and inhibition of T cell function. Biochemistry, v. 32, p. 530-536, 1993.

Bays, H.; Mandarino, L.; DeFronzo, R.A. Role of adipocyte, free fatty acids, and ectopic fat in pathogenesis of type 2 diabetes mellitus: peroxisomal proliferator-activated receptor agonists provide a rational therapeutic approach. J. Clin. Endocrinol. Metab., v. 89, p. 463478, 2004.

Berk, P.D. \& Stump, D.D. Mechanism of cellular uptake of long chain free fatty acids. Mol. Cell Biochem., v. 192, p. 17-31, 1999.

Bernardi, P.; Penzo, D.; Wojtczak, L. Mitochondrial energy dissipation by fatty acids. Vitam. Horm., v. 65, p. 97-126, 2002.

Bhattacharya, S. \& Haldar, S. Interactions between cholesterol and lipids in bilayer membranes. Role of lipid headgroup and hydrocarbon chain-backbone linkage. Biochim. Biophys. Acta., v.1467, p. 239-253, 2000.

Bihain, B.E.; Deckelbaum, R.J.; Yen, F.T.; Gleeson, A.M.; Carpentier, Y.A.; White, L.D. Unesterified fatty acids inhibit the binding of low density lipoproteins to the human fibroblast low density lipoprotein receptor. J. Biol. Chem., v. 264, p. 17316-17323, 1989.

Breen, E.P.; Gouin, S.G.; Murphy, A.F.; Haines, L.R.; Jackson, A.M.; Pearson, T.W.; Murphy, P.V.; Porter, R.K. On the mechanism of mitochondrial uncoupling protein 1 function. J. Biol. Chem., v. 281, p. 2114-2119, 2006.

Bruno, M.J.; Koeppe II, R.E.; Andersen, O.S. Docosahesaenoic acid alters bilayer elastic properties. Proc. Natl. Acad. Sci. USA, v. 104, p. 9638-9643, 2007. 
Chen, Q.-P.; Li, Q.-T. Effect of cardiolipin on proton permeability of phospholipid lipossomes: the role of hydration at the lipid-water interface. Arch. Biochem. Biophys., v. 389, p. 201-206, 2001.

Civelek, V.N.; Hamilton, J.A.; Tornhein, K.; Kelly, K.L.; Corkey, B.E. Intracellular pH in adipocytes: effects of free fatty acid diffusion across the plasma membrane, lipolytic agonists, and insulin. Proc. Natl. Acad. Sci. USA, v. 93, p. 10139-10144, 1996.

Clarke, S.D.; Thillier, P.; Baillie, R.A.; Sha, X. Peroxisome proliferator-activated receptor: a family of lipid-activated transcription factors. Am. J. Clin. Nutr., v. 70, p. 556-571, 1999.

Córsico, B.; Franchini, G.R.; Hsu, KT.; Storch, J. Electrostatic and hydrophobic interactions contribute to the collisional mechanism of fatty acid transfer from intestinal fatty acid binding protein to phospholipid membranes. J. Lipid Res., v. 46, p. 1765-1772, 2005.

Deamer, D.W. \& Nichols, J. W. Proton flux mechanisms in model and biological membranes. J. Membr. Biol., v. 107, p. 91-103, 1989.

Decoursey, T.E. Voltage-gated proton channels and other proton transfer pathways. Physiol. Rev., v. 83, p. 475-579, 2003.

Funari, S.S.; Barcelo, F.; Escriba, P.V. Effects of oleic acid and its congeners, elaidic and stearic acids, on the structural properties of phosphatidylethanolamine membranes. J. Lipid Res., v. 44, p. 567-575, 2003.

Gutknecht, J. Proton conductance through phospholipid bilayers: water wires or weak acids? J. Bioenerg. Biomembr., v. 19, p. 427-42, 1987.

Gutknecht, J. Proton conductance caused by long-chain fatty acids in phospholipid bilayer membranes. J. Membr. Biol., v. 106, p. 83-93, 1988.

Haines, T.H. Do sterols reduce proton and sodium leaks through lipid bilayers? Prog Lipid Res, v. 40, p. 299-324, 2001.

Haines, T.H. \& Dencher, N.A. Cardiolipin: a proton trap for oxidative phosphorylation. FEBS Lett., v. 528, p. 35-39, 2002. 
Hamilton, J.A.; Civelek, V.N.; Kamp, F.; Tornheim, K.; Corkey, B.E. Changes in internal pH caused by movement of fatty acids into and out of clonal pancreatic $\beta$-cells (HIT). J. Biol. Chem., v. 269, p. 20852-20856, 1994.

Hamilton, J.A. Fatty acid transport: difficult or easy? J. Lipid Res., v. 39, p. 467-481, 1998.

Hamilton, J.A. \& Kamp, F. How are free fatty acid transported in membranes? Is it by proteins or by free diffusion through the lipids? Diabetes, v. 48, p. 2255-2269, 1999.

Hannigan, G.E. \& Williams, B.R.G. Signal transduction by interferon-alpha through arachidonic acid metabolism. Science, v. 251, p. 204-207, 1991.

Hille, B. Elementary properties of ions in solution. In: Ionic channels of excitable membranes. Massachusetts: Sinauer Associates Inc., 2001. Chapter 10, p. 309-345.

Hirabara, S.M.; Silveira, L.R.; Abdulkader, F.R.; Alberice, L.C.; Procopio, J.; Carvalho, C.R.; Phiton-Curi, T.C.; Curi, R. Role of fatty acids in the transition from anaerobic to aerobic metabolism in skeletal muscle during exercise. Cell Biochem. Fuct., v. 24, p. 475-481, 2006.

Hoch, F.L. Cardiolipins and mitochondrial proton-selective leakage. J. Bionerg. Biomembr., v. 30, n. 6, p. 511-532, 1998.

Jezek, P. Fatty acid interaction with mitochondrial uncoupling proteins. J. Bionerg. Biomembr., v. 31, n. 5, p. 457-466, 1999.

Kamp, F. \& Hamilton, J.A. pH gradients across phospholipid membranes caused by fast flipflop of un-ionized fatty acids. Proc. Natl. Acad. Sci. USA, v. 89, p. 11367-11370, 1992.

Kamp, F. \& Hamilton, J.A. Movement of fatty acids, fatty acid analogues, and bile acids across phospholipid bilayers. Biochemistry, v. 32, p. 11074-11086, 1993.

Kamp, F.; Zakim, D.; Zhang, F.; Noy, N.; Hamilton, J.A. Fatty acid flip-flop in phospholipid bilayers is extremely fast. Biochemistry, v. 34, p. 11928-11937, 1995.

Klausner, R.D.; Kleinfeld, A.M.; Hoover, R.L.; Karnovsky, M.J. Lipid domains in membranes. Evidence derived from structural perturbations induced by free fatty acids and lifetime heterogeneity analysis. J. Biol. Chem., v. 255, p. 1286-1295, 1980. 
Kleinfeld, A.M. Lipid phase fatty acids flip-flop, is it fast enough for cellular transport. J. Membr. Biol., v. 175, p. 79-86, 2000.

Marszalek, J.R. \& Lodish, H.F. Docosahexaenoic acid, fatty acid-interacting proteins, and neuronal function: breastmilk and fish are good for you. Annu. Rev. Cell Dev. Biol., v. 21, p. 633-657, 2005.

McLaughlin, S.G.A.; Szabo, G.; Eisenman, G. Divalent ions and the surface potential of charged phospholipid membranes. J. Gen. Physiol., v. 58, p. 667-687, 1971.

McLaughlin, S. \& Dilger, P.J. Transport of protons across membranes by weak acids. Physiol. Rev., v. 60, p. 825-863, 1980.

Meshulam, T.; Simard, J.R.; Wharton, J.; Hamilton, J.A.; Pilch, P.F. Role of caveolin-1 and cholesterol in transmembrane fatty acid movement. Biochemistry, v. 45, p. 2882-2893, 2006.

Mitchell, P. Coupling of phosphorylation to electron and hidrogen transfer by a chemiosmotic type of mechanism. Nature, v. 191, p. 144-148, 1961.

Mueller, P.; Rudin, H.T.; Tien, T.; Wescott, W.C. Methods for the formation of single bimolecular lipid membranes in aqueous solutions. J. Phys. Chem., v. 67, p. 534-535, 1963.

Nagle, J.F. Theory pf passive proton conductance in lipid bilayers. J. Bioenerg. Biomembr., v. 19, p. 413-426, 1987.

Nichols-Smith, S.; Teh, S.Y.; Kuhl, T.L. Thermodynamic and mechanical properties of model mitochondrial membranes. Biochem. Biophys. Acta, v. 1663, p. 82-88, 2004.

Ordway, R.W.; Walsh, J.V.Jr.; Singer, J.J. Arachidonic acid and other fatty acids directly activate potassium channels in smooth muscle cells. Science, v. 244, p. 1176-1179, 1989.

Papahadjopoulos, D,; Nir, S.; Ohki, S. Permeability properties of phospholipid membranes: effect of cholesterol and temperature. Biochim. Biophys. Acta., v. 226, p. 561-583, 1971.

Pohl, E.; Peterson, U.; Sun, J.; Pohl, P. Changes of intrinsic membrane potentials induced by flip-flop of long-chain fatty acids Biochemistry, v. 39, p. 1834-1839, 2000. 
Pohl, J.; Ring, A.; Hermann, T.; Stremmel, W. Role of FATP in parenchymal cell fatty acid uptake. Biochim. Biophys. Acta., v. 1686, p. 1-6, 2004.

Ramsey, I.S.; Moran, M.M.; Chong, J.A.; Clapham, D.E. A voltage-gated proton-selective channel lacking the pore domain. Nature, v. 440, p. 1213-1216, 2006.

Romano-Fontes, L.G.; Curi, R.; Peres, C.M.; Nishiyama-Nakura, A.; Brunaldi, K.; Abdulkader, F.; Procopio, J. Fatty acid transport across lipid bilayer planar membranes. Lipids, v. 35, p. 31-34, 2000.

Schaffer, J. E. Fatty acid transport: the roads taken. Am. J. Physiol. Endocrinol. Metab., v. 282, p. 239-246, 2002.

Shibata, A.; Ikawa, K.; Shimooka, T.; Terada, H. Significant stabilization of the phosphatidylcholine bilayer structure by incorporation of small amounts of cardiolipin. Biochem. Biophys. Acta, v. 1192, p. 71-78, 1994.

Skulachev, V. P. Uncoupling: new approaches to and old problem of bioenergetics. Biochim Biophys Acta, v. 1363, p. 100-124, 1998.

Stahl, A.; Gimeno, R.E.; Tartaglia, L.A.; Lodish, H.F. Fatty acid transport proteins: a current view of a growing family. Trends Endocrinol. Metab., v. 12, p. 266-273, 2001.

Stillwell, W.; Dallman, T.; Dumaual, A.C.; Crump, F.T.; Jenski, L.J. Cholesterol versus alfatocopherol: effects on properties of bilayers made from heteroacid phosphotidylcholines. Biochemisty, v. 35, p. 13353-13362, 1996.

Stump, D.D.; Fan, X.; Berk, P.D. Oleic acid uptake and binding by rat adipocytes define dual pathways for cellular fatty acid uptake. J. Lipid Res., v. 42, p. 509-520, 2001.

Tilcock, C.P. Lipid Polymorphism. Chem. Phys. Lipids, v. 40, p. 109-125, 1986.

Voet, D. \& Voet, J. Biochemistry. 2 ed. New York, John Wiley \& Sons, Inc., 1995. 1361p.

Willianson, P. \& Schlegel, R.A. Transbilayer phospholipid movement and the clearance of apoptotic cells. Biochim. Biophys. Acta., v. 1585, p. 53-63, 2002. 
Zeng, Y.; Schlesinger, P.; Gross, R.W. Nonesterified fatty acids induce transmembrane monovalent cation flux: host-guest interactions as determinants of fatty acid-induced ion transport. Biochemistry, v. 37, p. 9497-9508, 1998.

Zhang, F.; Kamp, F; Hamilton, J.A. Dissociation of long and very long chain fatty acids from phospholipid bilayers. Biochemistry, v. 35, p. 16055-16060, 1996. 


\section{APÊNDICE 1 - Programa Chnew.bas}

Programa em linguagem Microsoft Quick Basic da família Chnew.bas que calcula a condutância da via de vazamento $\left(\mathrm{G}_{\text {leak }}\right)$ e a condutância da via de próton $\left(\mathrm{G}_{\mathrm{H}}{ }^{+}\right)$a partir dos valores experimentais obtidos usando o eletrômetro de alta impedância.

'---- Experimento:

'---- Lipídio DPhPC, área: 5 divisões ---

'---- ac. sulfúrico no lado cis: 60 microlitros

'---- Ac.Palmítico colocado bilateral, concentração final =

'---- solução: Trisma base $+\mathrm{KCl}+\mathrm{KH}_{2} \mathrm{PO}_{4}(5 \mathrm{mM}), \mathrm{pH} 7,4$

'---- pHs medidos no final: $\mathrm{pH}$ cis $=6.4 \mathrm{pH}$ trans $=7.2$

\section{CLS}

deltapH $=1.43$

$\mathrm{EH}=.06 *$ deltapH

Possíveis valores de Gleak e GH

GleakpS = $55 \quad$ 'condutância de vazamento em pS

$\mathrm{GHpS}=30 \quad$ 'condutância ao próton em $\mathrm{pS}$

Gleak $=$ GleakpS $*(1 \mathrm{E}-12)$

$\mathrm{GH}=\mathrm{GHpS} /(1 \mathrm{E}+12)$ 'Condutância da via de próton com 60 microlitros de H

$\mathrm{RH}=1 / \mathrm{GH} \quad$ 'Resistência da via de próton

Resistências e condutâncias do amperímetro

$\operatorname{Ramper}(1)=2 \mathrm{E}+14: \operatorname{Gamper}(1)=1 / \operatorname{Ramper}(1)$

Ramper(2) = 1E+11: Gamper(2) = $1 / \operatorname{Ramper}(2)$

$\operatorname{Ramper}(3)=1 \mathrm{E}+10: \operatorname{Gamper}(3)=1 / \operatorname{Ramper}(3)$

Ramper(4) = 1E+09: Gamper(4) = $1 / \operatorname{Ramper}(4)$

$\operatorname{Ramper}(5)=1 \mathrm{E}+08: \operatorname{Gamper}(5)=1 / \operatorname{Ramper}(5)$

$\operatorname{Ramper}(6)=1 \mathrm{E}+07: \operatorname{Gamper}(6)=1 / \operatorname{Ramper}(6)$

PRINT "R amper", "Vm (mV)", "Corr Prot", "Corr Amperimetro "

FOR $\mathrm{i}=1$ TO 6 
Gleaktotal $(\mathrm{i})=$ Gleak + Gamper(i): Rleaktotal $(\mathrm{i})=1 /$ Gleaktotal $(\mathrm{i})$

CorrenteProt $(\mathrm{i})=\mathrm{EH} /(\mathrm{RH}+$ Rleaktotal$(\mathrm{i}))$

$\mathrm{Vm}(\mathrm{i})=\mathrm{EH}-($ CorrenteProt $(\mathrm{i}) * \mathrm{RH})$

CorrenteAmper(i) $=$ Vm(i) / Ramper(i)

PRINT Ramper(i), Vm(i) * 1000, CorrenteProt(i) * (1E+12), CorrenteAmper(i) * (1E+12) NEXT i 
ANEXO 1 - Câmaras para a formação de bicamada lipídica plana
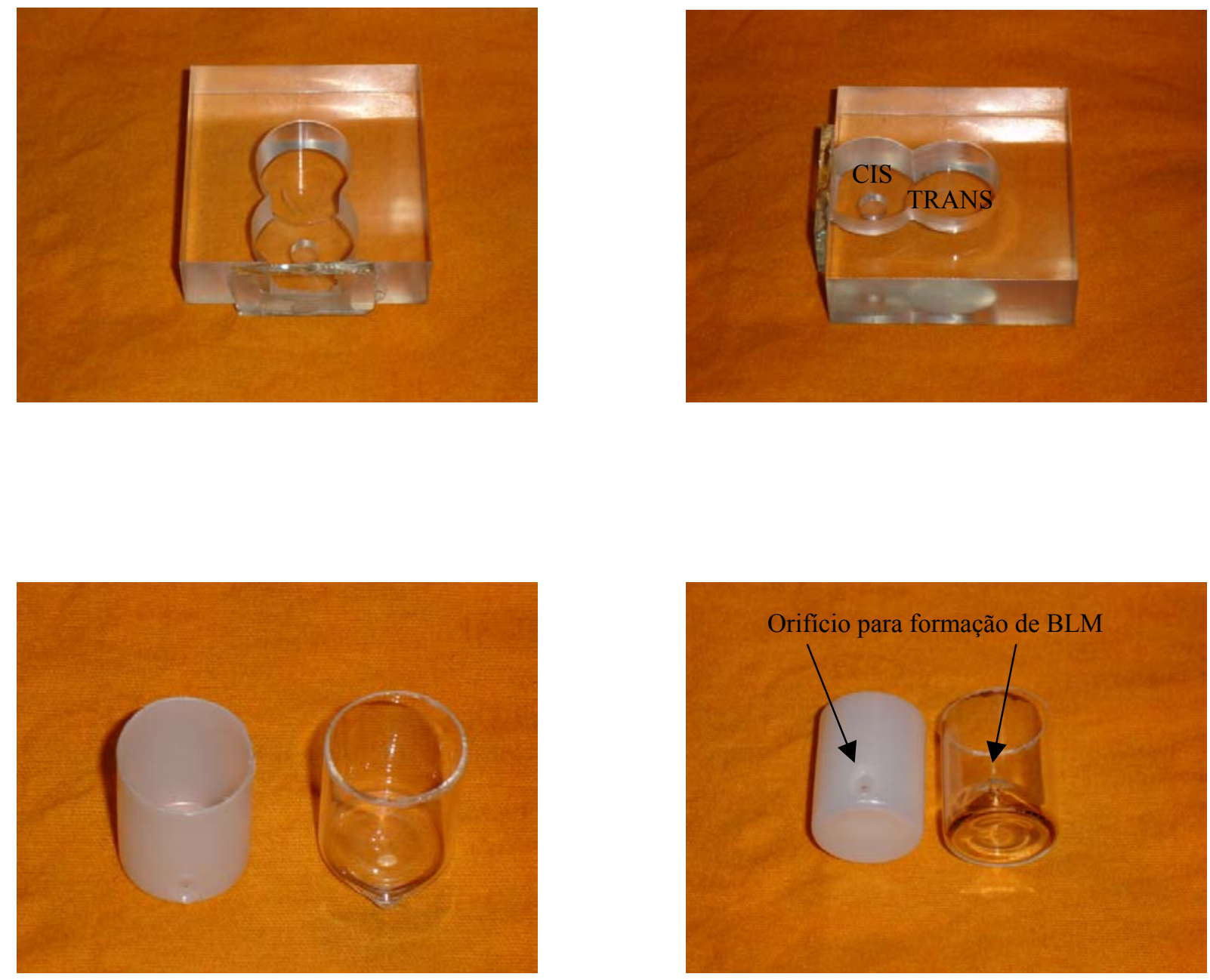
ANEXO 2 - Eletrômetro

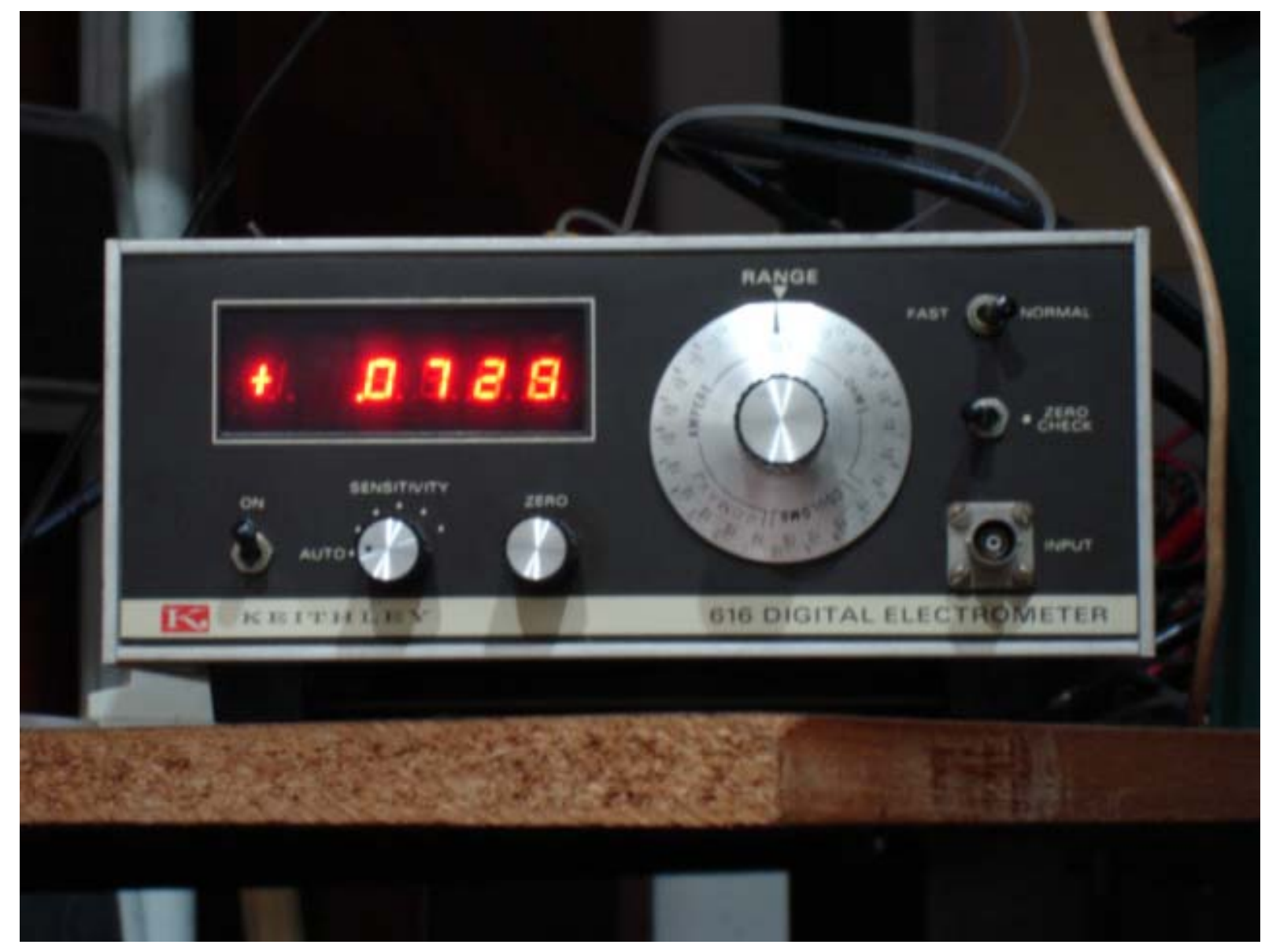




\section{ANEXO 3 - Amplificador de patch-clamp}
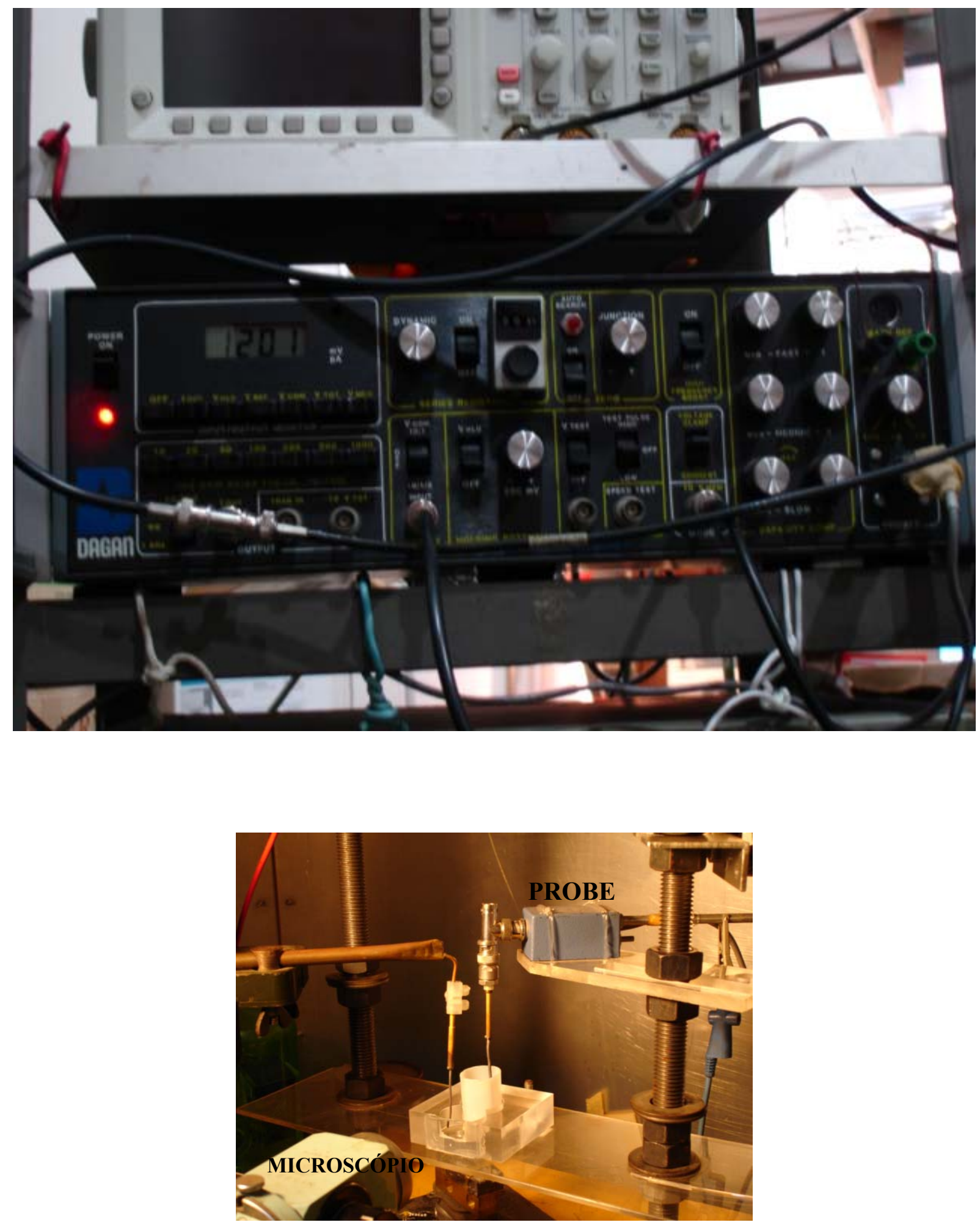


\section{ANEXO 4 - Artigo 1}

Brunaldi, K.; Miranda, M.A.; Abdulkader, F.; Curi, R.; Procopio, J. Effects of palmitic acid and cholesterol on proton transport across black lipid membranes. Bioelectrochemistry, $\mathrm{v}$. 65, p. 9-13, 2004.

We studied the effect of palmitic acid (PA) and cholesterol (approximately $17 \mathrm{wt} \%$ ) on proton translocation across asolectin (charged) and diphytanoylphosphatidylcholine (DPhPC, neutral) black lipid membranes (BLMs). Potential difference (PD), short circuit current (SCC), and conductance (G(total)) were measured with a digital electrometer. Membranes were exposed to $\mathrm{pH}$ gradients (0.4-2.0 units), followed by PA addition to bath (symmetrically, 40-65 microM). The membrane conductive pathway was subdivided into an unspecific and a proton-related routes. A computer program estimated the conductances $(\mathrm{G}(\mathrm{un})$ and $\mathrm{G}(\mathrm{H}))$ of the two pathways from the measured parameters. No significant differences in proton selectivity were found between DPhPC membranes and DPhPC/cholesterol membranes. By contrast, cholesterol incorporation into asolectin increases membranes selectivity to proton. Cholesterol dramatically reduced G(un) reflecting, probably, its ability of inducing order in lipid chains. In asolectin membranes, PA increases proton selectivity, probably by acting as a proton shuttle according to the model proposed by Kamp and et al. [Biochemistry 34 (1995) 11928]. Cholesterol incorporation into asolectin membranes eliminates the PA-induced increase in proton selectivity. In DPhPC and DPhPC/cholesterol membranes, PA does not affect proton selectivity. These results are discussed in terms of the presence of cardiolipin (CL) in asolectin, cholesterol/PA interactions, and cholesterol order-inducing effects on acylchains. 


\section{ANEXO 5 - Artigo 2}

Brunaldi, K.; Miranda, M.A.; Abdulkader, F.; Curi, R.; Procopio, J. Fatty acid flip-flop and proton transport determined by short-circuit current in planar bilayers. J. Lipid Res., v. 46, p. 245-251, 2005.

The effect of palmitic acid (PA) and oleic acid (OA) on electrical parameters of planar membranes was studied. We found a substantial difference between the effects of PA and OA on proton transfer. PA induced a small increase in conductance, requiring a new technique for estimating proton-mediated currents across low-conductance planar bilayers in which an electrometer is used to measure the transmembrane current under virtual short circuit (SCC). Open-circuit voltage and SCC were used to determine proton and leak conductances. OA caused a marked increase in membrane conductance, allowing the use of a voltage-clamp technique. From SCC data, we were able to estimate the flip-flop rate constants for palmitate $(1 \times 10(-6) \mathrm{s}(-1))$ and oleate $(49 \times 10(-6) \mathrm{s}(-1))$ anions. Cholesterol, included in the membrane-forming solution, decreased importantly the leak conductance both in membranes unmodified by FA and in membranes modified by PA added to the bath. 


\title{
ANEXO 6 - MANUSCRITO EM PREPARAÇÃO
}

\section{Proton flux induced by fatty acids across planar lipid bilayers: effect of fatty acid structure and membrane composition}

Manoel Arcisio-Miranda*, Kellen Brunaldi ${ }^{\S}$, Fernando Abdulkader, Rui Curi, Joaquim Procopio

Departamento de Fisiologia e Biofísica, Instituto de Ciências Biomédicas, Universidade de São Paulo, São Paulo, Brasil.

Running title: proton transport by fatty acids across membranes

\begin{abstract}
Abbreviations: Car, cardiolipin; Chol, cholesterol; DPhPC, diphytanoylphosphatidyl choline; $\mathrm{E}_{\mathrm{m}}$, spontaneous voltage; FFA, free fatty $\operatorname{acid}(\mathrm{s}) ; \mathrm{G}_{\text {leak }}$, leak conductance; $\mathrm{G}_{\mathrm{H}}{ }^{+}$, proton conductance; $\mathrm{G}_{\mathrm{m}}$, membrane conductance; $\mathrm{P}_{\mathrm{H}}{ }^{+}$, proton permeability; and $\mathrm{SCC}$, short-circuit current.
\end{abstract}

* Corresponding author: Manoel Arcisio-Miranda. Departamento de Fisiologia e Biofísica. Universidade de São Paulo. Av. Prof. Lineu Prestes, 1580 - sala 101A, 05508-900, São Paulo - Brasil. Phone: +55 11 3091-7284; Fax: +55 11 3091-7285. E-mail address: arcisio@icb.usp.br

\begin{abstract}
Free fatty acids (FFA) are important mediatiors of proton transport across membranes. However, little is known about the influence that the structural features of both FFA and the membrane environment have in proton translocation across phospholipid membranes and by which means this influence is brought about. Both the effects of FFA chain length and insaturation and membrane composition on proton transport have been addressed in this study by electrical measurements in planar lipid bilayers. Proton conductance $\left(\mathrm{G}_{\mathrm{H}}{ }^{+}\right)$and leak conductance $\left(\mathrm{G}_{\text {leak }}\right)$ were calculated from open-circuit voltage and short-circuit current measurements obtained using either an electrometer or a patch-clamp amplifier in voltage-
\end{abstract}


clamp mode. We found that cis-unsaturated FFA caused a more pronounced effect on proton transport as compared to saturated and trans-unsaturated FFA. Cholesterol and cardiolipin decreased membrane leak conductance. Cardiolipin also decreased proton conductance. These effects indicate a dual modulation of protein-independent proton transport by FFA through flip-flop and by an additional simple diffusional pathway. Moreover the membrane lipid environment is also an important modulator of both these processes. This might be relevant in considering the specific distribution of these lipids amongst cellular membranes as well as the different roles that FFA may have in these sites as a proton transporter.

\section{Introduction}

Free fatty acids (FFA) represent a minor fraction of the body lipid pool but play a central function in diverse biological mechanisms, acting as both source and storage of metabolic energy, as membrane constituents, as second messengers, and as $\mathrm{K}^{+}$and $\mathrm{Ca}^{2+}$ channel activators [1]. Among other functions, FFA also modulate the binding of low density lipoprotein to its receptor, and are known uncouplers of oxidative phosphorylation $[2,3]$. However, there is no general consensus as to the main process of FFA translocation across cell membranes in physiological conditions, whether it occurs by flip-flop diffusion or by a protein-mediated mechanism [4-7].

In favor of the diffusional mechanism, studies using $\mathrm{pH}$-sensitive probes in unilamellar vesicles [8] and in living cells [9-11] have suggested that FFA entry can be coupled to proton transport, requiring no specialized transporter. In this way, the $\mathrm{FFA}-\mathrm{H}^{+}$ species would act as proton shuttle.

Studies monitoring electrical parameters associated with FFA translocation across phospholipid membranes are very scarce being mainly based on proton conductance, suggesting that FFA increase proton transport across membranes [12]. These studies do not consider the membrane-unspecific conductance that contributes importantly to the total membrane current in response to voltage. On the other hand, there is evidence based on fluorescence polarization that membranes containing FFA (mainly cis-unsaturated FA) have reduced acyl chain order [13], what would lead to an increase in proton transport through aqueous defects. This simple diffusional mechanism could be influenced by some membrane components, such as cholesterol and cardiolipin. It is known that the organizing effect of cholesterol modulates passive proton transport [14]. Additionally, cardiolipin could collect and donate protons to another system of proton transport through its proton "antenna" 
mechanism and also probably modulates the passive proton translocation across phospholipid membranes [15].

Recently [16], our laboratory estimated proton translocation across black lipid membranes (BLM) through short-circuit current (SCC) and proton specific conductance measurements. Here, we investigate some structural features of FFA, such as acyl chain length, number and type of unsaturation (cis or trans), and how they interfere with the simple diffusional proton transport or with the FFA-mediated pathway across phospholipid membranes. Cholesterol, as a main constituent of mammal plasma membranes, and cardiolipin, which is found in the inner mitochondrial membranes, were tested regarding their interaction with FFA effects. We present evidence that the proton transport pathway that is coupled to FFA flip-flop may be a relevant mechanism for both proton and FFA translocation across cell membranes. In addition, we found that FFA structure and other membrane constituents are major determinants of this process.

\section{Materials and Methods}

\section{Materials}

1,2-Diphytanoyl-sn-Glycero-3-Phosphocholine (DPhPC) was obtained from Avanti Polar Lipids (Alabaster, AL). Bovine heart cardiolipin, and all FFA were obtained from Sigma (St. Louis, MO). Cholesterol was purchased from Serva Feinbiochemica (Heidelberg, GER) and $n$-decane was obtained from ICN Pharmaceuticals (Plainview, NY). All other reagents were of analytical grade. Solutions were prepared using bi-distilled water.

\section{Membrane formation and Electrical measurements}

Black lipid membranes (BLM) were formed according to the method of Mueller et al. [17] from DPhPC or from mixtures of DPhPC and cholesterol $(17 \% \mathrm{w} / \mathrm{w})$ or DPhPC and cardiolipin $(21 \% \mathrm{w} / \mathrm{w})$, in all cases dissolved in $n$-decane $\left(25 \mathrm{mg} \mathrm{mL}^{-1}\right)$. DPhPC was chosen as the main phospholipid for membrane formation in view of its known tightness to passive proton leakage $[18,19]$. The lipid solution was spread across a hole $(\approx 1 \mathrm{~mm})$ in a polypropylene cup inserted into an acrylic chamber, defining two 4-mL compartments (cis outside the cup and trans - inside the cup). Membranes were formed on an initially symmetrical buffer solution ( $\mathrm{KCl}-5 \mathrm{mM}, \mathrm{KH}_{2} \mathrm{PO}_{4}-5 \mathrm{mM}$, and Tris $-5 \mathrm{mM}$, pH 7.4). After stabilization of the membrane electrical recordings, an aliquot of sulfuric acid was added to the cis side to create a $\mathrm{pH}$ difference $(\Delta \mathrm{pH})$ across the membrane (0.5-0.8 $\mathrm{pH}$ units). Subsequently, an aliquot of FFA (stock ethanolic solution) was added to both cis and trans 
sides (final concentration: $40-50 \mu \mathrm{M}$ ). The final concentration of ethanol in the buffer solution was less than $0.1 \%$ and was not found to affect the electrical parameters of bilayers (data not shown). All experiments were carried out at room temperature $\left(23 \pm 2{ }^{\circ} \mathrm{C}\right)$.

Electrical measurements were done as described before [16]. Briefly, the buffer solutions were connected to the recording system through $\mathrm{Ag} / \mathrm{AgCl}$ electrodes. The cis side was grounded while the trans side was connected to the bilayer measuring device. Low conductance membranes were monitored by a high impedance electrometer (Keithley 616 Digital Electrometer) in either one of three operation modes: voltmeter, ohmmeter and ammeter to obtain respectively the spontaneous voltage $\left(E_{m}\right)$, the membrane resistance $\left(R_{m}\right)$ and the short-circuit current (SCC). Electrical parameters of higher conductance membranes were derived from current-to-voltage (I-V) relations by clamping the membrane potential from -120 to $+120 \mathrm{mV}$, using a patch-clamp amplifier (Dagan 8900) in the voltage-clamp mode (10 Gigaohm probe). From these I-V relations, the following parameters were obtained: the reversal potential $\left(E_{m}\right)$, the membrane resistance $\left(R_{m}\right)$ as the slope of the $I-V$ relation around zero current, and SCC.

The membrane conductance $\left(\mathrm{G}_{\mathrm{m}}\right)$, using either the electrometer or the patch-clamp amplifier, was obtained as $\mathrm{G}_{\mathrm{m}}=1 / \mathrm{R}_{\mathrm{m}}$.

\section{Calculation of proton conductance $\left(\mathrm{G}_{\mathrm{H}}^{+}\right)$and proton permeability $\left(\mathrm{P}_{\mathbf{H}}{ }^{+}\right)$}

$\mathrm{G}_{\mathrm{H}}{ }^{+}$and $\mathrm{P}_{\mathrm{H}}{ }^{+}$were calculated indirectly as described before [16]. Briefly, membrane conductance $\left(\mathrm{G}_{\mathrm{m}}\right)$, under a transmembrane $\Delta \mathrm{pH}$, was considered as a sum of two parallel and independent conductance routes, a proton conductance $\left(\mathrm{G}_{\mathrm{H}}{ }^{+}\right)$and a leak conductance $\left(\mathrm{G}_{\text {leak }}\right)$ :

$$
G_{m}=G_{H^{+}}+G_{\text {leak }}
$$

$\mathrm{G}_{\text {leak, }}$, present in all types of membranes, is unspecific and is assumed to have no associated electromotive force. The proton electromotive force, $\mathrm{E}_{\mathrm{H}}{ }^{+}$, is given by:

$$
E_{H^{+}}=0.059 \Delta p H
$$

Thus, the spontaneous (or open-circuit) voltage $\left(\mathrm{E}_{\mathrm{m}}\right)$ of the membrane is given by:

$$
E_{m}=\frac{\left(E_{H^{+}} \times G_{H^{+}}\right)+\left(E_{\text {leak }} \times G_{\text {leak }}\right)}{G_{H^{+}}+G_{\text {leak }}}
$$

Assuming $\mathrm{E}_{\text {leak }}=0$, the above equation can be rewritten as:

$$
E_{m}=\frac{E_{H^{+}} \times G_{H^{+}}}{G_{H^{+}}+G_{\text {leak }}}
$$


The proton-related SCC and $\mathrm{P}_{\mathrm{H}}{ }^{+}$, which is obtained from experimental SCC values, are given by:

$$
\begin{gathered}
S C C=E_{H^{+}} \times G_{H^{+}} \\
P_{H^{+}}=\frac{S C C}{F \times \Delta\left[H^{+}\right]}
\end{gathered}
$$

where $\mathrm{F}=95498 \mathrm{C} \mathrm{mol}^{-1}$ and $\Delta[\mathrm{H}+]$ is the proton concentration difference across the membrane.

\section{Data analysis}

Statistical significance (p) was determined by One-way ANOVA (and nonparametric) - Bonferroni's Multiple Comparison Test using GraphPad Software Prism 4 (GraphPad Software, Inc., CA). In all analysis, significance was set at $p<0.05$. Results are expressed as mean \pm standard error of the mean (S.E.M.).

\section{Results}

Unmodified membranes (i.e., without addition of FFA to the bath) display, under a $\mathrm{pH}$ difference (cis $\mathrm{pH}<$ trans $\mathrm{pH}$ ), a substantial potential difference (PD) and a short-circuit current (SCC), indicating a basal proton conductance (Figure 1B). The spontaneous PD in response to the $\mathrm{pH}$ difference ( $\mathrm{PD}$ in open-circuit, $\mathrm{E}_{\mathrm{m}}$ ) was shown to be appreciably smaller than the proton equilibrium potential, $\mathrm{E}_{\mathrm{H}}{ }^{+}$(Figure 1A), denoting a substantial current leak (Figure 1C). For example, in DPhPC membranes, $\mathrm{G}_{\text {leak }}$ was approximately 5 times higher than $\mathrm{G}_{\mathrm{H}}^{+}$.

Cholesterol incorporated to DPhPC membranes produced a substantial reduction of $\mathrm{G}_{\text {leak }}$ (figure 1C) while not affecting $\mathrm{G}_{\mathrm{H}}{ }^{+}$(Figure 1B), what possibly explains the effect of cholesterol in increasing the $\mathrm{E}_{\mathrm{m}} / \mathrm{E}_{\mathrm{H}}{ }^{+}$ratio (Figure 1A).

Cardiolipin, like cholesterol, reduced $\mathrm{G}_{\text {leak }}$ (Figure $1 \mathrm{C}$ ), but additionally reduced $\mathrm{G}_{\mathrm{H}}{ }^{+}$ by approximately 4.5 fold (Figure 1B). This dual effect of cardiolipin probably explains its lack of effect upon the $\mathrm{E}_{\mathrm{m}} / \mathrm{E}_{\mathrm{H}}^{+}$ratio (Figure 1A).

The corresponding SCCs of these FFA-unmodified membranes, under $\Delta \mathrm{pH}$ between $0.5-0.8$, were found to be in the range of few picoamperes and are listed on Table 1 . Collectively, these results indicate that cholesterol and cardiolipin attenuate the passive proton transport, presumably by a condensing effect. 
To analyze the effect of FFA acyl chain length and unsaturation degree, we performed experiments measuring the electrical parameters of DPhPC membranes in the presence of saturated FFA - palmitic (AP) and stearic (SA) acids - and cis-unsaturated FFA - oleic (OA), linoleic (LA), arachidonic (AA), and docosahexaenoic (DHA) acids. As shown in Figure 2 and Table 2, differently from PA and control membranes, SA and all cis-unsaturated FFA importantly increase the $\mathrm{E}_{\mathrm{m}} / \mathrm{E}_{\mathrm{H}}{ }^{+}$ratio, $\mathrm{G}_{\mathrm{H}}{ }^{+}, \mathrm{SCC}$, and $\mathrm{P}_{\mathrm{H}}{ }^{+}$. Unique to cis-unsaturated FFA, a $\mathrm{pH}$ difference $\left(\mathrm{pH}_{\text {cis }}<\mathrm{pH}_{\text {trans }}\right)$ yielded a rectified profile in the I-V relation with a significant increase in SCC (Table 2) and a shift of $E_{m}$ toward positive values (Figure 3). $G_{\text {leak }}$ was not affected (Figure 2C) by any of the FFA tested. These findings suggest an effect of these FFA enhancing either a FFA-mediated proton translocation or a diffusional proton-selective pathway.

Besides, three other aspects in these results are interesting to note: a) alterations in the number of cis-double bonds present in the acyl chain of FFA affected dramatically all electrical parameters measured. An example of this is seen when the effects of SA (18:0), OA (cis 9-18:1), and LA (cis 9,12-18:2) are compared (Figure 2: bars 3, 4, and 6, and Table 2: lines 3, 4 and 6, respectively); b) the electrical parameters are also sensitive to acyl chain length. This effect is clear when the effects of PA (16:0) and SA (18:0) are compared (Figure 2: bars 2 and 3, and Table 2: lines 2 and 3, respectively); and c) membranes treated with polyunsaturated FFA, mainly AA (cis 5,8,11,14-20:4) and DHA (cis 4,7,10,13,16,19-22:6), were found to be totally proton-selective, with the $\mathrm{E}_{\mathrm{m}} / \mathrm{E}_{\mathrm{H}}{ }^{+}$ratio approximating 1 (Figure $2 \mathrm{~A}$ and Figure 3).

To determine whether the type of double bond (cis or trans) is relevant to the overall effects of unsaturated FFA, we performed experiments measuring the same electrical parameters in the presence of elaidic acid (EA) (9-18:1), a mono-trans-unsaturated FA, and compared them with the results obtained with its congeners, saturated stearic (18:0) and mono-cis-unsaturated oleic (9-18:1) acids. As shown in Figure 2 and Table 2 (bars and lines 3,4 , and 5, respectively), EA is less effective than OA in enhancing proton transport, its effect being in the same range as that obtained with SA.

Collectively, these results demonstrate that the ability of FFA in transporting protons is dependent on their structural features, mainly on the number and type of double bonds, cis bonds being more effective than trans bonds.

Cell and organelle membranes are composed by a great variety of lipid species with different physico-chemistry properties. Two constituents with relevant physiological interest on FFA-mediated proton transport are cholesterol (in mammal plasma membranes) and 
cardiolipin (in inner mitochondrial membranes). Thus, to examine how these membrane constituents are relevant to FFA-mediated proton transport, we performed experiments with membranes having either a mixture of DPhPC and cholesterol or DPhPC and cardiolipin. These membranes were treated with OA because this FFA had an intermediate effect on proton transport when compared with saturated or polyunsaturated FFA (Figure 2B). As shown in Figure 4, cardiolipin produced a considerable increase in the $\mathrm{G}_{\mathrm{H}}{ }^{+}$(OA, DPhPCCardiolipin) $/ \mathrm{G}_{\mathrm{H}}{ }^{+}$(OA, DPhPC) ratio, a finding not observed with cholesterol.

Indeed, DPhPC membranes containing cardiolipin were shown to be 3 fold more selective to protons than pure DPhPC membranes when both groups were modified by OA (Figure 4).

\section{Discussion}

Recent studies [20-22] by different groups have demonstrated that the exposure of unilamellar vesicles or living cells to FFA resulted in rapid and reversible decrease in internal $\mathrm{pH}$, as monitored by fluorescent probes. Those findings suggest that part of the FFA translocation across living membranes is due to passive diffusional transport of protonated FFA.

Our present results support the idea that proton translocation across protein-free model membranes can be explained by a combination of free diffusion and FFA-mediated flip-flop working in parallel; this last also serving as a mechanism for FFA transport.

In this way, the proton-selective pathway is seen as two parallel routes: one in which the proton crosses the membrane through passive diffusional mechanism (described below), and another in which the proton is coupled to FFA-anion, i.e., the well-known flip-flop shuttle mechanism.

Ion permeation across membranes by simple diffusion involves the partitioning of the ion from one of the aqueous phases to one side of the membrane, its diffusion across the membrane core, and its exit from membrane to the opposite aqueous phase. In this process, it is considered that the diffusion of the ion through the lipid bilayer is the major limiting step to the ion permeation [23]. However, in the case of the protons, the existence of a considerable amount of water within the phospholipid acyl chains creates a proper environment for the anomalously high proton mobility through the various proposed mechanisms: proton wires, hydrogen-bonded water chains, and aqueous cluster contacts [14, 24-27]. 
On the other hand, permeability studies in artificial bilayers indicate that the more ordered portion of the hydrocarbon chains adjacent to the head-groups is likely the major hindrance to ion translocation [28].

Figure 1 and Table 1 show that proton passive transport is influenced by the membrane composition, probably modifying the lateral interactions between phospholipids. This effect, mainly evidenced by a decrease in $G_{\text {leak}}$, was more apparent when either cholesterol or cardiolipin were present in the membranes (Figure 1C).

It is known that the incorporation of cholesterol into phospholipid membranes greatly reduces the permeability to water, protons, and other ions [14, 29], probably by the wellknown condensing effect of cholesterol [30].

In the case of cardiolipin, the reduction of $\mathrm{G}_{\text {leak }}$ can be explained by a mechanism similar to that proposed for cholesterol. In addition to this reduction in $\mathrm{G}_{\text {leak }}$, our results show a reduction of $\mathrm{G}_{\mathrm{H}}^{+}$(Figure 1B) when cardiolipin is incorporated to $\mathrm{DPhPC}$ membranes. Previous works [31-33] have suggested three major effects of cardiolipin on the physical properties of phospholipid bilayers: (i) increase in the amount of bound water at the lipidwater interface, what might lower the activation energy for ion entry into the bilayer, enhancing the proton permeability, (ii) enhancement of the lateral interactions between adjacent phospholipid acyl chains within the membrane leaflets, causing a significant decrease in water permeability, and (iii) decrease in the inter-leaflet cohesive forces. Based on these effects of cardiolipin, the simultaneous reduction of $\mathrm{G}_{\text {leak }}$ and $\mathrm{G}_{\mathrm{H}}{ }^{+}$can be explained by a global increase in membrane compactness.

We found that PA (sixteen carbons), unlike SA (eighteen carbons), is not effective in increasing the proton permeability in DPhPC membranes (Figure 2 and Table 2), but was effective in increasing proton flow in asolectin membranes, a membrane composed by a mixture of phospholipid molecules with different acyl chain length [16]. In accordance with other groups [34], this indicates that the membrane microenvironment is relevant for FFA translocation.

Our results also show that the membrane proton selectivity parallels the unsaturation degree of the FFA (Figure 2, Figure 3 and Table 2). This is well evidenced when FFA with the same acyl length and different numbers of unsaturations are compared, as in the case of SA (saturate), OA (one double bond), and LA (two double bonds). The presence of unsaturation, mainly cis-unsaturation, probably produces: (i) a disorganization of the lipid bilayer, with a resulting increase in aqueous defects formation, leading to increase in the proton permeability through a proton passive pathway (water wires or water cluster 
mechanism) [35]; and/or (ii) an increase in membrane fluidity, with consequent decrease in the activation energy to formation of voids through which the FFA are proposed to diffuse $[36,37]$. In addition, the presence of double bonds creates bends into the acyl chain, shortening the FFA molecule. Depending on the phospholipid chain and the FFA this creates an optimal relation between FFA length and leaflet thickness, enhancing FFA flip-flop rate [38].

On the other hand, our results also showed that EA, a trans-unsaturated FFA, lacks the effects listed above, acting like its congener saturated FFA (SA) instead of its cis-unsaturated FFA congener (OA) (Figure 2 and Table 2). This may be attributable to the fact that, unlike the $c$ is isomer, the trans isomer adopts a more linear configuration, similar to that of saturated FFA. This leads to a tighter packing of the phospholipid bilayer, reducing the translocation of this FA across the membrane $[36,38]$.

Contrary to our expectations, based on the well-reported condensing effect of cholesterol, the incorporation of cholesterol into DPhPC membranes did not alter the proton selectivity mediated by OA (as shown in Figure 4). However, a recent study [39] has demonstrated an additional phase, named slow phase, in the decrease of internal $\mathrm{pH}$ in HEK 293 cell line, which was attributed to an association between regions containing cholesterol rafts and caveolin-1. Thus, the importance of cholesterol on the translocation of FFA across phospholipid membranes could be related to the presence of micro-regions in the cell, such as lipid rafts.

We found that the incorporation of cardiolipin into DPhPC membranes produced a substantial increase in the $\mathrm{G}_{\mathrm{H}}{ }^{+}\left(\mathrm{OA}\right.$, DPhPC-Cardiolipin) $/ \mathrm{G}_{\mathrm{H}}{ }^{+}(\mathrm{OA}, \mathrm{DPhPC})$ ratio (Figure 4). As discussed above for FFA-unmodified DPhPC-Cardiolipin membranes, cardiolipin is able to reduce the activation energy for the entry of ions into the bilayer [31]. Furthermore, the treatment with OA creates an additional proton-selective pathway (FFA pathway) across the membrane. Thus, in this system, cardiolipin probably acts collecting protons and donating them specifically to OA (proton antenna mechanism [14]), producing an increase in proton permeability by the FFA pathway. This may contribute to the mitochondrial uncoupling effect of FFA, relating with the activity of FFA, cardiolipin and uncoupling protein (UCP) into the buffering model of UCP function [34, 40-41].

Finally, taken together, these data lead us to conclude that the proton-shuttle mechanism for fatty acid translocation across phospholipid membranes can be modulated by a combination of diverse factors such as the structural features of FFA, and other lipids present 
in smaller proportions in the membrane, mainly cardiolipin. Also, it might be concluded that the FFA independent $\mathrm{H}^{+}$permeability is altered by cholesterol and cardiolipin.

\section{Acknowledgments}

This work was supported by grants from the National Council for Scientific and Technological Development (CNPq) and from the State of São Paulo Research Foundation (FAPESP). M.A.-M., F.A., R.C. and J.P. are recipients of CNPq scholarships.

\section{References}

[1] Hamilton, J.A. (1998) Fatty acid transport: difficult or easy? J. Lipid Res. 39: 467-481.

[2] McArthur, M.J., Atshaves, B.P., Frolov, A., Foxworth, W.D., Kier, A.B., Schroeder, F. (1999) Cellular uptake and intracellular trafficking of long chain fatty acids. J. Lipid Res. 40: 1371-1383.

[3] Skulachev, V.P. (1998) Uncoupling: new approaches to and old problem of bioenergetics. Biochem. Biophys. Acta 1363: 100-124.

[4] Hamilton, J.A., Kamp, F. (1999) How are free fatty acids transported in membranes? Is it by proteins or by free diffusion through the lipids? Diabetes 48: 2255-2269.

[5] Abumrad, N., Harmon, C., Ibrahimi, A. (1998) Membrane transport of long-chain acids: evidence for a facilitated process. J. Lipid Res. 39: 2309-2318.

[6] Kampf, J.P., Kleinfeld, A.M. (2004) Fatty acid transport in adipocytes monitored by imaging intracellular free fatty acid levels. J. Biol. Chem. 279: 35775-35780.

[7] Cupp, D., Kampf, J.P., Kleinfeld, A.M. (2004) Fatty acid - albumin complexes and the determination of the transport of long chain free fatty acids across membranes. Biochemistry 43: 4473-4481.

[8] Kamp, F., Hamilton, J.A. (1992) pH gradients across phospholipid membranes caused by fast flip-flop of un-ionized fatty acids. Proc. Natl. Acad. Sci. USA 89: 11367-11370. 
[9] Hamilton, J.A., Civelek, V.N., Kamp, F., Tornheim, K., Corkey, B.E. (1994) Changes in internal $\mathrm{pH}$ caused by movement of fatty acids into and out of clonal pancreatic beta-cells (HIT). J. Biol. Chem. 269: 20852-20856.

[10] Trigatti, B.L., Gerber, G.E. (1996) The effect of intracellular pH on long-chain fatty acid uptake in 3T3-L1 adipocytes: evidence that uptake involves the passive diffusion of protonated long-chain fatty acids across the plasma membrane. Biochem. J. 313: 487-494.

[11] Civelek, V.N., Hamilton, J.A., Tornheim, K., Kelly, K.L., Corkey, B.E. (1996) Intracellular $\mathrm{pH}$ in adipocytes: effects of free fatty acid diffusion across the plasma membrane, lipolytic agonists, and insulin. Proc. Natl. Acad. Sci. USA 93: 10139-10144.

[12] Gutknecht, J. (1988) Proton conductance caused by long-chain fatty acids in phospholipid bilayer membranes. J. Membr. Biol. 106: 83-93.

[13] Klausner, R.D., Kleinfeld, A.M., Hoover, R.L., Karnovsky, M.J. (1980) Lipid domains in membranes. Evidence derived from structural perturbations induced by free fatty acids and lifetime heterogeneity analysis. J. Biol. Chem. 255: 1286-1295.

[14] Haines, T.H. (2001) Do sterols reduce proton and sodium leaks through lipid bilayers? Prog. Lipid Res. 40: 299-324.

[15] Hoch, F.L. (1998) Cardiolipins and mitochondrial proton-selective leakage. J. Bioenerg. Biomembr. 30: 511-532.

[16] Brunaldi, K., Miranda, M.A., Abdulkader, F., Curi, R., Procopio, J. (2005) Fatty acid flip-flop and proton transport determined by short-circuit current in planar bilayers. J. Lipid Res. 46: 245-251.

[17] Mueller, P., Rudin, H.T., Tien, T., Wescott, W.C. (1963) Methods for the formation of single bimolecular lipid membranes in aqueous solutions. J. Phys. Chem. 67: 534-535.

[18] Yamauchi, K., Doi, K., Yoshida, Y., Kinoshita, M. (1993) Archaebacterial lipids: highly proton-impermeable membranes from 1,2-diphytanyl-sn-glycero-3-phosphocholine.

Biochem. Biophys. Acta 1146: 178-82.

[19] Baba, T., Minamikawa, H., Hato, M., Handa, T. (2001) Hydration and molecular motions in synthetic phytanyl-chained glycolipid vesicle membranes. Biophys. J. 81: 3377-86. 
[20] Trigatti, B.L., Gerber, G.E. (1996) The effect of intracellular on long-chain fatty acid uptake in 3T3-L1 adipocytes: evidence that uptake involves the passive diffusion of protonated long-chain fatty acids across the plasma membrane. Biochem. J. 313: 487-494.

[21] Jezek, P., Modriansky, M., Garlid, K.D. (1997) Inactive fatty acids unable to flip-flop across the lipid bilayer. FEBS Lett. 408: 161-165.

[22] Kamp, F., Guo, W., Souto, R., Pilch, P.F., Corkey, B.E., Hamilton, J.A. (2003) Rapid flip-flop of oleic acid across the plasma membrane of adipocytes. J. Biol. Chem. 278: 79887995.

[23] Hille, B. (2001) Ion channels of excitable membranes, Sinauer Associated Inc., Sunderland, pp. 309-345.

[24] Deamer, D.W., Nichols, J.W. (1989) Proton flux mechanisms in model and biological membranes. J. Membr. Biol. 107: 91-103.

[25] Nagle, J.F., Morowitz, H.J. (1978) Molecular mechanism for proton transport in membranes. Proc. Natl. Acad. Sci. 75: 298-302.

[26] Nagle, J.F. (1987) Theory of passive proton conductance in lipid bilayers. J. Bioenerg. Biomembr. 19: 413-426.

[27] Perkins, W.R., Cafiso, D.S. (1987) Characterization of $\mathrm{H}^{+} / \mathrm{OH}^{-}$currents in phospholipid vesicles. J. Bioenerg. Biomembr. 19: 443-455.

[28] Xiang, T.X., Chen, X., Anderson, B.D. (1992) Transport methods for probing the barrier domain of lipid bilayer membranes. Biophys. J. 63: 78-88.

[29] Lande, M.B., Donovan, J.M., Zeidel, M.L. (1995) The relationship between membrane fluidity and permeabilities to water, solutes, ammonia, and protons. J. Gen. Physiol. 106: 6784.

[30] Bhattacharya, S., Haldar, S. (2000) Interactions between cholesterol and lipids in bilayer membranes. Role of lipid headgroup and hydrocarbon chain-backbone linkage. Biochem. Biophys. Acta 1467: 39-53. 
[31] Chen, Q.-P., Li, Q.-T. (2001) Effect of cardiolipin on proton permeability of phospholipid lipossomes: the role of hydration at the lipid-water interface. Arch. Biochem. Biophys. 389: 201-206.

[32] Nichols-Smith, S., Teh, S.Y., Kuhl, T.L. (2004) Thermodynamic and mechanical properties of model mitochondrial membranes. Biochem. Biophys. Acta 1663: 82-88.

[33] Shibata, A., Ikawa, K., Shimooka, T., Terada, H. (1994) Significant stabilization of the phosphatidylcholine bilayer structure by incorporation of small amounts of cardiolipin. Biochem. Biophys. Acta 1192: 71-78.

[34] Bernardi, P., Penzo, D., Wojtczak, L. (2002) Mitochondrial energy dissipation by fatty acids. Vitam. Horm. 65: 97-126.

[35] Stillwell, W., Wassall, S.R. (2003) Docosahexahenoic acid: membrane properties of a unique fatty acid. Chem. Phys. Lipids. 126: 1-27.

[36] Roach, C., Feller, S.E., Ward, J.A., Shaikh, S.R., Zerouga, M., Stillwell, W. (2004) Comparison of cis and trans fatty acid containing phosphatidylcholines on membrane properties. Biochemistry 43: 6344-6351.

[37] Kleinfeld, A.M., Chu, P., Romero, C. (1997) Transport of long-chain native fatty acids across lipid bilayer membranes indicates that transbilayer flip-flop is rate limiting. Biochemistry 36: 14146-14158.

[38] Niu, S.-L., Mitchell, D.C., Litman, B.J. (2005) Trans fatty acid derived phospholipids show increased membrane cholesterol and reduced receptor activation as compared to their cis analogs. Biochemistry 44: 4458-4465.

[39] Meshulam, T., Simard, J.R., Wharton, J., Hamilton, J.A., Pilch, P.F. (2006) Role of caveolin-1 and cholesterol in transmembrane fatty acid movement. Biochemistry 45: 28822893.

[40] Wojtczak, L., Wieckowski, M.R. (1999) The mechanisms of fatty acid-induced proton permeability of the inner mitochondrial membrane. J. Bioenerg. Biomembr. 31: 447-455.

[41] Breen, E.P., Gouin, S.G., Murphy, A.F., Haines, L.R., Jackson, A.M., Pearson, T.W., Murphy, P.V., Porter, R.K. (2006) On the mechanism of mitochondrial uncoupling protein 1 function. J. Biol. Chem. 281: 2114-2119. 